UNIVERSIDADE DE SÃO PAULO

Faculdade de Filosofia, Ciências e Letras de Ribeirão Preto

Departamento de Psicologia

PROGRAMA DE PÓS-GRADUAÇÃO EM PSICOLOGIA

\title{
Avaliação neuropsicológica e afetiva de crianças e adolescentes com epilepsia
}

\author{
CAROLINA RUIZ LONGATO
}

Dissertação apresentada ao Programa de PósGraduação em Psicologia da Faculdade de Filosofia, Ciências e Letras de Ribeirão Preto da Universidade de São Paulo, como parte das exigências para a obtenção do título de Mestre em Ciências, Área: Psicologia.

Orientadora: Prof ${ }^{\mathrm{a}}$. Dr ${ }^{\mathrm{a}}$. Sonia Regina Pasian 
Autorizo a reprodução e divulgação total ou parcial deste trabalho, por qualquer meio convencional ou eletrônico, para fins de estudo e pesquisa, desde que citada a fonte.

Longato, Carolina Ruiz

Avaliação Neuropsicológica e Afetiva de Crianças e Adolescentes com Epilepsia, 2015

105p. : il, ; $30 \mathrm{~cm}$

Dissertação de Mestrado, apresentada à Faculdade de Filosofia, Ciências e Letras de Ribeirão Preto/USP. Área de concentração: Psicologia.

Orientador: Pasian, Sonia Regina.

1. Avaliação Psicológica. 2. Epilepsia. 3. Crianças. 4. Adolescentes. 5. Afetividade. 


\section{FOLHA DE APROVAÇÃO}

Nome: Longato, Carolina Ruiz

Título: Avaliação Neuropsicológica e Afetiva de Crianças e Adolescentes com Epilepsia

Dissertação de Mestrado apresentado ao Programa de Pós-Graduação em Psicologia do Departamento de Psicologia da Faculdade de Filosofia, Ciências e Letras de Ribeirão Preto, Universidade de São Paulo, Ribeirão Preto para a obtenção de título de Mestre em Ciências, Área: Psicologia.

Aprovado em:

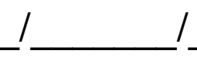

Banca Examinadora

Prof. Dr.

Instituição:

Assinatura:

Prof. Dr.

Instituição:

Assinatura:

Prof. Dr.

Instituição:

Assinatura: 

Dedicatória

A todas as crianças, adolescentes e familiares que participaram do presente estudo, pela confiança depositada em mim e pelos seus exemplos de vida. 



\section{AGRADECIMENTOS}

À minha orientadora, Profa. Dra. Sonia Regina Pasian que depositou sua confiança em mim, pelos seus estímulos ao aprendizado, contribuindo para meu crescimento científico e intelectual.

À Sara Rosset, que muito me ensinou, pela oportunidade oferecida e pela colaboração durante todo o processo, permitindo a realização deste trabalho.

À minha família, que sempre me apoiou - meus pais Valdete Maria Ruiz e Jorge de Jesus Longato e minha irmã Bianca Ruiz Longato, pela ajuda sempre que precisei, pelo incentivo e encorajamento.

À Maria Aparecida Morais, por toda a ajuda e a Renan Morais por sua constante presença e companheirismo, por acreditar em mim e por toda cooperação.

À toda a equipe do CIREP, em especial à Geisa Angelis e Gerson Silva Neto, pelos auxílios prestados.

Aos colegas do Centro de Pesquisa em Psicodiagnóstico (CPP), em especial à Katiusha Abreu, Jorge Sinval, Veridiana Ferrari e Fabiana Freitas, por toda a ajuda, conselhos e trocas de experiência.

À Coordenação de Aperfeiçoamento de Pessoal de Nível Superior (CAPES) pelo apoio financeiro com bolsa à pesquisadora.

Muito obrigada a todos! 



\section{RESUMO}

Longato, C. R. (2015). Avaliação Neuropsicológica e Afetiva de Crianças e Adolescentes com Epilepsia. Dissertação de Mestrado no Programa de Pós-Graduação em Psicologia do Departamento de Psicologia da Faculdade de Filosofia, Ciências e Letras de Ribeirão Preto, Universidade de São Paulo, Ribeirão Preto.

O estudo de características do funcionamento emocional de crianças com epilepsia é uma área relevante que pode proporcionar a compreensão do impacto deste quadro clínico crônico sobre o desenvolvimento afetivo e social infantil. A perspectiva de associar evidências empíricas da abordagem cognitiva e emocional, ampliando as estratégias comumente utilizadas nos processos de avaliação neuropsicológica pode permitir interpretações mais compreensivas sobre o quadro. Objetivou-se caracterizar o funcionamento cognitivo e afetivo de crianças e adolescentes com epilepsia, a partir de instrumentos específicos de avaliação psicológica, evidenciando recursos e eventuais dificuldades adaptativas ao contexto de vida. Foram avaliados dois grupos clínicos de crianças e adolescentes de sete a 16 anos de idade, regularmente atendidos no Centro de Cirurgia de Epilepsia (CIREP) do Hospital das Clínicas da Faculdade de Medicina de Ribeirão Preto da Universidade de São Paulo, a saber: Grupo 1 (pré-operatório, $\mathrm{n}=17$ ): pacientes com epilepsia internados no CIREP; Grupo 2 (pósoperatório, $n=18)$ : pacientes que realizaram cirurgia de epilepsia, com controle das crises e que frequentam o ambulatório do CIREP. Foi composto um terceiro grupo (grupo de comparação, $n=31$ ) com voluntários de escolas públicas, equiparados em idade e sexo aos grupos clínicos. Os instrumentos utilizados foram: Questionário de Capacidades e Dificuldades (SDQ), Escala de Inteligência Wechsler para Crianças (WISC-III), Teste de Blocos de Corsi (TBC) e Teste das Pirâmides Coloridas de Pfister. Foram realizadas análises descritivas e inferenciais, a fim de permitir caracterização neuropsicológica e do funcionamento afetivo das crianças e adolescentes. Por fim, foi realizado o perfil geral de resultados do grupo clínico $(n=35)$ em cada instrumento utilizado e comparação com seus dados normativos. As evidências obtidas pelo SDQ apontam que os grupos de pacientes de epilepsia apresentam mais problemas relacionados a sintomas emocionais, hiperatividade, problemas com colegas e aprendizado escolar do que as crianças e adolescentes do grupo de comparação. Por meio dos testes cognitivos (WISC-III e Teste de Corsi), verificou-se que os casos clínicos apresentaram desempenho cognitivo e funcionamento da memória espacial inferior ao grupo de comparação. Já o método projetivo de avaliação de personalidade (Teste de Pfister) apresentou indicativos de menor inibição afetiva nos casos clínicos, comparativamente às crianças e adolescentes não pacientes, embora, de maneira geral tenha sido verificado que as vivências emocionais estão preservadas em todos os casos. Em comparação com os dados normativos, o grupo clínico apresentou resultados mais baixos nos escores de QI e em todos os subtestes avaliados (WISC-III), médias inferiores nas pontuações diante do Teste de Corsi (versão direta e inversa), além dos seguintes achados no Teste de Pfister: porcentagens médias das cores marrom e cinza e da síndrome estímulo significativamente maiores, porcentagens médias de branco e da síndrome incolor significativamente inferiores à média normativa, com preferência pela realização de tapetes furados. O conjunto dos achados sugere menor funcionalidade cognitiva e sinais de instabilidade no controle dos afetos no grupo com epilepsia, confirmando necessidade de intervenções específicas com essas crianças e adolescentes ao longo de seu desenvolvimento, de modo a estimular adequado aproveitamento de seus potenciais.

Palavras-chave: Avaliação Psicológia, Epilepsia, Crianças, Adolescentes, Afetividade. 



\section{ABSTRACT}

Longato, C. R. (2015). Neuropsychological and Affective Assessment of Children and Adolescents with Epilepsy. Dissertação de Mestrado no Programa de Pós-Graduação em Psicologia do Departamento de Psicologia da Faculdade de Filosofia, Ciências e Letras de Ribeirão Preto, Universidade de São Paulo, Ribeirão Preto.

The study of the emotional functioning characteristics of children with epilepsy is an important area that can provide an understanding of the impact of chronic clinical picture of the emotional development and social kids. The prospect of linking empirical evidence of cognitive and emotional approach, expanding the strategies commonly used in neuropsychological assessment procedures may allow more comprehensive interpretations of the picture. This study aimed to characterize the cognitive and emotional functioning of children and adolescents with epilepsy from specific instruments of psychological assessment, highlighting resources and possible difficulties to adjust to the context of life. We evaluated two clinical groups of children and adolescents from seven to 16 years, regularly seen at the Epilepsy Surgery Center (CIREP), Hospital das Clínicas of the Ribeirão Preto Medical School, University of São Paulo, as follows: Group 1 (preoperative, $n=17$ ): patients with epilepsy hospitalized in CIREP; Group 2 (post-operatory, $\mathrm{n}=18$ ): patients who underwent epilepsy surgery, with control of seizures and attending the outpatient clinic of CIREP. He composed a third group (comparison group, $\mathrm{n}=31$ ) with volunteers from public schools, similar in age and sex to the clinical groups. The instruments used were: Strengths and Difficulties Questionnaire (SDQ), Wechsler Intelligence Scale for Children (WISC-III), Corsi Blocks test (TBC) and Test of Pfisters Color Pyramid. Descriptive and inferential analyzes were performed in order to allow neuropsychological characterization and emotional functioning of children and adolescents. Finally, we performed the general profile of results of the clinical group $(n=35)$ in each instrument, and compared to its normative data. The evidence obtained by the SDQ point out that epilepsy patients groups have more problems with emotional problems, hyperactivity, problems with colleagues and school learning than children and adolescents in the comparison group. Through the cognitive tests (III and W1SCCorsi test), it was found that the clinical cases showed a cognitive and spacial memory performance below the comparison group. The projective personality assessment method (Pfister test), on the other hand, showed indications of inhibition at lower affective clinical cases, compared with the nonpatients children and adolescents, although in general it has been found that the emotional experiences are preserved in all cases. Compared to normative data, the clinical group had lower scores on IQ scores and in all evaluated subtests (WISC-III), lower average scores in front of the Corsi Test (forward and reverse version), plus the following findings the Pfister test: medium percentages of brown and gray colors and significantly higher stimulation syndrome, medium percentages of white and colorless syndrome significantly below the standard average, with preference for the realization of punched carpets. The set of findings suggests lower cognitive function and signs of instability in the control of emotions in the group with epilepsy, confirming the need for specific interventions with these children and adolescents throughout their development, in order to encourage appropriate use of their potential.

Keywords: Psychological Assessment, Epilepsy, Children, Adolescents, Affectivity. 



\section{LISTA DE TABELAS}

Tabela 1: Estudos sobre metódos projetivos utilizados em processos de avaliação psicológica

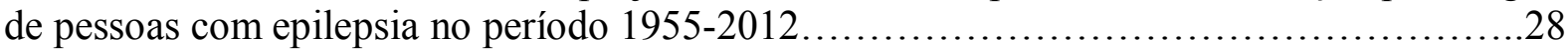

Tabela 2: Percurso amostral da pesquisa em função dos grupos estudados.

Tabela 3: Distribuição dos participantes em função do grupo (clínico e controle), idade e sexo.

Tabela 4: Resultados descritivos e comparação estatística da idade e anos de estudo dos participantes em função dos grupos.

Tabela 5: Resultados descritivos e comparação estatística do período de início das crises (em meses) e frequência das crises (mensais) de epilepsia em função do grupo clínico....

Tabela 6: Distribuição (em frequência simples e porcentagem) de características clínicas dos participantes em função de seu agrupamento (G1, G2 e total).

Tabela 7: Distribuição (em frequência simples e porcentagem) das variáveis clínicas dos participantes do grupo pós-operatório $(\mathrm{G} 2, \mathrm{n}=18)$.

Tabela 8: Distribuição (em frequência simples e porcentagem) e comparação estatística da distribuição dos casos segundo classificação no SDQ em função dos grupos (G1=préoperatório, G2=pós-operatório, G3=grupo de comparação)

Tabela 9: Resultados descritivos e comparação estatística do SDQ em função dos grupos (G1=pré-operatório, G2=pós-operatório, G3=grupo de comparação).

Tabela 10: Resultados descritivos e comparação estatística das dificuldades relatadas pelos pais no $\mathrm{SDQ}$ em função dos grupos ( $\mathrm{G} 1=$ pré-operatório, $\mathrm{G} 2=$ pós-operatório, $\mathrm{G} 3=$ grupo de comparação)

Tabela 11: Distribuição (em frequência simples e porcentagem) da classificação intelectual dos participantes no WISC-III em função dos grupos (G1=pré-operatório, G2=pós-operatório, G3= grupo de comparação)....

Tabela 12: Resultados descritivos e comparação estatística das somatórias dos pontos ponderados no WISC-III em função dos grupos (G1=pré-operatório, G2=pós-operatório, G3= grupo de comparação).

Tabela 13: Resultados descritivos e comparação estatística dos resultados ponderados dos subtestes do WISC-III em função dos grupos (G1=pré-operatório, G2=pós-operatório, G3= grupo de comparação).

Tabela 14: Resultados descritivos e comparação estatística dos resultados brutos no Teste de Blocos de Corsi em função dos grupos (G1=pré-operatório, $\mathrm{G} 2=$ =pós-operatório, G3=grupo de comparação) 
Tabela 15: Resultados descritivos e comparação estatística das porcentagens médias das cores do Teste de Pfister em função dos grupos (G1=pré-operatório, G2=pós-operatório, G3=grupo de comparação).

Tabela 16: Resultados descritivos e comparação estatística das porcentagens médias das principais síndromes cromáticas do Teste de Pfister em função dos grupos (G1=préoperatório, G2=pós-operatório, G3=grupo de comparação). .64

Tabela 17: Resultados descritivos e comparação estatística das porcentagens médias dos tipos de formação no Teste de Pfister em função dos grupos (G1=pré-operatório, G2=pósoperatório, G3=grupo de comparação)

Tabela 18: Resultados descritivos e comparação estatística das porcentagens médias dos processos de execução das pirâmides do Teste de Pfister em função dos grupos (G1=préoperatório, G2=pós-operatório, G3=grupo de comparação). .66

Tabela 19: Resultados descritivos e comparação estatística das porcentagens médias das fórmulas cromáticas do Teste de Pfister em função dos grupos (G1=pré-operatório, G2=pósoperatório, G3=grupo de comparação).

Tabela 20: Distribuição dos casos clínicos $(n=35)$ em função de sua classificação diagnóstica no WISC-III. .68

Tabela 21: Resultados descritivos e comparação estatística dos QI médios no WISC-III em função da amostra normativa brasileira (Figueiredo, 2002). .68

Tabela 22: Resultados descritivos e comparação estatística dos QI médios no WISC-III em função de amostra com epilepsia (Figueiredo, 2002).

Tabela 23: Resultados descritivos e comparação estatística dos pontos ponderados nos subtestes do WISC-III em função da amostra normativa brasileira (Figueiredo, 2002).........70

Tabela 24: Resultados descritivos e comparação estatística do TBC do grupo clínico (n=35) com referencial normativo brasileiro (Siquara, 2014).

Tabela 25: Porcentagens médias de escolhas cromáticas do grupo clínico $(n=34)$ no Teste de Pfister e comparação com dados normativos 72

Tabela 26: Porcentagens médias das síndromes cromáticas do grupo clínico $(n=34)$ no Teste de Pfister e comparação com dados normativos

Tabela 27: Distribuição (em frequência simples e em porcentagem) dos tipos de pirâmides do

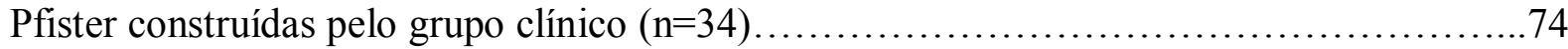

Tabela 28: Distribuição (em frequência simples e em porcentagem) dos processos de

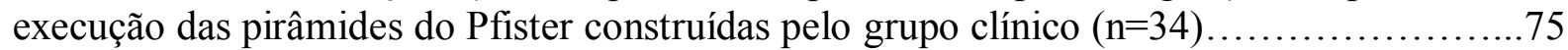

Tabela 29: Distribuição (em frequência simples e em porcentagem) das fórmulas cromáticas do grupo clínico $(\mathrm{n}=34)$ no Pfister, em função da amplitude e da estabilidade das escolhas...75

Tabela 30: Distribuição (em frequência simples e em porcentagem) dos tipos de pirâmides do Pfister em função do nível intelectual.................................................. 76 


\section{SUMÁRIO}

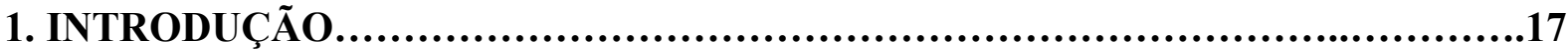

1.1. Avaliação psicológica.......................................................... 17

1.2. Avaliação psicológica de crianças e adolescentes com epilepsia........................21

1.3. Métodos projetivos de avaliação psicológica e epilepsia.............................27

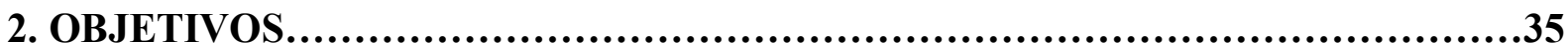

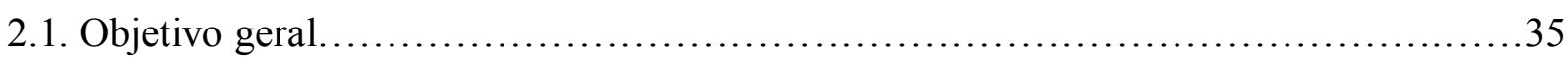

2.2. Objetivos específicos.....................................................

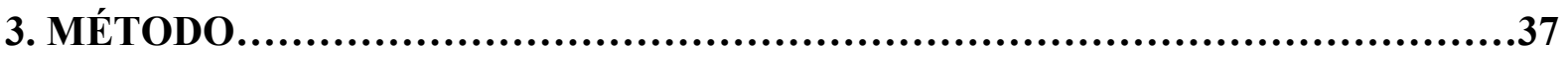

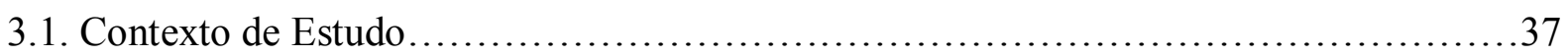

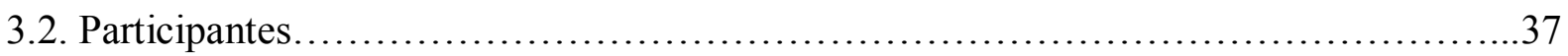

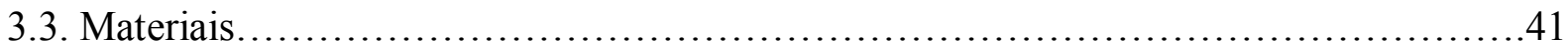

3.3.1. Questionário de Capacidades e Dificuldades - SDQ ..............................41

3.3.2. Escala de Inteligência Wechsler para crianças - WISC-III.........................42

3.3.3. Teste de Blocos de Corsi......................................................42

3.3.4. Teste das Pirâmides Coloridas de Pfister.......................................43

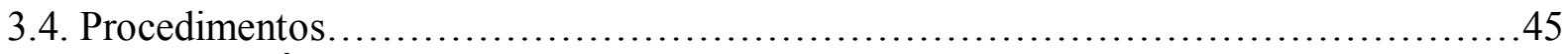

3.4.1. Aspectos Éticos............................................................. 45

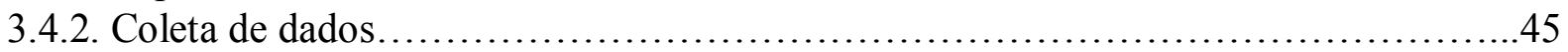

3.4.3. Análise dos Resultados.................................................47

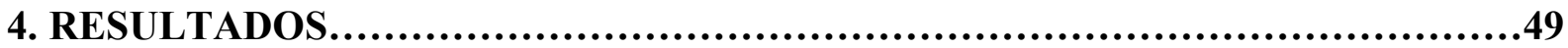

4.1. Caracterização sociodemográfica e clínica dos participantes.........................49

4.2. Resultados referentes ao SDQ................................................. 54

4.3. Resultados referentes ao WISC-III ............................................ 57

4.4. Resultados referentes ao Teste de Blocos de Corsi...................................61

4.5. Resultados referentes ao Teste de Pfister.........................................62

4.6. Perfil geral do grupo clínico e comparação com dados normativos......................67

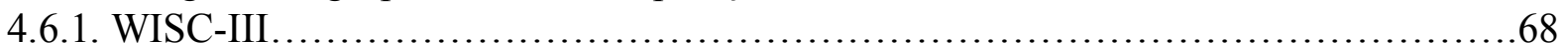

4.6.2. Teste de Blocos de Corsi.................................................... 70

4.6.3. Teste de Pfister............................................................. 71

4.7. Associação entre resultados no WISC-III e no Teste de Pfister.........................76

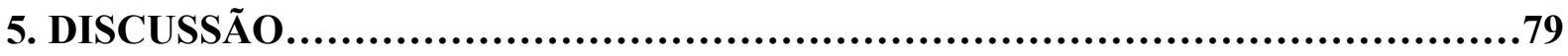

6. CONSIDERAÇÕES FINAIS...................................................89

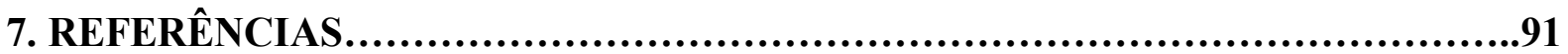

8. APÊNDICES e ANEXOS..............................................................99

8.1 APÊNDICE A: Termo de Consentimento Livre e Esclarecido (TCLE) para pais e/ou responsáveis de crianças ou adolescentes dos Grupos 1 e 2 (grupos clínicos)..................99 8.2 APÊNDICE B: Termo de Consentimento Livre e Esclarecido (TCLE) para pais e/ou responsáveis de crianças ou adolescentes do Grupo 3 (grupos de comparação)..............101 8.3 ANEXO 1: Documento de aprovação do projeto pelo Comitê de Ética em Pesquisa com

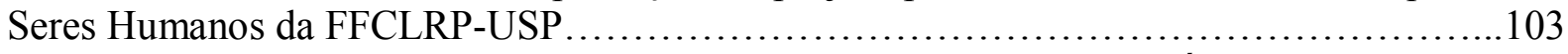
8.4 ANEXO 2: Documento de aprovação do projeto pelo Comitê de Ética em Pesquisa com Seres Humanos da FMRP-HC-USP. 



\section{INTRODUCC̃̃̃}

\subsection{Avaliação psicológica}

A área de avaliação psicológica formalizou-se no final do século XIX, dedicando-se à criação e aos estudos de instrumentos e técnicas destinados a explicar o funcionamento psicológico dos indivíduos, contribuindo para a evolução do conhecimento na Psicologia. Segundo Cunha (2000a), a expressão "avaliação psicológica" teve origem na publicação Assessment of Men, da Secretaria de Serviços dos EUA, em 1948. Esta obra possibilitou a melhor compreensão do termo psicodiagnóstico vigente até àquela época, com origem em um modelo médico de atuação. A partir disso, a avaliação psicológica passou a ser utilizada não somente para identificar aspectos deficitários e patológicos de um indivíduo, mas também para avaliar aspectos relacionados aos seus recursos potenciais e suas capacidades (Pacheco, 2005).

Trata-se de uma atividade complexa que visa à busca sistemática do conhecimento a respeito das características e do funcionamento psicológico das pessoas e constitui um recurso importante para auxiliar o psicólogo na tomada de decisões e orientar ações profissionais embasadas em situações e problemas específicos. O processo de avaliação psicológica pode ser aplicado em diferentes contextos de atuação profissional do psicólogo: clínica, escolar, organizacional, de pesquisa, entre outras (Pacheco, 2005; Pasquali, 1999; Primi, 2010).

No contexto clínico, junto a entrevistas e observações do comportamento, os testes psicológicos podem se constituir em instrumentos essenciais na coleta de dados. Possibilitam que o psicólogo avalie o paciente de forma sistemática, acessando informações úteis para o mapeamento de recursos individuais ou de grupos no tocante às diferentes funções psicológicas. Os resultados são interpretados à luz de pressupostos teóricos, a fim de identificar aspectos específicos, tanto para oferecer prognósticos quanto para auxiliar planejamento de intervenções de natureza psicológica (Cunha, 2000a; 2000b).

Alchieri e Cruz (2003) classificam, de modo clássico e didático, os testes psicológicos em dois grandes grupos: objetivos e projetivos. Entre os testes objetivos estão os instrumentos de avaliação das funções cognitivas, como os testes de inteligência e neuropsicológicos. De maneira geral, o indivíduo é submetido a instrumentos adequados a sua idade e nível de escolaridade, são levantados escores e consultadas tabelas de referência para classificação dos desempenhos e posterior interpretação dos resultados. Deste modo, os dados aparecem em 
forma quantitativa e podem servir de parâmetros para formular hipóteses sobre a presença de recursos e/ou de alterações cognitivas (Cunha, 2000b).

Já os testes neuropsicológicos têm como objetivo avaliar habilidades cognitivas mais específicas como: atenção, função executiva, memória, aprendizagem, linguagem, percepção, organização visoespacial, função visomotora e praxia. Segundo Costa, Azambuja, Portuguez e Costa (2004), os recursos técnicos da neuropsicologia estão voltados para a compreensão do funcionamento cerebral do indivíduo, recorrendo aos conhecimentos das Neurociências e da prática clínica em Psicologia, acessando dados sobre as funções cognitivas, comportamentais e de personalidade dos indivíduos. Ainda de acordo com estes autores, a avaliação neuropsicológica deve considerar também o contexto cultural, o nível educacional, a motivação e a cooperação do examinando durante a aplicação dos testes, bem como eventuais deficiências associadas a seu quadro clínico.

A escolha dos instrumentos de avaliação neuropsicológica depende dos objetivos da própria solicitação do exame, além dos achados clínicos do caso. No Brasil, pesquisadores e clínicos, atuantes em Neuropsicologia, enfrentam grande dificuldade com os instrumentos neuropsicológicos, frente a escassez de testes padronizados para o contexto sociocultural brasileiro. Alchieri (2004) faz referência aos principais testes psicológicos utilizados no Brasil e que têm sido utilizados no campo da neuropsicologia: Teste de Atenção Concentrada, Rapidez e Exatidão (ACRE), Bateria de Provas de Raciocínio (BPR-5), Teste de Inteligência Não Verbal D-70, Escala de Transtorno de Déficit de Atenção/Hiperatividade, Escala de Maturidade Mental Columbia (EMMC), Figuras Complexas de Rey, Teste de cópia e reprodução de memória de figuras geométricas complexas, Teste de Bender, Psicodiagnóstico Miocinético (PMK), Matrizes Progressivas Coloridas de Raven, Teste neuropsicológico computadorizado de atenção visual (TAVIS 2-R), Método de Rorschach, Teste de Desempenho Escolar (TDE), Teste de retenção visual de Benton e a WISC-III.

Nos últimos anos, a Neuropsicologia tem se mostrado cada vez mais importante para o diagnóstico de várias patologias, favorecendo adequada indicação de tratamento para diferentes indivíduos. No processo de avaliação neuropsicológica, a análise dos resultados dos testes visa identificar as áreas deficitárias, além de descobrir as potencialidades do indivíduo. Com posse dessas informações, podem ser elaboradas intervenções para beneficiar seu desenvolvimento e a aquisição de conhecimento para melhorar seu desempenho nas tarefas do cotidiano. Além disso, é possível orientar familiares e cuidadores, subsidiando apreciação mais adequada do quadro clínico, bem como o planejamento de intervenções psicológicas ou sociais (Alchieri \& Cruz, 2003). 
É importante lembrar que, diferentemente do adulto, o cérebro da criança ainda está em desenvolvimento e constante mudança de suas características neurobiológicas. Portanto, as baterias de testes neuropsicológicos adaptados para crianças devem levar em consideração a variação dos componentes do desenvolvimento mesmo entre crianças de mesma faixa etária.

Em comparação com os testes de natureza objetiva, os métodos projetivos de avaliação psicológica consideram, de maneira mais livre, o conjunto de variáveis expressas pelos indivíduos (Anzieu, 1978). Enfatizam interpretações holísticas e flexíveis, buscando entendimentos mais amplos sobre a pessoa. Os métodos projetivos são centrados na análise multivariada de semelhanças sistemáticas entre pessoas e, portanto, são mais próximos do raciocínio clínico (Primi, 2010). Cunha (2000b) acrescenta que as técnicas projetivas se baseiam em uma avaliação compreensiva e enfocam a personalidade de maneira mais global, no geral com base em pressupostos psicodinâmicos.

O método projetivo de avaliação psicológica, segundo Chabert (2004) e VillemorAmaral \& Franco (2008), permite que conhecimento sobre peculiaridades de quem o executa, tanto em aspectos estruturais quanto em sua dinâmica afetiva. Desse modo, as técnicas projetivas são capazes de expressar as modalidades de funcionamento psíquico próprias de cada sujeito em suas especificidades e articulações singulares. Importante sublinhar que os testes projetivos requerem validação diferenciada dos testes de aptidão e objetivos, na medida em que descrevem o indivíduo de acordo com um esquema dinâmico de variáveis (Anzieu, 1978). Desse modo, o controle do material proposto e as condições de aplicação são muito importantes por permitirem o tratamento quantitativo e qualitativo dos dados (Chabert, 2004).

A avaliação psicológica deve relacionar diferentes aspectos do funcionamento do indivíduo, integrando informações sobre funções cognitivas, afetivas e sociais, devidamente contextualizadas no ambiente vivenciado. Contudo, de acordo com Souza (2011), o tema das relações entre afetividade e aspectos cognitivos é usualmente deixado em segundo plano, o que pode levar a visões unilaterais sobre o desenvolvimento psicológico. A superação dessa dicotomia só pode ser alcançada com reflexões teóricas integradas a partir dos resultados de investigações empíricas que procurem interações entre esses componentes psíquicos, como, por exemplo, em estudos de natureza correlacional entre recursos intelectuais e afetivosociais.

Alguns esforços de pesquisa vêm sendo realizados com esse intuito no Brasil. No estudo conduzido por Costa e Villemor-Amaral (2004) foi avaliada a relação entre a estruturação das Pirâmides Coloridas de Pfister (método projetivo de avaliação de características de personalidade) e o nível cognitivo de seus participantes por meio da Bateria 
de Provas de raciocínio (BPR-5), a partir de grupos contrastantes (baixo e alto rendimento cognitivo). Participaram do estudo 200 alunos do ensino médio, de escolas da rede estadual e privada. Os participantes foram selecionados conforme seu desempenho na BPR-5, divididos em dois grupos: percentil igual ou superior a 70 e percentil igual ou menor que 30 . Os resultados encontrados apontam para uma relação significativa entre nível intelectual e aspecto formal das pirâmides, ao constatarem que adolescentes produziram pirâmides formalmente mais elaboradas na direta proporção de seu desempenho na prova de raciocínio. Assim, aqueles indivíduos com indicadores de maior potencial cognitivo construíram as pirâmides do Pfister com características mais elaboradas do ponto de vista formal. Este tipo de perspectiva de investigação científica mostra-se como promissor, sobretudo ao se pensar na diversidade de inter-relações possíveis de serem desenvolvidas entre as funções psicológicas nos mais variados contextos de aplicação dos testes psicológicos e também neuropsicológicos.

No Brasil, o Conselho Federal de Psicologia (CFP) é responsável pela regulamentação do uso dos instrumentos de avaliação psicológica. Esse processo foi aprimorado, a partir da criação, em 2001, do Sistema de Avaliação dos Testes Psicológicos (SATEPSI), apoiado pelo trabalho de uma Comissão Consultiva em Avaliação Psicológica, assessora do CFP (Nunes \& Primi, 2010). A partir dessas diretrizes institucionais, o uso dos testes psicológicos, no contexto brasileiro, requer demonstrações empíricas de suas evidências de validade, precisão e referenciais normativos para adequada interpretação dos resultados, embasados em elementos teóricos de sustentação destes instrumentos avaliativos (Nunes \& Primi, 2010). São exigidos, desta forma, cuidadosos estudos científicos de modo a sustentar os procedimentos avaliativos, bem como suas específicas aplicações no contexto nacional.

A partir dessas diretrizes foi possível identificar esforços na reestruturação da área de avaliação psicológica no Brasil, sobretudo na última década, como apontado por Primi (2010). Houve criação de laboratórios de testes psicológicos em universidades, com o aumento do número de instrumentos psicológicos disponíveis, bem como maior demanda de trabalhos sobre avaliação psicológica. Nesse sentido, torna-se fundamental que as pesquisas em avaliação psicológica invistam na criação de novos instrumentos e na atualização e aprimoramento dos materiais avaliativos já existentes, de acordo com os parâmetros técnicocientíficos requeridos pelas resoluções elaboradas pelo CFP (Nunes \& Primi, 2010). Dessa forma, pode-se garantir a cientificidade e qualificação do material psicológico disponível para avaliação (Noronha \& Vendramini, 2003; Pacheco, 2005; Schellini, 2007).

Primi (2010) lembra ainda que, mais especificamente nos contextos de Saúde, há escassez de pesquisas brasileiras sobre perfis de funcionamento psíquico de diferentes grupos 
clínicos, tornando-se relevante a contribuição dos recursos da avaliação psicológica. Torna-se, desta forma, necessário desenvolver investigações acerca das características do funcionamento afetivo, cognitivo e social de recortes populacionais e patologias específicas, de modo a poder compreender suas características psíquicas e propor intervenções psicológicas favorecedoras da qualidade de vida geral dos indivíduos, sobretudo quando em processo de adoecimento. Dentro desse contexto, destaca-se o foco de investigação do presente projeto de pesquisa, o grupo clínico de crianças e adolescentes com epilepsia, tópico a seguir explorado.

\subsection{Avaliação psicológica de crianças e adolescentes com epilepsia}

A epilepsia é uma doença crônica neurológica comum na infância, que se manifesta, geralmente, sob a forma de crises convulsivas recorrentes, cujos graus de intensidade e duração podem variar. De acordo com Guerreiro (1996), cerca de 1\% da população mundial apresenta essa patologia, sendo que na população infantil a prevalência varia de 3,2 a 5,1 por 1000 indivíduos. No Brasil a prevalência varia de 11,9 a 21,0 por 1000 crianças, apresentando taxas semelhantes às apresentadas em outros países em desenvolvimento (Noronha et al., 2007).

Existe uma série de causas para o surgimento da epilepsia, tais como: fatores genéticos, malformações congênitas, alterações metabólicas, tumores, infecções, traumatismos crânioencefálicos, causas tóxicas e mesmo causas idiopáticas (Guerreiro, 1996). Segundo a Liga Brasileira de Epilepsia (LBE, 2015), a epilepsia é mais comum na infância devido a maior vulnerabilidade a infecções do sistema nervoso central (meningite), acidentes (traumatismos crânio-encefálicos) e doenças como sarampo, varicela e caxumba, cujas complicações podem levar a crises epilépticas.

De acordo com a ILAE (1997) e considerando o critério etiologia, as epilepsias podem ser classificadas em: a) idiopáticas (epilepsias transmitidas geneticamente e que não são acompanhadas por lesões cerebrais estruturais ou outro sinal neurológico); b) sintomáticas (epilepsia cuja etiologia está determinada e consequente a lesões cerebrais); c) criptogênicas (epilepsias presumivelmente de base orgânica, porém cuja etiologia não pode ser identificada).

O diagnóstico da epilepsia é realizado fundamentalmente pelo histórico clínico do paciente, sendo que o eletroencefalograma (EEG) e exames de neuroimagem contribuem para 
auxiliar nesse processo investigativo. Entretanto, os resultados normais desses exames não excluem a possibilidade do paciente apresentar epilepsia (LBE, 2015).

Verifica-se, em paciente com epilepsia, alta prevalência de problemas de comportamento, dificuldades de ajustamento psicossocial e prejuízos na qualidade de vida (Fernandes \& Souza, 2001a). Além disso, nas crianças também são frequentes dificuldades de aprendizagem e déficits cognitivos associados a fatores clínicos como: idade de início, frequência das crises, tipo de crise, causa da epilepsia, tipo de drogas antiepilépticas utilizadas e duração da epilepsia (Souza-Oliveira, Escorsi-Rosset, Funayama, Terra, Machado \& Sakamoto, 2010).

Comarck et al. (2007) estudaram crianças com epilepsia refratária ao tratamento medicamentoso. Concluíram que, dentre diversas variáveis clínicas analisadas (como idade de início da epilepsia, duração da epilepsia, tipo de patologia e lado da ressecção), a "idade de início da epilepsia" foi considerada o melhor preditor de eficiência intelectual. As crianças que tiveram início da epilepsia no primeiro ano de vida apresentaram incidência de deficiência cognitiva em elevada proporção $(82,4 \%$ dos casos), sugerindo a importância do tratamento precoce para esses pacientes.

O tipo de crise pode variar em função do local e da extensão cerebral comprometida, bem como sua severidade, levando a diversidade de formas clínicas da epilepsia. Os sinais e sintomas de uma crise epiléptica, como distúrbios da consciência, dos movimentos ou da sensibilidade, refletem a ativação da respectiva área do cérebro afetada. Assim, apenas uma parte do cérebro pode ser afetada ou toda extensão dos hemisférios cerebrais, levando, respectivamente, à crise parcial (focal) ou generalizada (Guerreiro, 2006).

Em uma revisão de literatura, Schlindwein-Zanini, Portuguez e Costa (2007) encontraram que pacientes com epilepsia do lobo frontal podem apresentar transtornos psicológicos e neuropsicológicos, como déficits em funções executivas (cognição, planejamento e atenção), alterações comportamentais (controle de impulsos e agressividade), manifestações de crises epilépticas comportamentais e piora da qualidade de vida. Suas alterações podem ser confundidas com doenças psiquiátricas, reforçando a importância do diagnóstico diferencial e da avaliação psicológica completa desses casos.

Silva, Andrade e Oliveira (2007) investigaram a cognição de pacientes com epilepsia de lobo temporal que apresentavam ou não lesão mesial, segundo exame de ressonância magnética, com objetivo de identificar possíveis alterações funcionais. Os pacientes com lesão apresentaram desempenho cognitivo rebaixado (em relação a casos controle) em diversas atividades: memória, linguagem, resolução de problemas do cotidiano, enquanto os 
pacientes sem lesão mostraram-se mais compensados do ponto de vista clínico, apenas com sutis alterações atencionais.

Já crianças com epilepsia do lobo occipital podem apresentar desempenhos significativamente reduzidos em ampla variedade de tarefas cognitivas, dentre elas habilidades visuoespaciais e motoras (Gulgonen et al., 2000). Mais especificamente, Germano et al. (2005) encontraram redução das habilidades de leitura, escrita e cálculo, associadas com dificuldades no plano da memória visual e das habilidades grafomotoras. Entretanto, deve-se ressaltar que, em função da maneira integrada de funcionamento da estrutura cerebral, uma lesão localizada pode comprometer várias tarefas cognitivas aparentemente independentes (Luria, 1994).

Em termos de fatores desencadeantes de crises epilépticas, a literatura científica da área aponta que mudanças súbitas da intensidade luminosa ou luzes a piscar, privação de sono, ingestão alcoólica, febre, drogas e medicamentos, ansiedade, cansaço e nervosismo, constituem os principais elementos disparadores desta sintomatologia. Existem casos também de pessoas portadoras ou não de epilepsia que podem manifestar crises decorrentes de desejo consciente ou inconsciente de mais atenção e cuidados (LBE, 2015). A identificação destes fatores desencadeadores de crises epilépticas certamente favorece medidas de intervenção de natureza protetora e preventiva, em alguns casos.

No entanto, o manejo da epilepsia requer também o recurso da intervenção medicamentosa. Na maioria dos casos, as drogas antiepilépticas são eficazes no controle de crises, conseguindo-se diminuir seus efeitos colaterais. A remissão das crises pode ser alcançada em cerca de $70 \%$ dos pacientes. Entretanto, em crianças, o uso das medicações por tempo prolongado pode causar prejuízos cognitivos progressivos em um cérebro que ainda está em desenvolvimento. Se, por um lado, as drogas reduzem as crises através da diminuição da excitabilidade ou aumento da inibição neuronal, elas também acarretam sedação, sonolência, distração e insônia, fatores estes que podem ocasionar ou intensificar prejuízos na performance acadêmica (Loring \& Meador, 2004). Estudos indicam que as drogas antiepilépticas desenvolvidas nos últimos anos, potencialmente, prejudicariam menos a cognição do que as drogas mais antigas, e essas diferenças levariam a um importante impacto na melhora da qualidade de vida das crianças (Ortinski \& Meador, 2004).

Ainda assim, 30\% dos pacientes possuem epilepsia refratária ao tratamento medicamentoso. Nesses casos, a abordagem neurocirúrgica pode ser uma terapia alternativa promissora para o controle das crises, especialmente em pacientes com crises focais (SouzaOliveira, Escorsi-Roset, Terra, Muxfeldt-Bianchin, Machado \& Sakamoto, 2012). Segundo os 
referidos autores, a cirurgia de epilepsia na criança tem como objetivos o controle das crises com mínima ou nenhuma sequela neurológica, a retomada ou a manutenção do desenvolvimento neuropsicomotor, além da melhora das questões comportamentais, do funcionamento cognitivo e, consequentemente, do desempenho escolar. Esse tipo de intervenção médica em pacientes pediátricos é particularmente complexo, visto que a criança se encontra em desenvolvimento e constante mudança em suas características neurobiológicas.

Há outros estudos apontando que quanto mais precoce a cirurgia para controle da epilepsia, maior será seu potencial favorável de repercussão ao desenvolvimento da criança, já que ocorre num momento de grande plasticidade neuronal, possibilitando maior reorganização e adaptação pós-cirúrgica (Da Costa \& Portela, 2006). Para realização dessa abordagem, o paciente deverá passar por minucioso processo investigativo para a correta localização da área cerebral responsável pelas crises epilépticas, utilizando-se o vídeo-EEG para seu registro, bem como exames funcionais e anatômicos de neuroimagem (Da Costa \& Portela, 2006).

Em comparação com os adultos, os pacientes pediátricos apresentam mais frequentemente EEGs não localizatórios. Isso provavelmente está associado a elevada incidência de lesões extratemporais e anormalidades do desenvolvimento cortical nesses casos infantis (Wyllie, 1998).

No que se refere à avaliação neuropsicológica nos pacientes indicados para abordagem neurocirúrgica, seu principal objetivo estaria voltado à predição cognitiva, a partir da interpretação dos padrões de desempenho em ampla bateria de testes neuropsicológicos. Dessa forma, seria possível caracterizar o funcionamento cognitivo do paciente e elaborar alguma estimativa de possíveis prejuízos relacionados à lesão cerebral (Fernandes \& Souza, 2001b). Deve-se ainda avaliar se a remoção da área afetada poderia acarretar déficits neurológicos funcionais ainda maiores ao paciente, com cuidado especial nas áreas da linguagem e da memória (Da Costa \& Portela, 2006). Cerca de 70\% dos adultos com epilepsia refratária apresentam foco epileptogênico no lobo temporal, o qual está relacionado com essas funções (Portuguez, Costa \& Marroni, 2005). Após a cirurgia, o neuropsicólogo pode analisar as mudanças (melhora, manutenção ou piora) do desempenho cognitivo do paciente em relação a seus resultados antes do procedimento cirúrgico.

O impacto da cirurgia de epilepsia na vida dos pacientes, contudo, ainda é pouco investigado. Sabe-se que crianças com crises epilépticas bem controladas apresentam melhor desempenho cognitivo quando comparadas àquelas com epilepsia refratária, como apontaram, Souza-Oliveira et al. (2010). Nesse sentido, a cirurgia de epilepsia pode causar impacto 
positivo no funcionamento cognitivo da criança que fica livre de crises após esse procedimento médico, ainda que invasivo e de alta complexidade e riscos.

O método utilizado para determinar a eficiência da cirurgia é a ocorrência ou não de crises no pós-operatório. Um sistema utilizado para exame dessa eficiência cirúrgica é o da classificação de Engel (1993): a) classe I: completa remissão de crises após a cirurgia, ou presença somente de crises parciais simples sem morbidade desde a cirurgia ou nos últimos dois anos, ou ocorrência de crises tônico-clônicas generalizadas desencadeadas por retirada das drogas antiepilépticas; b) classe II: crises raras desde a cirurgia ou pelo menos nos dois últimos anos, ou presença exclusivamente de crises noturnas; c) classe III: melhora significativa, com redução maior que $75 \%$ da frequência de crises quando comparadas ao préoperatório ou intervalos prolongados livres de crises maiores do que metade do período de seguimento, mas não menor que dois anos; d) classe IV: redução não significativa, nenhuma mudança na frequência de crises ou piora das mesmas.

Em uma revisão de 23 artigos da literatura científica atual sobre cirurgia da epilepsia em crianças e adolescentes, Da Costa e Portela (2006) encontraram que mais de $60 \%$ dos pacientes tiveram boa evolução pós-operatória. Além disso, identificaram que aproximadamente 30 a $40 \%$ dos pacientes entre dois e oito anos de idade melhoraram em algum aspecto do seu comportamento, tais como atenção, agressividade e hiperatividade, além do que $16 \%$ iniciaram a atividade escolar após a cirurgia. Além disso, os pais notaram a melhora no comportamento social em aproximadamente $2 / 3$ das crianças.

Apesar dos esforços técnicos, os processos avaliativos dos quadros de epilepsia, sobretudo no tocante às investigações psicológicas, têm focalizado os componentes cognitivos de maneira enfática. Conforme Fernandes e Souza (2001b; 2001c), um aspecto fundamental que vem sendo frequentemente negligenciado nos serviços especializados de avaliação do paciente com epilepsia são os componentes emocionais e sociais. Sentimentos como medo, raiva, confusão e tristeza são entendidos como um processo natural frente ao diagnóstico da doença. Quando os filhos apresentam este tipo de problemática, os pais, geralmente, adotam atitudes de excesso de vigilância, ansiedade e superproteção, mesmo nos casos de epilepsia bem controlada, muitas vezes favorecendo cristalização de comportamentos pouco adaptativos e não favorecedores do desenvolvimento infantil. As autoras alertam que essas atitudes parentais podem provocar consequências bastante negativas nos filhos, como baixa autoestima, isolamento social, dificuldades de relacionamento e infantilidade.

As pesquisadoras também chamam a atenção para o fato de que, no ambiente escolar, além dos problemas de aprendizagem que podem estar associados aos sintomas da epilepsia, 
as crianças tendem a enfrentar estigmas e discriminação. Em outras palavras, argumentam sobre a vulnerabilidade a que fica exposta a criança com esta patologia, ainda que esforços para sua integração sejam desenvolvidos no ambiente acadêmico, dada a noção geral de perdas e de descontrole comportamental comumente atribuído ao quadro de epilepsia na infância.

Para além destas implicações do convívio social, há dados clássicos referentes às dificuldades comportamentais e psiquiátricas associadas às síndromes epilépticas. Como exemplo disso pode-se tomar o estudo realizado por Austin et al. (2002), que apontou que crianças com epilepsia tiveram escores médios totais no Child Behavior Checklist (CBCL questionário que avalia competência social e problemas de comportamento) mais altos e mais problemas comportamentais internalizantes, como ansiedade e depressão.

Já de acordo com Gaitatzis, Trimble e Sander (2004), as comorbidades psiquiátricas e de personalidade são encontradas em 30\% das crianças e adolescentes com epilepsia, sendo frequentemente diferentes dos transtornos psiquiátricos em adultos. A investigação conduzida por Davies, Heyman e Goodman (2003) identificou taxa de 37\% de transtornos psiquiátricos, sendo encontrados como principais diagnósticos: autismo, transtorno de conduta, transtorno do déficit de atenção e hiperatividade, ansiedade, depressão e psicose. Além disso, estes pesquisadores relataram que crianças com epilepsia refratária possuem, em geral, maior probabilidade de apresentar transtornos psiquiátricos do que aquelas com epilepsia controlada. Diante destas evidências empíricas, grande esforço tem sido desenvolvido no sentido do controle das crises e dos sintomas associados à epilepsia, independentemente de sua origem e de seu desenvolvimento, buscando-se evitar maior complexidade clínica nos casos.

$\mathrm{Na}$ maioria das vezes, os transtornos psiquiátricos e de personalidade de pacientes com epilepsia são diagnosticados por meio de observações clínicas ou de instrumentos baseados na classificação categórica fundamentada nos critérios do DSM-IV (Davies, Heyman \& Goodman, 2003). Entretanto, segundo Gomes (2008), um diagnóstico diferencial pode ser difícil já que, muitas vezes, as queixas cognitivas e somáticas podem estar relacionadas à própria epilepsia ou ao seu tratamento, em especial ao uso de medicamentos, fazendo com que estas variáveis confundam os diagnósticos.

A esse respeito, Maia Filho, Costa e Gomes (2006) enfatizam que, atualmente, a abordagem clínica da criança com epilepsia deve ultrapassar o simples controle das crises. Nesse sentido, os autores recomendam oferecer atenção especial ao adequado diagnóstico e tratamento das consequências psicológicas e sociais nos pacientes e em sua família. 
Da Costa e Portela (2006) ampliam os argumentos anteriormente apontados, afirmando que deve ser realizada adequada e ampla avaliação de crianças e adolescentes com epilepsia, com necessidade de se investigar tanto aspectos relacionados à doença (tipo, frequência, severidade das crises, etiologia, entre outros), como suas implicações comportamentais, psicológicas, culturais, sociais e emocionais. Na concepção destes pesquisadores, os serviços especializados devem estar qualificados para tratar também desses problemas.

Compreende-se, assim, que a epilepsia mobiliza complexa gama de variáveis biológicas e fatores interacionais, de diferente natureza (emocionais, cognitivos, familiares, sociais e institucionais). Conforme Gomes (2008), nos casos de epilepsia refratária os fatores interacionais ocupariam maior relevância, exigindo investigações mais aprimoradas para seu correto tratamento e intervenções eficazes. Diante desse contexto, ferramentas e recursos técnicos que auxiliem o clínico e os profissionais que lidam com a epilepsia infantil na avaliação de componentes estruturais e funcionais da cognição e da afetividade podem proporcionar melhor atendimento a esses pacientes e diminuir o impacto negativo em sua vida e de suas famílias.

Frente ao conjunto de considerações prévias, o estudo de características do funcionamento emocional de crianças com epilepsia torna-se uma área promissora e relevante, a fim de proporcionar a compreensão do impacto deste quadro clínico crônico sobre o desenvolvimento afetivo e social infantil. A perspectiva de associar evidências empíricas da abordagem cognitiva e emocional, ampliando as estratégias comumente utilizadas nos processos de avaliação neuropsicológica poderá permitir interpretações compreensivas sobre o quadro, buscando-se entendimento sobre o paciente, principalmente crianças e adolescentes. No entanto, até o presente momento, pouco pode ser identificado de investimento brasileiro na avaliação psicológica de crianças e adolescentes com epilepsia na busca de indicadores afetivos, o que estimula ainda mais esta vertente de pesquisa, o que pode ser efetivado por métodos projetivos de avaliação psicológica, como a seguir explorado.

\subsection{Métodos projetivos de avaliação psicológica e epilepsia}

O campo dos testes psicológicos cognitivos e neuropsicológicos na avaliação de pacientes com epilepsia encontra-se em crescente desenvolvimento, tanto no Brasil quanto em nível internacional. Entretanto, nota-se pouco investimento em pesquisas que utilizem métodos projetivos de avaliação psicológica com esse grupo clínico. 
Nesse sentido, foi realizada revisão sistemática da literatura científica a respeito de pesquisas que utilizaram testes projetivos como método de avaliação psicológica de pessoas com epilepsia, no sentido de mapear o conhecimento relativo ao impacto deste quadro clínico crônico sobre o desenvolvimento afetivo dos indivíduos. Recorreu-se, para o levantamento bibliográfico, às seguintes bases de dados: Portal de Periódicos da CAPES, Biblioteca Virtual em Saúde (BVS), PubMed, PsycInfo e Web of Science. As palavras-chave utilizadas foram epilepsy AND projective test, selecionando-se somente artigos em periódicos e que se apresentassem em português, inglês e espanhol (por critério de conveniência técnica), excluindo-se, dessa forma, grande quantidade de trabalhos identificados em língua alemã e francesa.

Foram encontrados 333 trabalhos, sendo 24 repetidos entre bases de dados e excluídos 273 artigos por focalizarem: a) síndromes neurológicas específicas, em que um dos sintomas é a epilepsia; b) avaliação psicológica de cuidadores de pessoas com epilepsia; c) crises não epiléticas; d) apenas exames médicos e que não utilizavam teste projetivo. Desse modo foram selecionados para estudo sistemático 35 trabalhos, sendo possível recuperar, de modo integral, 21 artigos completos. Muitos dos estudos identificados não foram recuperados por suas datas de publicação muito antigas, o que dificultava o acesso ao texto. As publicações integrais recuperadas envolveram o período de 1955 a 2012, sinteticamente apresentados na Tabela 1.

Tabela 1: Estudos sobre metódos projetivos utilizados em processos de avaliação psicológica de pessoas com epilepsia no período 1955-2012.

\begin{tabular}{|c|c|c|c|c|}
\hline Ano & Título & Autores & Instrumentos projetivos & Principais resultados \\
\hline 2012 & $\begin{array}{l}\text { Art therapy focus } \\
\text { groups for children and } \\
\text { adolescents with } \\
\text { epilepsy }\end{array}$ & $\begin{array}{l}\text { Stafstrom, } \\
\text { Havlena, \& Krezinski }\end{array}$ & $\begin{array}{l}\text { Seizure Drawing Task } \\
\text { (SDT), Person Picking } \\
\text { an Apple from a Tree } \\
\text { (PPAT) e Levick } \\
\text { Emotional and Cognitive } \\
\text { Art Therapy Assessment } \\
\text { (LECATA) }\end{array}$ & $\begin{array}{l}\text { Os escores de avaliação de } \\
\text { arteterapia para o } \\
\text { desenvolvimento global foram } \\
\text { inferiores em relação a idade } \\
\text { cronológica dos participantes nos } \\
\text { três instrumentos. }\end{array}$ \\
\hline 2012 & $\begin{array}{l}\text { Research on the use of } \\
\text { the Hand Test in } \\
\text { clinical assessment of } \\
\text { children and } \\
\text { adolescents }\end{array}$ & $\begin{array}{l}\text { Vladislava, Marcb, } \\
\text { Agavriloaeic, } \\
\text { Maracineanud, \& Stefane }\end{array}$ & Hand Test (HT) & $\begin{array}{l}\text { O grupo com epilepsia teve } \\
\text { escores maiores nas variáveis: } \\
\text { ativo, ambiental, tensão, mal } \\
\text { ajustamento, descrição, falha, } \\
\text { retirada e variáveis patológicas e } \\
\text { escores mais baixos nas variáveis: } \\
\text { afeto, direção, respostas } \\
\text { interpessoais negativas, } \\
\text { interpessoais e total. }\end{array}$ \\
\hline 2006 & $\begin{array}{l}\text { Norms of the } \\
\text { Rorschach test for } \\
\text { indian subjects }\end{array}$ & $\begin{array}{l}\text { Chaudhury, Augustine, } \\
\text { Saldanha, Srivastava, } \\
\text { Kundeyawala, } \\
\text { Pawar \& Ryali }\end{array}$ & Rorschach & $\begin{array}{l}\text { O tempo de reação de pacientes } \\
\text { com epilepsia foi maior do que o } \\
\text { de indivíduos "normais". Os } \\
\text { grupos de esquizofrênicos e } \\
\text { pacientes com epilepsia deram } \\
\text { respostas confabulatorias. }\end{array}$ \\
\hline
\end{tabular}


Beghi, Spagnoli,

Emotional and affective Airoldi, Fiordelli,

2002 disturbances in patients Appollonio, Bogliun, with epilepsy
Picture Frustration Study (PFS)
Frattola \& Da Prada.

Pacientes com epilepsia e os outros dois grupos tiveram escores semelhantes no PFS. Escores

também foram semelhantes para o comportamento agressivo e escala de apatia. Pacientes com epilepsia tiveram escores de depressão mais elevados.

Crianças com crises parciais motoras desenharam partes do

Seizure drawings: insight into the selfimage of children with

Stafstrom \& Havlena epilepsy

\section{Desenho}

(cena de como é ter uma convulsão) corpo distorcidas. Aquelas com crises parciais complexas

representaram sintomas sensoriais e alterações do estado mental.

Crianças com crises generalizadas tônico-clônicas mostraram agitação.

"Método de Projeção Estruturada" (histórias descrevem situações que provocam sentimentos de

Negative emotions in

2000 children with newly diagnosed epilepsy
Oostrom, Schouten, Olthof,

Peters, \& JennekensSchinkel vergonha e/ou culpa no protagonista; a criança é convidada a indicar em uma escala de cinco pontos quanta vergonha e culpa o protagonista sente nessa situação)

Drawing of the family and of the human figure: a comparative study between children with epilepsy and a control group
Desenho da Figura

Humana (DFH)

e Bender
Crianças com epilepsia e crianças saudáveis apresentaram maneiras semelhantes de atribuir culpa e vergonha. Ambos os grupos atribuíam mais vergonha e incompetência devido à epilepsia do que a incompetência devido a outras doenças.

Para o DFH, a análise globa demonstrou que a idade mental atribuida às crianças epilépticas foi inferior a idade cronológica. Mãos estavam ausentes nos desenhos das crianças epilépticas.

No início do tratamento o DFH mostrou imaturidade e gradualmente maior controle dos impulsos e amadurecimento. Sobre o Bender, no início demonstrou fraco controle de impulso, baixa tolerância à frustração e problemas de desempenho; durante o tratamento a coordenação visomotora melhorou.

Comparative study of the cognitive functions and symbolic order in temporal and centerencephalic epilepsy of long development of difficult therapeutic control

1972 Personality traits of disabled epileptics

Mendilaharsu, Pérez, Pasquet \& Mirabal

Desenho (cubo, casa)

A representação gráfica do espaço projetivo (cubo, casa) foi paralela ao enfraquecimento operatório.

\begin{tabular}{|c|c|c|c|c|}
\hline & & & & pouca capacidade de se adaptar. \\
\hline 1969 & $\begin{array}{l}\text { A study of the rhythm } \\
\text { of petit mal absences in } \\
\text { children in relation to } \\
\text { prevailing situations. } \\
\text { The use of EEG } \\
\text { telemetry during } \\
\text { psychological } \\
\text { examinations, school } \\
\text { exercises and periods of } \\
\text { inactivity }\end{array}$ & $\begin{array}{l}\text { Guey Bureau, } \\
\text { Dravet, \& Roger }\end{array}$ & $\begin{array}{l}\text { Desenho (pessoa, árvore) } \\
\text { e Rorschach }\end{array}$ & $\begin{array}{l}\text { Durante os testes projetivos o } \\
\text { índice-e-onda de pico mais baixo } \\
\text { (EEG) foi encontrado em cerca de } \\
75 \% \text { dos indivíduos, a atitude do } \\
\text { psicólogo foi mais neutra e os } \\
\text { desempenhos menos propensos a } \\
\text { serem tratados num sistema de } \\
\text { certo-errado (como nos testes de } \\
\text { inteligência). }\end{array}$ \\
\hline
\end{tabular}

O teste de Rorschach confirmou: "achatamento da personalidade", lentidão, rigidez, estereotipia, pouca capacidade de se adaptar. ais baixo psicólogo foi mais neutra e os desempenhos menos propensos a inteligência). 
The gyrus cinguli and aggressivity

Jimeno \& Paniagua
Os autores afirmam que utilizaram método projetivo para avaliação da agressividade, mas não deixam claro qual o instrumento usado.
Relation between
Os autores afirmam que usaram método projetivo de avaliação da personalidade, mas não deixam claro o instrumento usado.

Cirurgia do cíngulo resultou no desaparecimento de agressão e normalização das tendências agressivas, mostrando-se tratamento útil quando todos os outros dispositivos terapêuticos fracassaram.

Alguns pacientes com TOC apresentaram alterações eletroencefalográficas semelhantes aos da epilepsia do lobo temporal, com sintomas e comportamentos semelhantes aos encontrados no período interctal (labilidade afetiva, irritabilidade, zelo religioso excessivo, hipossexualidade e preocupação excessiva com eventos triviais) e alguns pacientes com epilepsia do lobo temporal apresentam altos escores em testes de personalidade que medem características obsessivas.

Estudio Comparativo

entre los Aspectos

Clinicos,

1968 Electroencefalogrfificos Dorazco-Valdes y la Prueba del Dibujo

de la Figura Humana en el Nifio Epileptico
The personality of

1962 epiletics: a discussion Tizard of the evidence
Rorschach e

Teste de Apercepção Temática (TAT)
Foram encontradas variações no nível cognitivo medidas pelo DFH, com maior ou classificação de acordo com os resultados do EEG.

Cinco teorias básicas sobre a personalidade dos epilépticos estão descritas, analisadas segundo o olhar clínico e investigações psicológicas. Os resultados de estudos que utilizaram o teste de Rorschach mostram-se contraditórios e insuficientes.

Os resultados sugerem que o padrão psicológico das medidas projetivas da personalidade do paciente epiléptico pode não auxiliar na discriminação entre epilepsia de lobo temporal, focal e difusa.

Houve correlações entre o eletroencefalograma (EEG) e os testes projetivos de avaliação psicológica, com identificação de aspectos deficitários e patológicos das crianças com epilepsia.

A avaliação de QI não mostrou sinais de deterioração intelectual.

Temporal-lobe epilepsy
1957 associated with severe behavioral disturbances

Holden

Teste de Apercepção Temática (TAT)

A técnica projetiva sugeriu possível associação entre o comportamento e o ambiente em casa.

Os resultados não confirmam a maioria dos supostos indicadores Rorschach para pacientes com epilepsia.

Os resultados parecem indicar que indivíduos epilépticos

The use of the Bender-

1956 Gestal Test with epileptic children
Shaw \& Cruickshank Bender-Gestalt Test individuos apresentarem mais dificuldade que os controles na elaboração das figuras. 
(a) todos os epilépticos são emocionalmente explosivos, mas $\mathrm{CF}$ e $\mathrm{C}$ de Rorschach não medem

The Rorschach

1955 experience balance in epileptics
Pruyser \& Folsom

Rorschach essa dimensão; ou (b) $\mathrm{CF}$ e $\mathrm{C}$ são indicadores válidos de explosão emocional, mas epilépticos como um grupo não são caracterizados por este traço.

O que mais chamou a atenção nesta revisão bibliográfica foi o grande número de publicações sobre o tema nas décadas de 1950 e 1960, com queda acentuada nos estudos até os anos 1990, identificando-se elevação de publicações sobre o tema a partir do ano 2000. Almeida e Cruz (1988) discutem esse cenário e fazem uma análise dos fatores explicativos do apogeu e declínio no uso dos testes psicológicos nesse campo, o que, segundo eles, associa-se a duas formas diferentes de conceituar a prática psicológica.

De acordo com os autores, na primeira metade do século $\mathrm{XX}$, período em que o movimento dos testes psicológicos atingiu o seu ponto máximo, a prática psicológica seguia o "modelo médico" de intervenção. Concebia-se que problemas apresentados pelo indivíduo tinham causas internas subjacentes, compreendidas como traços estáveis. Perante este quadro, o psicólogo assumia uma posição passiva e seu trabalho reduzia-se à explicitação das possíveis causas dos problemas ou patologias. Pode-se dizer que os testes foram utilizados em sentido mais negativo, focalizando os aspectos deficitários dos indivíduos, voltados a uma análise comparativa e classificatória de habilidades e competências diversas.

Pode-se notar na presente revisão bibliográfica que os estudos das décadas de 1950 e 1960 eram voltados ao diagnóstico de envolvimento cortical e correlações entre exames clínicos, mais especificamente o eletroencefalograma (EEG) e os testes projetivos de avaliação psicológica (Shaw \& Cruickshank, 1956; Holden, 1957; Woscoboinik, 1960; Mirsky, Primac, Marsan, Rosvold \& Stevens, 1960; Dorazco-Valdes, 1968; Guey, Bureau, Dravet \& Roger, 1969). Além disso, as pesquisas tentavam buscar o padrão psicológico de personalidade do paciente com epilepsia e identificar aspectos deficitários e patológicos desse grupo clínico.

De acordo com o artigo teórico de Tizard (1962), recuperado na atual revisão bibliográfica, nessa época era utilizado o termo "personalidade epilética". A teoria central vigente argumentava que todos, ou a maioria dos indivíduos com epilepsia, apresentavam características de personalidade específicas, entre elas: "viscosidade", explosões emocionais, desconfiança, religiosidade, meticulosidade e egoísmo. De acordo com algumas teorias da "personalidade epilética", a própria predisposição para apresentar convulsões seria constitutiva da personalidade desses indivíduos. Segundo Tizard (1962), o indivíduo com 
epilepsia vivia um estigma social, já que seus sintomas eram vistos como disfunção da personalidade, notando-se um ambiente frustrante e pouco facilitador do pleno desenvolvimento humano.

De acordo com Alchieri (2003), nessa época a área da Saúde estava voltada basicamente para o conhecimento da físiologia e da fisiopatologia para compreender diversos quadros nosológicos, especialmente na neurologia. Por isso, a atenção dos estudos dirigia-se mais para os aspectos patológicos das desordens, tanto no diagnóstico quanto no tratamento. A Psicologia também estava voltada às dimensões fisiológicas e psicofísicas, na tentativa de compreender as determinações do comportamento dos indivíduos.

Já na segunda metade do século XX, os testes psicológicos e o modelo médico de cuidado em Saúde passaram a ser contestados em várias situações (Almeida \& Cruz, 1988). A partir desse momento, alguns regimes governamentais democráticos tiveram início e convenções internacionais sobre direitos humanos aconteceram, além da defesa constitucional dos direitos individuais em muitos países, o que não condizia com os métodos de avaliação psicológica até então utilizados. Surge na década de 1970, por sua vez, a Psicologia da Saúde (Capitão, Scortegagna \& Baptista, 2005), com o objetivo de responder a novas exigências apresentadas no campo da Saúde. Um dos principais desafios, então, era a superação do modelo biomédico centrado na doença.

O artigo identificado na presente revisão referente à década de 1970 (Matulay \& Pavlovkin, 1972) foi o primeiro que levantou considerações sobre os problemas sociais das pessoas com epilepsia. Os autores discutiram que não só as crises e as drogas, mas também o estado psíquico do paciente e seu ambiente exerciam papel proeminente na posição social do indivíduo com epilepsia. Assim, afirmaram que o estudo mais aprofundado do problema exigiria a avaliação do estado psíquico e das características de personalidade, de como a conhecer como se relacionam com reabilitação do paciente em seu ambiente. Nesse sentido, o objetivo do referido estudo foi delinear alguns fatores específicos decisivos para o status social da epilepsia, além das variáveis usuais, incluindo exame psiquiátrico e neurológico, EEG, história do paciente, aspectos sociais e psicológicos.

Um pouco mais a frente foi possível encontrar, na década de 1980, uma investigação científica que focalizou a contribuição de técnicas gráficas de avaliação psicológica como úteis e válidas para revelar conflitos internos básicos de portadores de epilepsia, considerando a importância do acompanhamento psicológico a esse tipo de paciente (Kaplan De-Nour \& Bauman, 1980). Os autores concluem que no início do tratamento o Desenho da Figura Humana (DFH) sinalizou imaturidade e, gradualmente, foi demonstrando maior controle dos 
impulsos e amadurecimento individual. Sobre o Bender, no início terapêutico evidenciou fraco controle de impulso, baixa tolerância à frustração e muitos problemas de desempenho, mas durante o tratamento a coordenação visomotora melhorou. Ainda discutem que o caso indica claramente problemas psicológicos que se colocam na presença de danos cerebrais graves e que estas reações podem dificultar a reabilitação, embora as deficiências psicológicas causadas pela lesão cerebral possam melhorar. Sugere-se, portanto, que pacientes com danos cerebrais devem receber tratamento psiquiátrico e psicológico especializados.

Ao retomar as considerações abordadas por Capitão, Scortegagna e Baptista (2005), atualmente os psicólogos da área da Saúde realizam uma variedade de atividades voltadas aos fatores psicossociais relacionados à adesão e recuperação do paciente, oferecendo intervenções diretas para auxiliar pacientes em sua adaptação a doenças crônicas. Assim, a Psicologia na área da Saúde objetiva a prevenção e o tratamento de doenças e suas complicações derivadas. Nesse contexto, destaca-se a importância da avaliação psicológica, já que a detecção precoce de problemas comportamentais ou transtornos psicológicos e psiquiátricos em pacientes inseridos em ambientes médicos pode significar um grande diferencial com relação ao tipo e qualidade de seu atendimento, favorecedor da diminuição do sofrimento.

$\mathrm{Na}$ atual revisão bibliográfica também foi possível identificar essa mudança conceitual nos estudos realizados com pacientes com epilepsia. Observou-se que os artigos encontrados a partir de 2000 utilizaram os métodos projetivos de avaliação psicológica para uma diversidade diferente de objetivos, com olhar voltado mais para os recursos, potenciais, capacidades e possibilidades dos indivíduos com epilepsia, retirando uma vertente apenas classificatória e patológica.

Os principais objetivos dos artigos recuperados na revisão a partir de 2000 foram: identificar vivências de sentimentos e emoções de portadores de epilepsia (Oostrom, Schouten, Olthof, Peters \& Jennekens-Schinkel, 2000; Stafstrom \& Havlena, 2003; Stafstrom, Havlena \& Krezinski, 2012); verificar transtornos de internalização e externalização (Vladislava, Marcb, Agavriloaeic, Maracineanud \& Stefane, 2012); avaliar a agressividade em resposta aos estímulos estressantes evocados pelos acontecimentos da vida diária (Beghi et al., 2002); auxiliar a área da Psiquiatria nos diagnósticos diferenciais (Chaudhury, Augustine, Saldanha \& Srivastava, 2006).

A partir da diversidade de recursos técnicos investigados, destacam-se, nesse momento, alguns trabalhos que ilustraram aplicações de métodos projetivos de avaliação psicológica para compreender quadros epilépticos. De acordo com Stafstrom e Havlena (2003), os 
desenhos representam um recurso investigativo de natureza projetiva com potencial para permitir expressão de sentimentos por estratégia não verbal, facilitando estudo do desenvolvimento infantil. Segundo os autores, os desenhos contêm símbolos e metáforas que podem representar e ilustrar vivências da doença e das experiências da criança, permitindo sua visualização concreta por profissional habilitado em seu processo interpretativo. Outra vantagem de se usar o desenho para explorar o ajustamento psicológico à doença crônica inclui sua facilidade de administração. Por sua vez, Chaudhury, Augustine, Saldanha e Srivastava (2006) apontam que os testes projetivos podem ser alternativa promissora para avaliar portadores de epilepsia com diferentes níveis de educação, formação e cultura, permitindo expressões espontâneas de respostas, indicativas de suas peculiaridades internas.

Em outra perspectiva, alguns artigos encontrados a partir de 2000 apontaram dificuldades e limitações no uso de testes projetivos na investigação de quadros epilépticos. Vladislava, Marcb, Agavriloaeic, Maracineanud e Stefane (2012) ressaltam, por exemplo, que o uso de métodos projetivos de avaliação psicológica em diagnóstico diferencial pode provocar polêmica, principalmente devido à falta de padronização e de referenciais interpretativos internacionais a respeito de parâmetros para compreensão do desenvolvimento de crianças e adolescentes. Por sua vez, Stafstrom e Havlena (2003) apontam que as desvantagens em utilizar métodos projetivos incluem dificuldade de interpretação, o viés de memória, a falta de vontade e o baixo nível cognitivo dos participantes. Ressaltam, portanto, que a pesquisa sobre epilepsia que use metodologia projetiva de avaliação psicológica deve ser rigorosamente controlada, sendo que a extrapolação dos resultados para aplicações clínicas deve ser feita com cautela.

Apesar dos limites dos achados da presente revisão bibliográfica, sua utilidade é clara em sistematizar a diversidade de resultados obtidos no campo do estudo da epilepsia com métodos projetivos de avaliação psicológica, além de evidenciar a escassez de estudos na área, em especial com indivíduos em desenvolvimento e com quadros refratários de epilepsia. Diante do exposto, propõe-se o estudo de instrumentos de avaliação psicológica que contemplem tanto variáveis cognitivas quanto afetivas de crianças e adolescentes com epilepsia, inter-relacionando seus achados. A busca destas evidências empíricas, no Brasil, tem por meta auxiliar o psicólogo a obter informações clinicamente relevantes para lidar com estes quadros graves de epilepsia, possibilitando, assim, promover tratamentos mais efetivos, com enfoque na promoção de saúde e na qualidade de vida dos indivíduos nesta faixa etária e relevante etapa do desenvolvimento humano. 


\section{OBJETIVOS}

\subsection{Objetivo geral}

O objetivo central desse trabalho foi caracterizar o funcionamento cognitivo e afetivo de crianças e adolescentes com quadros de epilepsia, a partir de instrumentos específicos de avaliação psicológica, evidenciando recursos e eventuais dificuldades adaptativas ao contexto de vida.

\subsection{Objetivos específicos}

2.2.1. Examinar e analisar o desempenho cognitivo e afetivo de crianças e adolescentes com quadros de epilepsia em diferentes momentos de seu tratamento cirúrgico (período préoperatório e pós-operatório), comparativamente a um grupo de escolares não pacientes.

2.2.2. Caracterizar e comparar o desempenho cognitivo e afetivo de crianças e adolescentes com quadros de epilepsia em relação a expectativas normativas disponíveis para sua faixa etária.

2.2.3. Examinar possível associação entre indicadores do desempenho cognitivo no Teste WISC-III e do funcionamento lógico sinalizado pelo Teste de Pfister de crianças e de adolescentes com epilepsia.

2.2.4. Verificar evidências de validade do Teste de Blocos de Corsi, contrastando o desempenho das crianças e adolescentes com epilepsia aos indicadores obtidos com o grupo de não pacientes.

2.2.5. Verificar evidências de validade do Teste de Pfister, contrastando o desempenho das crianças e adolescentes com epilepsia aos indicadores obtidos com o grupo de não pacientes. 



\section{MÉTODO}

Este trabalho caracteriza-se como um estudo transversal, descritivo e de comparação entre grupos, pautado em uma perspectiva quantitativa e interpretativa de resultados advindos de instrumentos de avaliação psicológica. Também foi realizado um estudo de correlação entre achados dos instrumentos utilizados.

\subsection{Contexto de Estudo}

Os objetivos delineados para a presente investigação foram configurados a partir de trabalho de colaboração e de parceria institucional com o Centro de Cirurgia de Epilepsia (CIREP) do Hospital das Clínicas da Faculdade de Medicina de Ribeirão Preto da Universidade de São Paulo (HC-FMRP-USP). O Centro de Cirurgia de Epilepsia (CIREP) foi inaugurado em 1995 e funciona no quarto andar do Hospital das Clínicas da Faculdade de Medicina de Ribeirão Preto, vinculado ao Departamento de Neurociências e Ciências do Comportamento. É um centro de referência em cirurgia da epilepsia e pesquisa, vinculado ao Sistema Único de Saúde (SUS) e recebe pacientes de todas as regiões do Brasil. Possui quatro leitos e realiza aproximadamente 250 monitorizações, 100 cirurgias e 10 mil consultas por ano, com uma equipe multidisciplinar com cerca de 40 profissionais. Por meio do serviço oferecido pelo CIREP, até o final de 2013 foram realizadas mais de 1.330 cirurgias em crianças e adultos, com alto índice de controle das crises de epilepsia.

O serviço do CIREP foi escolhido pelo Ministério da Saúde para ser o órgão consultor desse tipo de cirurgia junto à Central Nacional de Regulação de Alta Complexidade (CNRAC). Desse modo, fica declarado o reconhecimento desse centro de investigação científica, utilizado como contexto para o desenvolvimento do presente trabalho.

\subsection{Participantes}

Dentre os casos regularmente atendidos no CIREP do Hospital das Clínicas da Faculdade de Medicina de Ribeirão Preto da Universidade de São Paulo, após as devidas autorizações institucionais, foram selecionados, por conveniência, dois grupos clínicos de crianças e adolescentes de sete a 16 anos de idade, de ambos os sexos, assim caracterizados: 
a) Grupo 1 - Pré-operatório $(\mathrm{G} 1, \mathrm{n}=17)$ : pacientes com epilepsia, internados no serviço do CIREP.

b) Grupo 2 - Pós-operatório operatório $(\mathrm{G} 2, \mathrm{n}=18)$ : pacientes que realizaram cirurgia de epilepsia, com controle das crises epiléticas, e que frequentam o ambulatório do CIREP.

Cada um destes grupos foi composto a partir da disponibilidade do serviço e da adesão dos voluntários, recrutados entre pacientes regularmente atendidos nos serviços clínicos desenvolvidos no CIREP durante o ano de 2013, com a direta colaboração da coordenadora do setor de avaliação neuropsicológica deste centro. Dos casos que preencheram os critérios prévios, foram excluídos aqueles que apresentaram sinais de sério limite na compreensão de instruções (o que poderia representar impedimento para a aplicação dos testes psicológicos). Cabe esclarecer que os possíveis voluntários ao estudo foram contatados e convidados em seus próprios retornos médicos ao hospital, respeitando-se a agenda dos serviços do CIREP. Desse modo, ao longo de 2013, os potenciais participantes foram abordados pela pesquisadora, buscando-se compor grupos clínicos com pelo menos 15 participantes. Houve casos que atendiam aos critérios da pesquisa e que não foram convidados para o estudo por não possuírem atendimento clínico agendado no período efetivado para coleta de dados, respeitando-se as condições de disponibilidade do serviço clínico que colaborou com a pesquisa.

Além desses dois grupos de crianças e adolescentes, foi composto um terceiro grupo de voluntários $(\mathrm{G} 3, \mathrm{n}=31)$, recrutados na região de Ribeirão Preto, interior de São Paulo, equiparados em termos etários e de sexo aos participantes dos grupos clínicos (G1 e G2), regularmente matriculados no ensino formal. Entre os voluntários possíveis, foram incluídos no estudo aqueles sem relato de dificuldades significativas no desenvolvimento, a partir de avaliação específica realizada por instrumento padronizado de avaliação psicológica (SDQ, descrito nos materiais). Estes estudantes apresentaram indicadores de desenvolvimento típico para sua faixa etária, compondo, assim, um grupo de não pacientes, utilizado como grupo de comparação em relação aos demais casos clínicos.

Cabe esclarecer que a delimitação numérica destes três grupos de participantes foi pautada por conveniência e critério de viabilidade prática do estudo, além de atender a condições mínimas para as análises estatísticas necessárias para cumprimento dos objetivos do trabalho. A Tabela 2 apresenta o percurso amostral da pesquisa em função dos grupos de participantes. 
Tabela 2: Percurso amostral da pesquisa em função dos grupos estudados.

\begin{tabular}{lcccc}
\hline \multicolumn{1}{c}{ Participantes } & G1 & G2 & G3 & TOTAL \\
\hline Disponíveis nos serviços do CIREP & 223 & 76 & - & 299 \\
Adequados aos critérios de inclusão & 97 & 38 & - & 135 \\
Convidados ao estudo & 25 & 22 & 39 & 86 \\
Autorizados & 17 & 18 & 35 & 70 \\
Excluídos & 0 & 0 & 4 & 4 \\
Avaliados & 17 & 18 & 31 & 66 \\
\hline
\end{tabular}

Cabe aqui ressaltar que os pacientes disponíveis nos serviços do CIREP (299 casos) representavam o total de indivíduos da faixa etária do estudo que constavam no banco de dados do serviço, somados aos casos novos que procuraram o CIREP durante o ano de 2013, quando foi realizada a coleta dos dados desse trabalho. Além disso, é necessário explicar a perda de 135 possíveis participantes desse banco inicial de pacientes, visto que a grande maioria possuía grave dificuldade de comunicação, sem condições para responder aos instrumentos propostos nessa investigação. Além disso, houve perdas de alguns casos por faltas dos pacientes no dia e hora agendados para seu retorno ao CIREP, o que inviabilizou o convite à pesquisa.

É possível observar que 25 pacientes do pré-operatório $(\mathrm{G} 1)$ e 22 pacientes do pósoperatório (G2) tiveram retorno médico agendado durante o período de coleta de dados (2013) e foram convidados para a pesquisa. Destes, foram respectivamente autorizados 17 e 18 casos, devidamente avaliados. Por sua vez, os casos de G3 (grupo de comparação) foram identificados em contatos informais da pesquisadora, sendo moradores da região de Ribeirão Preto, caracterizando padrão sociocultural similar aos indivíduos dos grupos clínicos que frequentam o serviço do CIREP. Foram procurados de modo a comporem grupo pareado com G1 e G2, mas dentre os voluntários identificados foi necessário excluir quatro casos por não atingirem a classificação total no SDQ compatível com a classificação normal ou limitrofe. Assim, em G3 houve um total de 31 participantes. A caracterização da amostra pode ser visualizada na Tabela 3. 
Tabela 3: Distribuição dos participantes em função do grupo (clínico e controle), idade e sexo.

\begin{tabular}{|c|c|c|c|c|c|c|c|c|}
\hline \multirow{2}{*}{\multicolumn{2}{|c|}{$\begin{array}{l}\text { GRUPO } \\
\text { IDADE } \\
\text { (em anos) }\end{array}$}} & \multicolumn{2}{|c|}{$\begin{array}{c}\text { Grupo clínico } \\
\text { (com epilepsia) }\end{array}$} & \multirow[t]{2}{*}{ Subtotal } & \multicolumn{2}{|c|}{$\begin{array}{c}\text { Grupo de } \\
\text { comparação* } \\
\text { (sem epilepsia) }\end{array}$} & \multirow[t]{2}{*}{ Subtotal } & \multirow[t]{2}{*}{ TOTAL } \\
\hline & & Masculino & Feminino & & Masculino & Feminino & & \\
\hline \multirow{7}{*}{$\begin{array}{c}\text { Pré- } \\
\text { operatório } \\
\text { (G1) }\end{array}$} & 10 & - & 1 & 1 & - & 1 & 1 & 2 \\
\hline & 11 & 2 & 1 & 3 & 1 & 1 & 2 & 5 \\
\hline & 12 & - & - & - & 1 & - & 1 & 1 \\
\hline & 13 & - & 1 & 1 & - & 1 & 1 & 2 \\
\hline & 14 & 2 & 2 & 4 & 1 & 2 & 3 & 7 \\
\hline & 15 & 3 & 1 & 4 & 1 & 1 & 2 & 6 \\
\hline & 16 & 3 & 1 & 4 & 4 & 1 & 5 & 9 \\
\hline \multicolumn{2}{|c|}{ Subtotal } & 10 & 7 & 17 & 8 & 7 & 15 & 32 \\
\hline \multirow{7}{*}{$\begin{array}{c}\text { Pós- } \\
\text { operatório } \\
\text { (G2) }\end{array}$} & 9 & 1 & - & 1 & 1 & - & 1 & 2 \\
\hline & 11 & 1 & - & 1 & 1 & - & 1 & 2 \\
\hline & 12 & 2 & 1 & 3 & 1 & 1 & 2 & 5 \\
\hline & 13 & - & - & - & 1 & - & 1 & 1 \\
\hline & 14 & 1 & 2 & 3 & 1 & 1 & 2 & 5 \\
\hline & 15 & 5 & 3 & 8 & 2 & 4 & 6 & 14 \\
\hline & 16 & - & 2 & 2 & 1 & 2 & 3 & 5 \\
\hline \multicolumn{2}{|c|}{ Subtotal } & 10 & 8 & 18 & 8 & 8 & 16 & 34 \\
\hline \multicolumn{2}{|c|}{ TOTAL } & 20 & 15 & 35 & 16 & 15 & 31 & 66 \\
\hline
\end{tabular}

* O grupo de comparação foi apresentado aqui de modo a oferecer a visualização do pareamento alcançado entre os participantes, embora obviamente não se dividam em casos de pré ou pós-operatório.

A distribuição dos participantes alcançada, frente aos objetivos propostos para a presente investigação científica, mostrou-se adequada às análises pretendidas. Cabe por fim reafirmar que somente foram inclusos no estudo os voluntários devidamente autorizados para a pesquisa. 


\subsection{Materiais}

Para o desenvolvimento do presente projeto de pesquisa foi necessário consultar os prontuários médicos dos casos selecionados do CIREP do HC-FMRP-USP, de modo a se verificar a história clínica dos participantes. Este procedimento foi formalmente autorizado pela parceria estabelecida com o Setor de Avaliação Neuropsicológica do CIREP, coordenado pela psicóloga Sara Rosset Escorsi, a quem são expressos os agradecimentos e a intensa colaboração para o bom andamento do trabalho. Além disso, foram utilizados os materiais descritos a seguir.

\subsubsection{Questionário de Capacidades e Dificuldades - SDQ}

O Questionário de Capacidades e Dificuldades (Strengths and Difficulties Questonnaire, SDQ) é instrumento objetivo de avaliação psicológica, que rastreia recursos e problemas na área de saúde mental infantil, examinando cinco áreas: comportamento prósocial, hiperatividade, problemas emocionais, problemas de conduta e dificuldades de relacionamento. Este instrumento pode ser aplicado a pais e professores. Foi construído em 1997 por Goodman e validado no Brasil em 2000 por Fleitlich, Cartázar e Goodman (Saur, Correia, Pasian \& Loureiro, 2009), compondo o referencial analítico-interpretativo aqui utilizado para exame de seus resultados.

No presente estudo foi utilizada a versão do SDQ dirigida aos pais, de modo a permitir a identificação dos recursos pessoais e das limitações funcionais cotidianas das crianças e dos adolescentes participantes deste estudo, assim como selecionar participantes para o grupo de comparação (G3, composto por voluntários sem relato de dificuldades significativas a partir do SDQ). Este instrumento de avaliação foi respondido por pais e/ou responsáveis logo após sua assinatura do Termo de Consentimento Livre e Esclarecido desta pesquisa. As informações permitem classificar a criança como pertencente a um dos grupos: normal ( 0 a 13 pontos), limítrofe (14 a 16 pontos) ou clínico/anormal (17 ou mais pontos).

As vantagens na utilização do SDQ foram evidenciadas em relação outros instrumentos avaliativos da área de saúde mental infantil, possuindo formatação mais compacta, maior focalização das capacidades e dificuldades, melhores informações sobre dificuldades de atenção/hiperatividade, relação com colegas e comportamento pró-social (Fleitlich et al., 2000). 
3.3.2. Escala de Inteligência Wechsler para crianças - WISC-III

A Escala de Inteligência Wechsler para Crianças (WISC-III) destina-se a crianças e adolescentes entre seis e 16 anos de idade e tem por finalidade avaliar a capacidade intelectual do indivíduo. Além disso, constitui-se como importante instrumento de avaliação neuropsicológica (Cunha, 2000a).

O WISC-III é composto por 13 subtestes que avaliam diferentes habilidades cognitivas, agrupados em Escala Verbal (Informação; Semelhanças; Vocabulário; Compreensão; Aritmética; Dígitos) e Escala de Execução (Completar Figuras; Arranjo de Figuras; Armar Objetos; Códigos; Cubos; Procurar Símbolos; Labirinto). Os resultados desses subtestes são resumidos em três medidas que oferecem estimativas da capacidade intelectual da criança: QI Verbal, QI de Execução e QI Total. Adicionalmente, são obtidos quatro índices fatoriais por intermédio dos escores nos respectivos subtestes que compõem cada fator, que avaliam a compreensão verbal, a organização perceptual, a resistência à distração e a velocidade de processamento mental.

Para o estudo foi utilizada a adaptação e padronização do WISC realizada por Figueiredo (2002) em amostra brasileira. O manual apresenta indicadores de fidedignidade para os subtestes, as escalas em QI e para os índices fatoriais do WISC-III, além de estudos sobre teste-reteste (precisão) e consistência entre examinadores independentes. As escalas de QI apresentaram coeficientes de fidedignidade entre 0,81 e 0,93 e os índices fatoriais entre 0,74 e 0,91 . Já os índices de precisão obtidos para cada subteste permaneceram entre 0,63 e 0,82 (Figueiredo, 2002). Foram investigadas evidências de validade do WISC-III para crianças brasileiras, recorrendo a estudo de validade de critério por meio de análises preditivas (notas escolares) e validação concorrente (com o Teste de Raven). Os dados encontrados indicam que o WISC-III é um teste válido para as crianças brasileiras.

\subsubsection{Teste de Blocos de Corsi}

Uma das tarefas comportamentais mais utilizadas para avaliar memória espacial é o Teste de Blocos de Corsi (TBC). Foi desenvolvido originalmente por P. Corsi, com o objetivo de avaliar a aprendizagem incidental por pacientes com epilepsia submetidos a procedimentos cirúrgicos (Orsini, Pasquadibisceglie \& Picone, 2001).

O TBC tem sido aplicado com sucesso em crianças a partir de seis anos de idade. A aplicação do teste é simples e rápida, durando em torno de oito minutos. O teste é realizado com um tabuleiro de madeira no qual estão distribuídos, de modo irregular, nove blocos de dimensões iguais, que podem ser identificados pelo examinador, mas não pelo indivíduo, por 
meio dos números em uma de suas faces. Durante a avaliação, o examinador toca com o dedo indicador uma série de blocos, numa taxa de um bloco por segundo e, logo em seguida, o respondente deve apontar os blocos na mesma ordem em que foram apontados pelo examinador. A dificuldade é elevada progressivamente, aumentando-se o número de blocos em cada série, até que a recordação se mostre incorreta. A capacidade da memória espacial é definida pela extensão da maior série corretamente recordada (De Renzi \& Nichelli, 1975; Orsini et al., 2001).

Além do número de blocos tocados em cada série, o desempenho no TBC é afetado por características espaciais da série, tais como a extensão linear da trajetória, o número de cruzamentos (Busch, Farrell, Lisdahl-Medina \& Krikorian, 2005; Orsini et al., 2001; Parmentier \& Andrés, 2006) ou pela simetria do percurso (Rossi-Arnaud, Pieroni \& Baddeley, 2006; Galera \& Souza, 2010).

Além da versão clássica, na qual os itens são recordados na ordem direta em que são apresentados, tem havido crescente interesse na recordação dos blocos na ordem inversa. Por exemplo, Cornoldi e Mammarella (2008) sugerem que a recordação na ordem direta e na ordem inversa apresentam padrões diferentes. Garcia, Mammarella, Doriana e Cornoldi (comunicação pessoal) sugerem que a avaliação na ordem inversa pode ser relevante não só em termos teóricos, mas importante também para a caracterização clínica de crianças com dificuldades de aprendizagem associadas à dislexia e a déficits de memória espacial.

Dentro de nosso conhecimento não existem normas brasileiras disponíveis para o TBC. Desse modo, recorreu-se aos dados publicados por Siquara (2014) como parâmetros normativos adotados no presente trabalho. Nesse estudo de referência foram avaliadas 149 crianças de sete a 12 anos, estudantes regularmente matriculados no ensino fundamental no Estado da Bahia, compreendendo a faixa etária também avaliada no presente estudo.

\subsubsection{Teste das Pirâmides Coloridas de Pfister}

O Teste das Pirâmides Coloridas de Pfister é instrumento projetivo de avaliação de características da personalidade, podendo ser aplicado a indivíduos de diferentes faixas etárias e condições clínicas, desde crianças até idosos. Baseia-se em atividade não verbal (construção de pirâmides) que possibilita manifestações simbólicas dos sentimentos e da organização afetiva, oferecendo indicadores técnicos relativos à autopercepção e aos contatos interpessoais. Os indicadores do teste permitem que se conheçam aspectos da dinâmica afetiva e emocional, bem como das funções estruturais e cognitivas do examinando. Anzieu 
(1978) ressalta, ainda, que se trata de um teste de boa receptividade, agradando aos respondentes por seu caráter lúdico.

O material do teste é composto por três cartões (em papel de cor neutra) com um desenho do esquema de uma pirâmide em cada um deles, um conjunto de quadrículos coloridos de 10 cores diferentes, distribuídas em 24 tonalidades, e a folha de registro dos dados. As cores que compõem o material do teste são o azul, verde e vermelho (quatro tonalidades de cada), violeta (três tonalidades), amarelo, laranja e marrom (duas tonalidades cada), preto, branco e cinza.

A aplicação é individual e leva aproximadamente quinze minutos. Consiste em solicitar ao participante que preencha três esquemas de pirâmide, utilizando os quadrículos coloridos, de modo a alcançar pirâmides bonitas, que agradem ao indivíduo. $\mathrm{O}$ examinador deve fazer anotações sobre a postura do participante frente ao teste, seus comentários e atitudes, e registrar as escolhas das cores e local da pirâmide em que são colocadas. Ao término da terceira pirâmide preenchida é realizado um inquérito para verificar a preferência do examinando pelas pirâmides e cores.

Em relação à precisão do teste, Villemor-Amaral (2005) analisou a concordância da codificação entre avaliadores independentes a respeito da variável "aspecto formal das pirâmides" e da variável "fórmula cromática", obtendo porcentagens de concordância de $86 \%$ e 92\%, respectivamente, valores aceitos como adequados índices de precisão para os métodos projetivos de avaliação psicológica. Encontrou também resultados positivos quanto à validade desse instrumento psicológico, por meio da validade de critério embasada na comparação de grupos clínicos com diferentes diagnósticos psicopatológicos.

Para o presente estudo foram utilizados como parâmetros de classificação dos resultados do Teste de Pfister os dados normativos do estudo de Barroso (2013) com adolescentes não pacientes de 12 a 14 anos, produzidos no interior do Estado de São Paulo, envolvendo a faixa etária predominante também nesse trabalho. Esses parâmetros normativos foram posteriormente incluídos no novo manual do Pfister, publicado por Villemor-Amaral (2014). 


\subsection{Procedimentos}

\subsubsection{Aspectos Éticos}

Esse trabalho foi submetido ao Comitê de Ética em Pesquisa com Seres Humanos da Faculdade de Filosofia, Ciências e Letras de Ribeirão Preto da Universidade de São Paulo (FFCLRP-USP) e ao Comitê de Ética em Pesquisa do HC-FMRP-USP, de acordo com as exigências do Conselho Nacional de Saúde. A partir de suas análises e aprovações (ANEXOS 1 e 2), foram tomados os devidos cuidados no sentido de adequada e responsável implementação de suas etapas de coleta de dados, envolvendo o CIREP (Centro de Cirurgia de Epilepsia) do HC-FMRP-USP e os casos do grupo de comparação.

Um termo de consentimento livre e esclarecido (TCLE) foi elaborado com a finalidade de esclarecer os objetivos da pesquisa aos pais e/ou responsáveis pelas crianças ou adolescentes, de modo a avaliar a proposta e documentar seu espontâneo consentimento para a participação de seu(ua) filho(a) na pesquisa. Foi utilizado um TCLE dirigido aos pais e/ou responsáveis por estudantes dos Grupos 1 e 2 e outro para possíveis participantes do Grupo 3, respeitando suas características específicas e contextos específicos (hospital, ambulatório médico ou desenvolvimento típico). Estes materiais estão apresentados nos APÊNDICES A e B.

Cabe esclarecer que os resultados da avaliação psicológica dessa pesquisa, nos casos de G1 e G2, agregaram informações adicionais relevantes para o seguimento clínico no CIREP, oferecendo retorno indireto a sua participação na pesquisa. No caso de G3 houve o compromisso da pesquisadora em orientar os pais ou responsáveis caso fossem identificadas dificuldades no desenvolvimento dos voluntários, encaminhando-os, caso necessário, para atendimento específico em serviços de saúde de sua cidade. Nos quatro casos em que as crianças atingiram a classificação total no SDQ compatível com a classificação anormal, os pais foram orientados e encaminhados a atendimentos nos serviços de saúde da respectiva cidade.

\subsubsection{Coleta de dados}

O desenvolvimento do projeto de pesquisa foi planejado de forma a primeiramente serem coletados os casos G1 e G2, portanto, das crianças e dos adolescentes atendidos nos serviços do CIREP. Inicialmente foram levantados, do arquivo institucional deste serviço clínico, os casos que preenchiam os requisitos necessários para possível inclusão no estudo, sendo, posteriormente, realizado o convite a sua participação por intermédio de seus pais e/ou 
responsáveis. Foi respeitado o livre desejo da criança e do adolescente na participação das atividades, além de sua devida autorização formal para a pesquisa. Uma vez identificada e confirmada a inclusão neste estudo, os prontuários arquivados no SAME (Serviço de Arquivo Médico e Estatístico) do HC-FMRP-USP de todos os pacientes foram detalhadamente revistos quanto às variáveis clínicas.

No caso de G3, composto por crianças e adolescentes não pacientes, foi realizada uma busca de participantes por conveniência e viabilidade prática em três cidades do interior de São Paulo na região de Ribeirão Preto. Optou-se por procurar voluntários que estudassem em escola pública devido à maior similaridade econômica e sociocultural com os pacientes atendidos no CIREP. Foram selecionados crianças e adolescentes que possuíam sexo e idade similares àquelas dos voluntários de G1 e G2 (grupos clínicos). Foi feito contato com os responsáveis legais das crianças e adolescentes, fornecendo-lhes informações acerca desse trabalho e solicitando sua autorização para a pesquisa, assim como a anuência das próprias crianças e adolescentes em questão. Foram, então, solicitados a assinar o Termo de Consentimento Livre e Esclarecido, no caso de concordarem com a participação voluntária no estudo, conforme diretrizes das resoluções vigentes do Conselho Nacional de Ética em Pesquisa (CONEP), informando sobre a preservação da identidade dos participantes e sobre a possibilidade de desistência a qualquer momento da pesquisa, sem que isso gerasse quaisquer prejuízos a si ou a seus filhos.

Independentemente do grupo a que pertencem os voluntários do estudo, todos foram submetidos aos mesmos procedimentos de coleta de dados, respeitando-se, obviamente suas específicas condições clínicas e de desenvolvimento, bem como os locais onde foram realizadas as avaliações.

A avaliação psicológica das crianças e dos adolescentes foi realizada em local adequado e em sessões individuais e previamente agendadas com os voluntários. No caso dos grupos de crianças e adolescentes com epilepsia pré (G1) e pós-operatório (G2), essa avaliação ocorreu no ambulatório do CIREP. A aplicação do WISC-III foi realizada por uma psicóloga do serviço do CIREP, visto que esse é procedimento padrão para os pacientes desse serviço. A seguir foi aplicado o Teste de Blocos de Corsi e o Teste das Pirâmides Coloridas de Pfister, conduzidos pela pesquisadora.

Com relação às crianças e aos adolescentes do G3 (grupo de comparação), as avaliações ocorreram nas casas dos respectivos participantes, em sessão individual previamente agendada. A pesquisadora foi responsável pela aplicação de todos os instrumentos. 
Os instrumentos de avaliação psicológica foram aplicados e avaliados conforme seus respectivos padrões técnicos, descritos em seus respectivos manuais. Assim, no caso do WISC-III foram utilizados os referenciais normativos desenvolvidos por Figueiredo (2002). Para a análise da produção nos Blocos de Corsi foi tomado como padrão analítico o material produzido por Siquara (2014). Para o Teste de Pfister foram utilizados os dados normativos do estudo de Barroso (2013) com adolescentes de 12 a 14 anos, trabalho que foi posteriormente incluído na nova versão do manual do referido teste (Villemor-Amaral, 2014).

\subsubsection{Análise dos Resultados}

Os dados obtidos foram sistematizados de acordo com as normas disponíveis nos respectivos manuais dos instrumentos utilizados, de modo a investigar as especificidades de produção dos participantes. Esses resultados foram sistematizados em planilhas computacionais do Programa Excel, compondo bases de dados a serem posteriormente examinados, em termos descritivos e inferenciais, por meio do software "Statistical Package for Social Sciences" (SPSS), versão 22.0.

Foram realizadas análises descritivas (medidas de tendência central e de variabilidade) e análises inferenciais (testes de hipóteses referentes à eventual similaridade ou não no desempenho entre os grupos estudados), a fim de permitir análises detalhadas a respeito das características neuropsicológicas e do funcionamento afetivo das crianças e adolescentes aqui avaliados.

Os procedimentos estatísticos específicos para o conjunto das análises foram definidos a partir da análise das distribuições encontradas no perfil de resultados dos diferentes instrumentos de avaliação psicológica utilizados. Em todas as análises inferenciais foi adotado o nível de significância de $5 \%(p \leq 0,05)$.

Para as variáveis nominais, foi realizado teste de Qui-Quadrado para testar se os grupos avaliados diferem ou não com relação as suas características indicadas pelos intrumentos utilizados. Ainda para as variáveis qualitativas foi utilizado como medida de dimensão do efeito o $V$ de Cramer para verificar a significância prática das diferenças encontradas entre os grupos.

Também foi realizada a ANOVA one-way para verificar a existência ou não de diferenças significativas entre as crianças e adolescentes com epilepsia (G1 e G2) e os indicadores obtidos com o grupo de não pacientes (G3). Para comparação múltipla das médias foi utilizado o teste de Bonferroni. Além disso, foi realizado teste de dimensão do efeito $(d$ de Cohen) para verificar a significância prática das diferenças encontradas entre os grupos. 
Também foi realizado o teste $t$ de Student para verificar se as médias dos dois grupos com epilepsia eram significativamente diferentes em suas variáveis clínicas. A mesma estratégia técnica foi utilizada para contrastar o desempenho do grupo clínico geral (crianças e adolescentes com epilepsia) com relação a expectativas normativas dos testes psicológicos utilizados, disponíveis para sua faixa etária. 


\section{RESULTADOS}

Os dados foram sistematizados em função de cada instrumento de avaliação psicológica utilizado, ou seja, para o SDQ, WISC-III, Teste de Corsi e Teste de Pfister, seguindo diretrizes específicas de seus parâmetros técnicos. Os resultados são apresentados de forma inicialmente descritiva, acrescidos de análises inferenciais comparando-se resultados médios (ANOVA, $p \leq 0,05$ ) entre os três grupos de crianças e adolescentes avaliados (G1, G2 e G3).

Também foi realizado o perfil geral de resultados do grupo clínico e comparação com dados normativos e, por fim, análise de associação clínica entre resultados do WISC-III e do Teste de Pfister. Antes, porém, dessas análises, são apresentadas as informações de caracterização dos participantes do estudo, procurando-se comparar os grupos clínicos em relação ao grupo de não pacientes, de modo a evidenciar a adequada composição da amostra frente aos objetivos delineados para a presente investigação. Esses dados compõem parte dos resultados, pois, apesar dos critérios de seleção utilizados para os participantes, mapeiam condições específicas dos voluntários presentemente avaliados.

\subsection{Caracterização sociodemográfica e clínica dos participantes}

Procurou-se verificar a existência de equivalência etária e acadêmica (anos de estudo) entre os grupos avaliados. Os resultados descritivos e comparativos dessa variável demográfica podem ser vistos na Tabela 4.

Tabela 4: Resultados descritivos e comparação estatística da idade e anos de estudo dos participantes em função dos grupos.

\begin{tabular}{clccccccc}
\hline Variável & \multicolumn{1}{c}{ Grupo } & N & Média & D.P. & Mínimo & Máximo & F & $\boldsymbol{p}$ \\
\hline \multirow{2}{*}{ Idade } & Pré-operatório (G1) & 17 & 13,88 & 2,00 & 10 & 16 & & \\
& Pós-operatório (G2) & 18 & 13,89 & 1,91 & 9 & 16 & 0,04 & 0,96 \\
& Comparação (G3) & 31 & 13,74 & 2,08 & 8 & 16 & & \\
& & & & & & & & \\
Anos de & Pré-operatório (G1) & 17 & 7,24 & 2,95 & 1 & 11 & & \\
estudo & Pós-operatório (G2) & 18 & 8,39 & 2,09 & 4 & 11 & 1,72 & 0,19 \\
& Comparação (G3) & 31 & 8,55 & 2,28 & 3 & 11 & & \\
\hline
\end{tabular}


Observa-se que não houve diferença estatisticamente significativa na média etária dos participantes das crianças e adolescentes, bem como na média de anos de estudo dos três grupos. Desse modo, fica assegurada a possibilidade de comparação de seus resultados nas variáveis em foco no presente trabalho (características cognitivas e afetivas).

Com relação aos grupos clínicos (G1 e G2), faz-se necessário apresentar algumas variáveis de seu histórico médico que, segundo a literatura científica da área, exercem efeito importante na evolução dos quadros de epilepsia. Desse modo, a Tabela 5 traz informações referentes ao período de início das crises de epilepsia, bem como de sua frequência, para ambos os subgrupos clínicos examinados no estudo, comparando-os estatisticamente.

Tabela 5: Resultados descritivos e comparação estatística do periodo de início das crises (em meses) e frequência das crises (mensais) de epilepsia em função do grupo clínico.

\begin{tabular}{clcccccc}
\hline Variáveis clínicas & Grupo & Média & D. P. & Mínimo & Máximo & $\boldsymbol{t}$ & $\boldsymbol{p}$ \\
\hline \multirow{2}{*}{ Início das crises } & Pré-operatório (G1) & 68,65 & 43,13 & 3 & 132 & \multirow{2}{*}{2,45} & $\mathbf{0 , 0 2}$ \\
& Pós-operatório (G2) & 35,94 & 35,54 & 1 & 108 & & \\
& & & & & & & \\
\multirow{2}{*}{ Frequência das crises } & Pré-operatório (G1) & 116,82 & 178,24 & 0 & 560 & \multirow{2}{*}{2,11} & $\mathbf{0 , 0 4}$ \\
& Pós-operatório (G2) & 25,11 & 44,81 & 0 & 140 & & \\
\hline
\end{tabular}

Destaca-se que houve diferença estatisticamente significativa com relação ao início das crises e à frequência das crises entre os grupos clínicos. $\mathrm{O}$ grupo de crianças e adolescentes do pré-operatório $(\mathrm{G} 1)$ apresentou número médio de crises epiléticas mensais significativamente superior ao grupo clínico pós-operatório (G2), o que já era esperado, visto o objetivo da cirurgia. No entanto, destaca-se o elevado número de crises de epilepsia vivenciadas por esses voluntários, deduzindo-se sua sobrecarga de estímulos acumulada durante o desenvolvimento. Torna-se interessante ainda comentar que G1 mostrou início das crises de epilepsia, em média, mais tardio (média de 68,65 meses, ou seja, por volta dos cinco anos de vida), enquanto os participantes de G2 tiveram início mais precoce de seus sintomas da epilepsia (em média com 36 meses, ou seja, três anos de vida). Esse dado clínico merece aqui a devida atenção, para futura reflexão frente aos achados nos demais instrumentos de avaliação psicológica.

Embora sem aparente relevância para diferenciar os participantes de G1 e de G2, os dados apresentados na Tabela 6 constituem-se em informações muito importantes para caracterização clínica das crianças e adolescentes avaliados, bem como permitem visualização global do conjunto de pacientes. Referem-se às principais características dos voluntários do 
estudo em termos de tipo de crise, dominância manual, região cerebral envolvida na epilepsia, ingestão de anticonvulsivantes e de benzodiazepínicos, bem como sobre principais dados da ressonância pré-operatória.

Tabela 6: Distribuição (em frequência simples e porcentagem) de características clínicas dos participantes em função de seu agrupamento (G1, G2 e total).

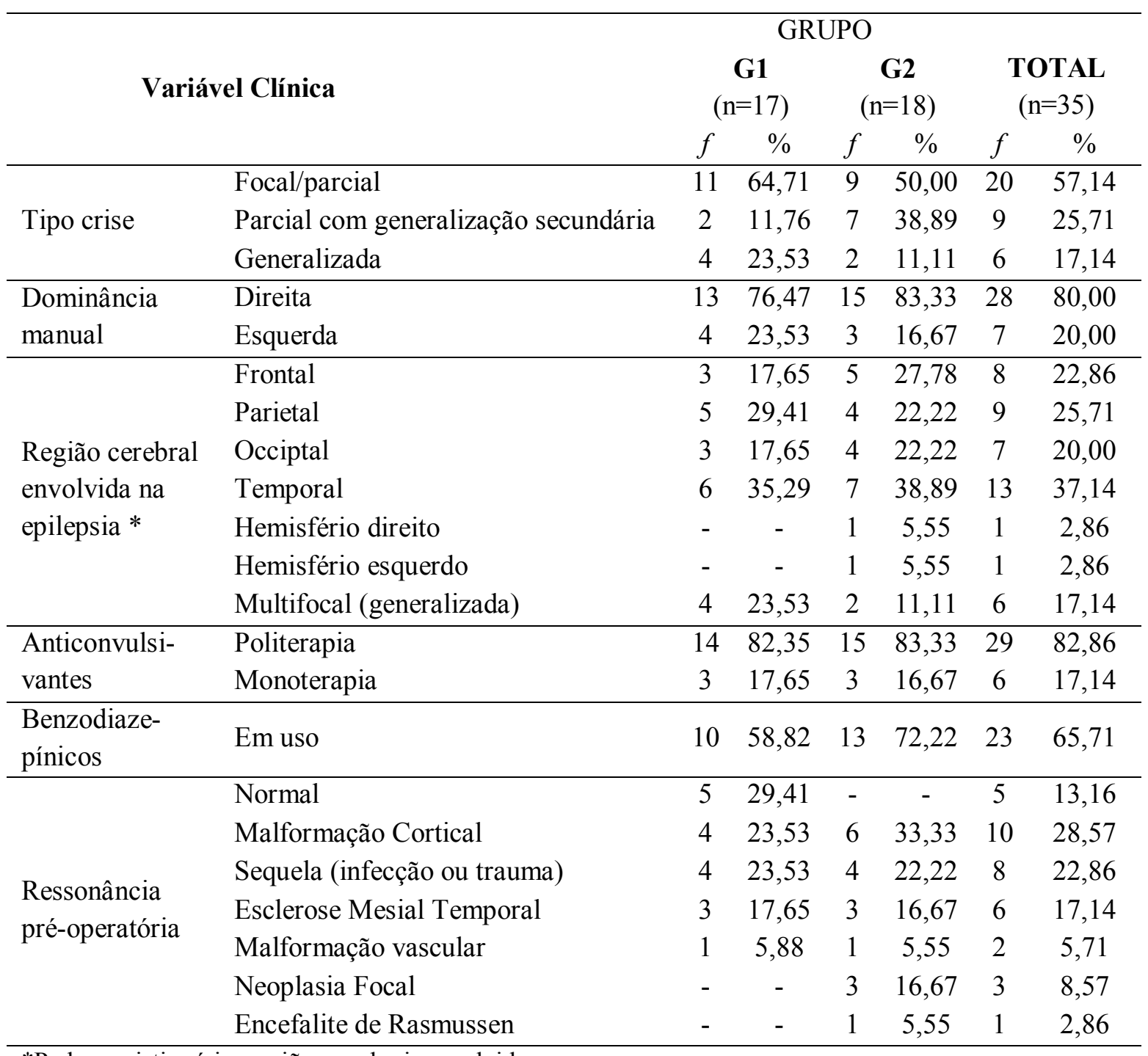

*Podem existir várias regiões cerebrais envolvidas num mesmo caso.

Nota-se predomínio de crises focais de epilepsia nos voluntários do presente estudo e com dominância manual direita. Sobre os dados clínicos relativos à região cerebral envolvida na epilepsia, deve-se destacar que um mesmo paciente pode ter mais de um lobo cerebral envolvido, sendo assim, o total de cada grupo pode somar mais de $100 \%$ na tabela. A maioria dos participantes faz uso de politerapia medicamentosa e está em uso de benzodiazepínicos. O número de participantes em cada condição é reduzido, visto se tratar de grupos clínicos 
selecionados por múltiplas variáveis, limitando a condição técnica para sua comparação estatística em termos de resultados nos instrumentos de avaliação psicológica, como inicialmente pensado para a presente investigação científica.

Destaca-se a diversidade de fatores envolvidos na causa da epilepsia, avaliados pela ressonância magnética pré-operatória, sendo as mais frequentes: malformação cortical (29\% dos casos) e sequela de hipóxia, infecção ou trauma (aproximadamente $23 \%$ dos pacientes). Depois apareceram as alterações anatômicas levando a perda neuronal (esclerose mesial temporal, com cerca de 17\% dos casos), neoplasia focal (massa anormal de tecido, em quase 9\% dos casos), anomalias na formação dos vasos sanguíneos do cérebro (malformação vascular, com quase $6 \%$ dos pacientes), e encefalite de Rasmussem (um caso dessa síndrome neurológica rara e progressiva). Além desses, cinco dos 35 casos clínicos (os cinco casos são de G1) apresentaram a ressonância magnética pré-operatória com resultado compatível ao normal.

Pode-se agregar aos dados clínicos sistematizados, o destaque de existir, no grupo préoperatório $(\mathrm{G} 1, \mathrm{n}=17)$, cinco pacientes que apresentaram relato de sintomas psiquiátricos associados ao quadro da epilepsia, entre eles: TDAH, transtorno psicótico, sintomas disfóricos, convulsões dissociativas, ansiedade e distúrbio da fala. Já no grupo pós-operatório $(\mathrm{G} 2, \mathrm{n}=18)$, seis casos apontaram, nos registros clínicos de prontuário médico, sintomas psiquiátricos associados à epilepsia, entre eles: sintomas depressivos, sintomas disfóricos, enurese noturna, transtorno psicótico e ansiedade.

Por fim, são apresentados dados clínicos específicos do grupo pós-operatório na Tabela 7. Tratam-se de informações, também de seus respectivos prontuários médicos, relativas à intervenção cirúrgica da epilepsia e indicadores de seus resultados pós-cirúrgicos. 
Tabela 7: Distribuição (em frequência simples e porcentagem) das variáveis clínicas dos participantes do grupo pós-operatório $(G 2, n=18)$.

\begin{tabular}{clcc}
\hline & Variáveis clínicas & $\boldsymbol{f}$ & $\mathbf{\%}$ \\
\hline \multirow{3}{*}{ Tipo de cirurgia } & Lobectomia & 8 & 44,44 \\
& Lesionectomia & 7 & 38,89 \\
& Hemisferectomia & 2 & 11,11 \\
& Quandratectomia & 1 & 5,55 \\
& & & \\
Lado da cirurgia & Direito & 3 & 16,67 \\
& Esquerdo & 15 & 83,33 \\
& & & \\
Resultado exame & Malformação cortical & 6 & 33,33 \\
anátomo-patológico & Esclerose Temporal Mesial & 4 & 22,22 \\
& Sequela & 4 & 22,22 \\
& Neoplasia focal & 3 & 16,67 \\
& Sem laudo & 1 & 55,55 \\
& & \multicolumn{2}{c}{6} \\
& I - livre de crises incapacitantes & 12 & 66,67 \\
& III - melhora evidente & 6 & 33,33 \\
\hline
\end{tabular}

Além dos dados apresentados na tabela, cabe destacar que os participantes do grupo pós-operatório foram incluídos no estudo após um intervalo mínimo de quatro meses após sua cirurgia, com tempo máximo de 91 meses (cerca de sete anos e meio). Apesar dessa grande variabilidade, o tempo médio entre a cirurgia da epilepsia e a coleta dos dados foi de 45,6 meses, ou seja, quase quatro anos. Esse longo período de acompanhamento dos casos pelo CIREP é rotina do serviço, de modo a poder examinar o processo evolutivo dessas crianças e adolescentes ao longo de seu desenvolvimento.

Pode-se notar que os pacientes passaram por diferentes tipos de cirurgia, entre elas a lobectomia, a lesionectomia, a hemisferectomia e a quadratectomia, com maior frequência dos dois primeiros procedimentos. A maioria dos participantes realizou a cirurgia do dado esquerdo do cérebro.

Já o exame anátomo-patológico após a cirurgia revelou mais especificamente os fatores envolvidos na causa da epilepsia: malformação cortical, sequela de hipóxia, infecção ou trauma, esclerose mesial temporal e neoplasia focal. Um participante não apresentou laudo conclusivo em seu exame pós-cirúrgico.

Destaca-se que a maior parte dessas crianças e adolescentes (12 casos) ficaram livres de crises incapacitantes após a cirurgia. Os demais pacientes apresentaram melhora evidente, 
comparativamente às frequências de crises de epilepsia apresentadas antes da cirurgia, o que já pode ser visualizado também na Tabela 5 anteriormente apresentada.

\subsection{Resultados referentes ao SDQ}

Como já informado, o SDQ foi utilizado com a função de rastrear possíveis problemas de saúde mental infantil em cinco áreas: comportamento pró-social, hiperatividade, problemas emocionais, de conduta e de relacionamento. Objetivou-se caracterizar o padrão geral de saúde mental de crianças e adolescentes com epilepsia (em pré ou pós-operatório) e aquelas sem epilepsia, comparando seus resultados. A Tabela 8 sintetiza os principais achados da classificação dos resultados obtidos no SDQ com a amostra presentemente avaliada.

Tabela 8: Distribuição (em frequência simples e porcentagem) e comparação estatística da distribuição dos casos segundo classificação no $S D Q$ em função dos grupos (G1=préoperatório, G2=pós-operatório, G3=grupo de comparação).

\begin{tabular}{|c|c|c|c|c|c|c|c|c|c|c|}
\hline \multirow{3}{*}{ SDQ } & \multirow{3}{*}{ Grupo } & \multicolumn{6}{|c|}{ Classificação diagnóstica SDQ } & \multirow{3}{*}{$\chi^{2}$} & \multirow{3}{*}{$p$} & \multirow{3}{*}{ V de Cramer } \\
\hline & & \multicolumn{2}{|c|}{ Normal } & \multicolumn{2}{|c|}{ Limítrofe } & \multicolumn{2}{|c|}{ Anormal } & & & \\
\hline & & $f$ & $\%$ & $f$ & $\%$ & $f$ & $\%$ & & & \\
\hline \multirow{3}{*}{ Total } & G1 & 6 & 35 & 2 & 12 & 9 & 53 & \multirow{3}{*}{19,20} & \multirow{3}{*}{$<0,001$} & \multirow{3}{*}{0,38} \\
\hline & G2 & 10 & 55 & 3 & 17 & 5 & 28 & & & \\
\hline & G3 & 25 & 81 & 6 & 19 & $*$ & $*$ & & & \\
\hline \multirow{3}{*}{$\begin{array}{l}\text { Sintomas } \\
\text { Emocionais }\end{array}$} & G1 & 3 & 18 & 6 & 35 & 8 & 47 & \multirow{3}{*}{8,42} & \multirow{3}{*}{0,08} & \multirow{3}{*}{0,25} \\
\hline & G2 & 10 & 56 & 3 & 17 & 5 & 28 & & & \\
\hline & G3 & 18 & 58 & 4 & 13 & 9 & 29 & & & \\
\hline \multirow{3}{*}{$\begin{array}{l}\text { Problemas } \\
\text { de conduta }\end{array}$} & G1 & 10 & 59 & 1 & 6 & 6 & 35 & \multirow{3}{*}{3,29} & \multirow{3}{*}{0,51} & \multirow{3}{*}{0,16} \\
\hline & $\mathrm{G} 2$ & 11 & 61 & 3 & 17 & 4 & 22 & & & \\
\hline & G3 & 23 & 74 & 3 & 10 & 5 & 16 & & & \\
\hline \multirow{3}{*}{ Hiperatividade } & G1 & 11 & 65 & 1 & 6 & 5 & 29 & \multirow{3}{*}{21,61} & \multirow{3}{*}{$<0,001$} & \multirow{3}{*}{0,41} \\
\hline & G2 & 10 & 56 & 5 & 28 & 3 & 17 & & & \\
\hline & G3 & 31 & 100 & - & - & - & - & & & \\
\hline \multirow{3}{*}{ Problemas com colegas } & G1 & 3 & 18 & 4 & 24 & 10 & 59 & \multirow{3}{*}{17,20} & \multirow{3}{*}{$<\mathbf{0 , 0 0 1}$} & \multirow{3}{*}{0,36} \\
\hline & $\mathrm{G} 2$ & 11 & 61 & 3 & 17 & 4 & 22 & & & \\
\hline & G3 & 24 & 77 & 1 & 3 & 6 & 19 & & & \\
\hline \multirow{3}{*}{$\begin{array}{l}\text { Comportamento } \\
\text { Pró-social }\end{array}$} & G1 & 14 & 82 & - & - & 3 & 18 & \multirow{3}{*}{6,51} & \multirow{3}{*}{0,16} & \multirow{3}{*}{0,22} \\
\hline & $\mathrm{G} 2$ & 17 & 94 & 1 & 6 & - & - & & & \\
\hline & G3 & 25 & 81 & 4 & 13 & 2 & 6 & & & \\
\hline
\end{tabular}

* Um dos critérios de inclusão para o grupo de comparação (G3) era apresentar pontuação total suficiente para alcançar a classificação normal ou limitrofe no $S D Q$.

Verifica-se que os grupos de pacientes do pré-operatório e de pós-operatório apresentaram significativa maior frequência de problemas no resultado total do SDQ e nos 
fatores relacionados a hiperatividade e problemas com colegas. O tamanho do efeito dessas diferenças estatisticamente significativas pode ser considerado como moderado, mas se constitui em resultado claramente diferenciador das crianças e adolescentes com epilepsia, comparativamente aqueles sem epilepsia.

Em complemento, a Tabela 9 apresenta os resultados descritivos e comparação estatística (ANOVA, $p \leq 0,05$ ) dos dados médios no SDQ em função dos grupos de crianças e adolescentes.

Tabela 9: Resultados descritivos e comparação estatística do SDQ em função dos grupos ( $G 1=$ pré-operatório, $G 2=$ pós-operatório, $G 3=$ grupo de comparação).

\begin{tabular}{|c|c|c|c|c|c|c|c|c|}
\hline SDQ & Grupo & Média & D.P. & Mínimo & Máximo & $\mathbf{F}$ & $p$ & $\begin{array}{c}\text { d de } \\
\text { Cohen }\end{array}$ \\
\hline \multirow{3}{*}{ Total } & G1 & 17,76 & 7,28 & 8 & 30 & \multirow{3}{*}{11,8} & \multirow{3}{*}{$<0,001$} & \multirow{3}{*}{0,27} \\
\hline & $\mathrm{G} 2$ & 13,06 & 7,02 & 4 & 33 & & & \\
\hline & G3 & 8,84 & 4,79 & 0 & 16 & & & \\
\hline \multirow{3}{*}{ Sintomas Emocionais } & G1 & 5,18 & 1,94 & 2 & 8 & \multirow{3}{*}{4,64} & \multirow{3}{*}{$\mathbf{0 , 0 1}$} & \multirow{3}{*}{0,13} \\
\hline & $\mathrm{G} 2$ & 4,06 & 2,29 & 1 & 9 & & & \\
\hline & G3 & 3,26 & 2,05 & 0 & 8 & & & \\
\hline \multirow{3}{*}{$\begin{array}{l}\text { Problemas de } \\
\text { Conduta }\end{array}$} & G1 & 3,00 & 2,65 & 0 & 8 & \multirow{3}{*}{2,72} & \multirow{3}{*}{0,07} & \multirow{3}{*}{0,08} \\
\hline & $\mathrm{G} 2$ & 2,33 & 2,14 & 0 & 9 & & & \\
\hline & G3 & 1,58 & 1,59 & 0 & 5 & & & \\
\hline \multirow{3}{*}{ Hiperatividade } & G1 & 5,41 & 2,48 & 2 & 10 & \multirow{3}{*}{14,64} & \multirow{3}{*}{$<\mathbf{0 , 0 0 1}$} & \multirow{3}{*}{0,32} \\
\hline & $\mathrm{G} 2$ & 4,50 & 2,26 & 1 & 9 & & & \\
\hline & G3 & 2,26 & 1,69 & 0 & 5 & & & \\
\hline \multirow{3}{*}{$\begin{array}{l}\text { Problemas com } \\
\text { Colegas }\end{array}$} & G1 & 4,18 & 2,16 & 0 & 8 & \multirow{3}{*}{10,90} & \multirow{3}{*}{$<0,001$} & \multirow{3}{*}{0,26} \\
\hline & $\mathrm{G} 2$ & 2,22 & 1,83 & 0 & 6 & & & \\
\hline & G3 & 1,74 & 1,44 & 0 & 5 & & & \\
\hline \multirow{3}{*}{$\begin{array}{l}\text { Comportamento } \\
\text { Pró-Social }\end{array}$} & G1 & 7,53 & 2,48 & 2 & 10 & \multirow{3}{*}{0,91} & \multirow{3}{*}{0,41} & \multirow{3}{*}{0,03} \\
\hline & $\mathrm{G} 2$ & 8,50 & 1,29 & 5 & 10 & & & \\
\hline & G3 & 8,06 & 2,29 & 2 & 10 & & & \\
\hline
\end{tabular}

Foi possível identificar diferenças estatisticamente significativas entre os grupos no resultado total do SDQ e nos fatores relacionados aos sintomas emocionais, hiperatividade e problemas com colegas. Pelo Teste pós-hoc de Bonferroni $(p \leq 0,05)$, realizado a partir da 
pontuação alcançada no SDQ, verificou-se que essa diferenciação deveu-se ao resultado superior dos grupos clínicos (G1 e G2), comparativamente ao grupo de comparação (G3), sem diferenciação entre crianças e adolescentes do pré e do pós-operatório. O tamanho do efeito dessas diferenças, no entanto, mostrou-se moderado apenas no índice geral do SDQ e na hiperatividade e nos problemas com colegas. A diferença estatisticamente significativa identificada entre os grupos no tocante aos problemas emocionais pareceu pouco relevante no conjunto dos dados.

Ainda como parte da análise dos dados obtidos a partir do relato dos pais sobre suas crianças e adolescentes, o SDQ permite identificar dificuldades possivelmente enfrentadas. Como realizado anteriormente, procurou-se ilustrar os resultados descritivos e a comparação estatística (ANOVA, $p \leq 0,05$ ) das dificuldades referidas pelos pais no SDQ em função dos grupos de crianças e adolescentes (Tabela 10).

Tabela 10: Resultados descritivos e comparação estatística das dificuldades relatadas pelos pais no SDQ em função dos grupos (G1=pré-operatório, G2=pós-operatório, G3=grupo de comparação).

\begin{tabular}{lccccccccc}
\hline \begin{tabular}{c} 
Dificuldades relatadas \\
\multicolumn{1}{c}{ pelos pais }
\end{tabular} & Grupo & Média & D.P. & Mínimo & Máximo & $\mathbf{F}$ & $\boldsymbol{p}$ & $\begin{array}{c}d d e \\
\text { Cohen }\end{array}$ \\
\hline Incomodam ou & G1 & 0,59 & 0,62 & 0 & 2 & & & \\
aborrecem a criança & G2 & 0,56 & 0,86 & 0 & 2 & 6,53 & $<\mathbf{0 , 0 0 1}$ & 0,17 \\
& G3 & 0,06 & 0,25 & 0 & 1 & & & \\
\cline { 2 - 7 } Interferem no & G1 & 0,29 & 0,47 & 0 & 1 & & & \\
dia-a-dia em casa & G2 & 0,39 & 0,70 & 0 & 2 & 2,72 & 0,07 & 0,08 \\
& G3 & 0,06 & 0,36 & 0 & 2 & & & \\
\cline { 2 - 7 } Interferem nas amizades & G1 & 0,35 & 0,70 & 0 & 2 & & & \\
& G2 & 0,33 & 0,69 & 0 & 2 & 2,27 & 0,11 & 0,07 \\
Interferem no & G3 & 0,06 & 0,25 & 0 & 1 & & & \\
aprendizado escolar & G1 & 1,00 & 0,79 & 0 & 2 & & & \\
& G2 & 0,78 & 0,80 & 0 & 2 & 19,89 & $<\mathbf{0 , 0 0 1}$ & 0,39 \\
Interferem nas & G3 & - & - & 0 & 0 & & & \\
atividades de lazer & G1 & 0,29 & 0,69 & 0 & 2 & & & \\
& G2 & 0,17 & 0,38 & 0 & 1 & 0,91 & 0,41 & 0,03 \\
\hline
\end{tabular}

Foi possível identificar diferenças estatisticamente significativas entre os resultados das respostas dos pais no tocante ao incômodo ou aborrecimento e à interferência no aprendizado escolar derivados de dificuldades vivenciadas por seus filhos. Pelo Teste pós-hoc de Bonferroni $(p \leq 0,05)$, realizado a partir dos pontos alcançados no SDQ, verificou-se que essa 
diferenciação ocorreu apenas entre grupos clínicos e grupo de comparação, com superior influência das dificuldades nas crianças e adolescentes de G1 e G2, comparativamente a G3. Os pacientes do pré-operatório e do pós-operatório não mostraram, segundo relato dos pais, efeitos diferentes de suas dificuldades nos diferentes campos examinados pelo SDQ.

Em síntese, os achados desse instrumento de avaliação psicológica apontaram que o nível de saúde mental das crianças e dos adolescentes com epilepsia (G1 e G2) apresentou significativos indicadores de maior comprometimento, comparativamente ao padrão referido pelos pais do grupo de comparação (G3). Os resultados, desse modo, atestam efeito relevante da epilepsia nas vivências relativas à saúde mental nessa faixa etária, conforme avaliado pelo SDQ.

\subsection{Resultados referentes ao WISC-III}

Como previamente informado, foram realizadas análises descritivas (medidas de tendência central e de variabilidade) e análises inferenciais (testes de hipóteses referentes à eventual similaridade ou não no desempenho entre os grupos estudados), a fim de se conhecer características cognitivas das crianças e adolescentes avaliados por meio do WISC-III. Cabe destacar que um participante de G1 e cinco indivíduos de G2 apresentaram resultados que seriam classificados apenas como inferiores ao QI 50, sem detalhamento exato de seu rendimento, conforme tabela normativa disponível para o instrumento. Dada a possível influência dessa distribuição nas análises estatísticas, optou-se por utilizar os dados do WISCIII em termos de somatórias dos pontos ponderados para as análises.

Uma primeira descrição dos achados no WISC-III refere-se à classificação diagnóstica da inteligência alcançada pelas crianças e adolescentes dos três grupos presentemente avaliados. Esses resultados compõem a Tabela 11.

Tabela 11: Distribuição (em frequência simples e porcentagem) da classificação intelectual dos participantes no WISC-III em função dos grupos (G1=pré-operatório, G2=pósoperatório, G3=grupo de comparação).

\begin{tabular}{lccccccccc}
\hline \multicolumn{1}{c}{ Classificação intelectual } & \multicolumn{2}{c}{ G1 } & \multicolumn{2}{c}{ G2 } & \multicolumn{2}{c}{ G3 } & \multirow{2}{*}{$\boldsymbol{V}$ de } \\
& $f$ & $\%$ & $f$ & $\%$ & $f$ & $\%$ & $\boldsymbol{p}$ & Cramer \\
\hline Deficiente e Limítrofe & 13 & 76 & 10 & 56 & 3 & 10 & & & \\
Média inferior e Média & 4 & 24 & 8 & 44 & 20 & 64 & 26,99 & $<\mathbf{0 , 0 0 1}$ & 0,45 \\
Média superior e Superior & - & - & - & - & 8 & 26 & & & \\
\hline
\end{tabular}


Verifica-se que a maior parte das crianças e adolescentes, tanto do grupo pré-operatório (G1), quanto do grupo pós-operatório (G2), apresentam classificação intelectualmente deficiente ou limítrofe. Por outro lado, a maior parte dos participantes do grupo de comparação (G3) apresenta classificação intelectual média inferior ou média. Um dado que chama a atenção é que não houve nenhum caso, nos dois grupos clínicos, que alcançaram as classificações média superior ou superior. A comparação estatística entre a distribuição dos casos pelos níveis intelectuais apontou diferença estatisticamente significativa (e de efeito importante) entre os grupos.

A exploração mais detalhada dos resultados do WISC-III envolve a descrição dos diferentes escores sistematizados a partir desse instrumento de avaliação psicológica. Esses achados podem ser visualizados na Tabela 12 .

Tabela 12: Resultados descritivos e comparação estatística das somatórias dos pontos ponderados no WISC-III em função dos grupos (G1=pré-operatório, G2=pós-operatório, G3= grupo de comparação).

\begin{tabular}{|c|c|c|c|c|c|c|c|c|}
\hline WISC-III & Grupo & Média & D.P. & Mínimo & Máximo & $\mathbf{F}$ & $p$ & $\begin{array}{c}\text { d de } \\
\text { Cohen }\end{array}$ \\
\hline \multirow{3}{*}{ Total } & G1 & 54,88 & 22,59 & 22 & 95 & & & \\
\hline & G2 & 56,89 & 34,55 & 12 & 113 & 21,37 & $<0,001$ & 0,40 \\
\hline & G3 & 96,94 & 20,30 & 51 & 110 & & & \\
\hline \multirow{3}{*}{ Verbal } & G1 & 27,29 & 9,91 & 8 & 43 & & & \\
\hline & $\mathrm{G} 2$ & 27,83 & 16,74 & 6 & 63 & 18,81 & $<0,001$ & 0,37 \\
\hline & G3 & 47,29 & 12,07 & 22 & 72 & & & \\
\hline \multirow{3}{*}{ Execução } & G1 & 28,76 & 13,11 & 13 & 56 & & & \\
\hline & $\mathrm{G} 2$ & 29,06 & 19,17 & 5 & 55 & 18,50 & $<0,001$ & 0,37 \\
\hline & G3 & 49,97 & 10,66 & 29 & 68 & & & \\
\hline \multirow{3}{*}{ Compreensão verbal } & G1 & 22,41 & 8,55 & 6 & 38 & & & \\
\hline & $\mathrm{G} 2$ & 23,41 & 13,43 & 5 & 53 & 14,96 & $<0,001$ & 0,33 \\
\hline & G3 & 37,26 & 9,79 & 18 & 56 & & & \\
\hline \multirow{3}{*}{$\begin{array}{l}\text { Organização } \\
\text { visoespacial }\end{array}$} & G1 & 22,76 & 11,50 & 8 & 48 & & & \\
\hline & $\mathrm{G} 2$ & 25,53 & 15,97 & 4 & 45 & 14,77 & $<0,001$ & 0,32 \\
\hline & G3 & 40,16 & 9,43 & 20 & 55 & & & \\
\hline \multirow{3}{*}{ Resistência à distração } & G1 & 9,59 & 4,46 & 1 & 17 & & & \\
\hline & $\mathrm{G} 2$ & 11,82 & 6,27 & 2 & 22 & 17,64 & $<0,001$ & 0,36 \\
\hline & G3 & 18,42 & 5,24 & 8 & 29 & & & \\
\hline \multirow{3}{*}{$\begin{array}{l}\text { Velocidade de } \\
\text { processamento }\end{array}$} & G1 & 12,06 & 6,22 & 1 & 21 & & & \\
\hline & $\mathrm{G} 2$ & 9,65 & 5,54 & 2 & 18 & 28,13 & $<0,001$ & 0,48 \\
\hline & G3 & 20,26 & 4,18 & 12 & 30 & & & \\
\hline
\end{tabular}


Foram verificadas diferenças estatisticamente significativas em todas as variáveis analisadas do WISC-III. Pelo Teste pós-hoc de Bonferroni $(p \leq 0,05)$ observou-se que o grupo de comparação (G3) é quem se diferencia dos demais (G1 e G2), sempre com indicadores de melhor desempenho cognitivo. Não foram encontradas diferenças estatisticamente significativas entre os grupos de pacientes do pré e do pós-operatório.

A seguir os resultados do WISC-III foram sistematizados a partir dos pontos ponderados em cada subteste. A Tabela 13 apresenta esses dados descritivos e sua comparação estatística (ANOVA, $p \leq 0,05$ ) em função dos grupos presentemente considerados. 
Tabela 13: Resultados descritivos e comparação estatística dos resultados ponderados dos subtestes do WISC-III em função dos grupos (G1=pré-operatório, G2=pós-operatório, G3= grupo de comparação).

\begin{tabular}{|c|c|c|c|c|c|c|c|c|}
\hline $\begin{array}{c}\text { Subtestes do } \\
\text { WISC-III }\end{array}$ & Grupo & Média & D.P. & Mínimo & Máximo & $\mathbf{F}$ & $p$ & $\begin{array}{c}\text { d de } \\
\text { Cohen }\end{array}$ \\
\hline \multirow{3}{*}{ Informação } & G1 & 4,59 & 2,67 & 1 & 10 & \multirow{3}{*}{9,81} & \multirow{3}{*}{$<0,001$} & \multirow{3}{*}{0,24} \\
\hline & $\mathrm{G} 2$ & 4,67 & 3,97 & 1 & 15 & & & \\
\hline & G3 & 8,23 & 3,17 & 2 & 15 & & & \\
\hline \multirow{3}{*}{ Semelhanças } & G1 & 5,18 & 2,88 & 1 & 12 & \multirow{3}{*}{17,13} & \multirow{3}{*}{$<0,001$} & \multirow{3}{*}{0,35} \\
\hline & $\mathrm{G} 2$ & 5,72 & 4,21 & 1 & 16 & & & \\
\hline & G3 & 10,39 & 3,19 & 5 & 16 & & & \\
\hline \multirow{3}{*}{ Aritmética } & G1 & 4,88 & 2,45 & 1 & 9 & \multirow{3}{*}{21,06} & \multirow{3}{*}{$<0,001$} & \multirow{3}{*}{0,40} \\
\hline & $\mathrm{G} 2$ & 5,39 & 3,52 & 1 & 12 & & & \\
\hline & G3 & 10,09 & 3,17 & 4 & 16 & & & \\
\hline \multirow{3}{*}{ Vocabulário } & G1 & 6,00 & 1,87 & 1 & 9 & \multirow{3}{*}{12,72} & \multirow{3}{*}{$<0,001$} & \multirow{3}{*}{0,29} \\
\hline & G2 & 6,22 & 2,73 & 2 & 11 & & & \\
\hline & G3 & 9,68 & 3,34 & 4 & 15 & & & \\
\hline \multirow{3}{*}{ Compreensão } & G1 & 6,65 & 3,29 & 1 & 12 & \multirow{3}{*}{6,71} & \multirow{3}{*}{0,002} & \multirow{3}{*}{0,18} \\
\hline & $\mathrm{G} 2$ & 5,83 & 4,26 & 1 & 15 & & & \\
\hline & G3 & 8,90 & 1,79 & 5 & 12 & & & \\
\hline \multirow{3}{*}{ Dígitos } & G1 & 4,76 & 2,22 & 1 & 9 & \multirow{3}{*}{7,81} & \multirow{3}{*}{$<0,001$} & \multirow{3}{*}{0,20} \\
\hline & G2 & 6,06 & 3,67 & 1 & 14 & & & \\
\hline & G3 & 8,16 & 2,86 & 4 & 15 & & & \\
\hline \multirow{3}{*}{ Completar Figuras } & G1 & 6,88 & 3,28 & 1 & 12 & \multirow{3}{*}{4,72} & & \\
\hline & G2 & 7,17 & 4,78 & 1 & 14 & & $\mathbf{0 , 0 1}$ & 0,13 \\
\hline & G3 & 10,03 & 3,81 & 3 & 16 & & & \\
\hline & G1 & 4,88 & 2,85 & 1 & 10 & & & \\
\hline Códigos & $\mathrm{G} 2$ & 4,67 & 3,18 & 1 & 10 & 31,25 & $<0,001$ & 0,50 \\
\hline & G3 & 9,77 & 1,94 & 6 & 13 & & & \\
\hline & G1 & 6,35 & 3,72 & 1 & 14 & & & \\
\hline Arranjo de Figuras & G2 & 5,78 & 4,68 & 1 & 17 & 9,52 & $<0,001$ & 0,23 \\
\hline & G3 & 9,84 & 2,53 & 3 & 15 & & & \\
\hline & G1 & 5,82 & 3,34 & 1 & 13 & & & \\
\hline Cubos & G2 & 6,11 & 3,74 & 1 & 12 & 21,38 & $<0,001$ & 0,40 \\
\hline & G3 & 11,23 & 2,91 & 6 & 16 & & & \\
\hline & G1 & 4,24 & 3,40 & 1 & 12 & & & \\
\hline Armar Objetos & G2 & 5,33 & 4,39 & 1 & 12 & 12,53 & $<0,001$ & 0,29 \\
\hline & G3 & 9,10 & 3,04 & 1 & 14 & & & \\
\hline & G1 & 7,24 & 3,82 & 1 & 15 & & & \\
\hline Procurar Símbolos & $\mathrm{G} 2$ & 4,78 & 2,78 & 1 & 9 & 23,00 & $<0,001$ & 0,42 \\
\hline & G3 & 10,68 & 2,62 & 5 & 17 & & & \\
\hline
\end{tabular}


Foi possível identificar diferenças estatisticamente significativas entre G1, G2 e G3 em todos os subtestes do WISC-III, sendo todas com efeito moderado, ou seja, bastante importante do ponto de vista clínico. De acordo com o Teste pós-hoc de Bonferroni $(p \leq 0,05)$ os resultados foram similares entre os grupos clínicos (G1 e G2), destacando-se do grupo de comparação (G3) de modo significativo. Os desempenhos das crianças e dos adolescentes sem epilepsia foram estatisticamente superiores em todos os subtestes do WISC-III, atestando efeito relevante desse quadro clínico (epilepsia) sobre o potencial e funcionamento cognitivo nessa faixa etária.

\subsection{Resultados referentes ao Teste de Blocos de Corsi}

O mesmo padrão geral de análise desenvolvido até o momento foi adotado para o exame dos resultados no Teste de Blocos de Corsi (TBC). Procurou-se, portanto, análises descritivas e inferenciais dos resultados de G1, G2 e G3, a fim de caracterizar o funcionamento da memória espacial das crianças e adolescentes avaliados.

A Tabela 14 apresenta os resultados descritivos e a comparação estatística (ANOVA, $p$ $\leq 0,05)$ dos resultados brutos no TBC em função dos grupos.

Tabela 14: Resultados descritivos e comparação estatística dos resultados brutos no Teste de Blocos de Corsi em função dos grupos (G1=pré-operatório, G2=pós-operatório, G3=grupo de comparação).

\begin{tabular}{ccccccccc}
\hline TBC & Grupo & Média & D.P. & Mínimo & Máximo & F & $\boldsymbol{p}$ & $\begin{array}{c}\boldsymbol{d} \boldsymbol{d} \boldsymbol{e} \\
\text { Cohen }\end{array}$ \\
\hline \multirow{4}{*}{ Direto } & G1 & 5,65 & 1,94 & 2 & 9 & & & \\
& $\mathrm{G} 2$ & 5,50 & 2,18 & 2 & 9 & 18,26 & $<\mathbf{0 , 0 0 1}$ & 0,37 \\
& $\mathrm{G} 3$ & 8,16 & 1,29 & 6 & 11 & & & \\
& & & & & & & & \\
\multirow{5}{*}{ Inverso } & $\mathrm{G} 1$ & 4,00 & 1,94 & 1 & 8 & & & \\
& $\mathrm{G} 2$ & 3,44 & 2,50 & 0 & 8 & 16,50 & $<\mathbf{0 , 0 0 1}$ & 0,34 \\
& $\mathrm{G} 3$ & 6,71 & 2,00 & 2 & 10 & & & \\
\hline
\end{tabular}

A análise desses achados evidencia a existência de diferenças estatisticamente significativas no desempenho de G1, G2 e G3 no Teste de Blocos de Corsi, tanto na aplicação direta, quanto na inversa. Essas especificidades de resultados tiveram efeito moderado, ou 
seja, configuram-se como clinicamente relevantes para diferenciar crianças e adolescentes dos três grupos aqui considerados. Foi possível verificar, a partir do Teste pós-hoc de Bonferroni $(p \leq 0,05)$ que G3 (grupo sem epilepsia) apresentou resultado significativamente superior nas duas tarefas do TBC. Não foram encontradas diferenças estatisticamente significativas entre os grupos pacientes do pré-operatório (G1) e pós-operatório (G2), ou seja, entre crianças e adolescentes com epilepsia, independentemente de sua condição atual de tratamento clínico. Os achados atestam o prejuízo relevante na memória espacial advindo da condição de portador de epilepsia.

\subsection{Resultados referentes ao Teste de Pfister}

A sistematização dos resultados no Teste de Pfister seguiu os parâmetros técnicos específicos de seu manual (Villemor-Amaral, 2005). Foram realizadas análises descritivas e inferenciais dos dados, de modo a caracterizar variáveis representativas do funcionamento afetivo de crianças e adolescentes.

Destaca-se que os resultados de um participante do grupo G1 e de um participante do grupo G3 tiveram que ser eliminados, visto que eles não completaram o teste.

A Tabela 15 apresenta os resultados descritivos e comparação estatística (ANOVA, $p \leq$ $0,05)$ das porcentagens médias das cores do Teste de Pfister em função dos grupos de crianças e adolescentes. 
Tabela 15: Resultados descritivos e comparação estatística das porcentagens médias das cores do Teste de Pfister em função dos grupos (G1=pré-operatório, G2=pós-operatório, G3= grupo de comparação).

\begin{tabular}{|c|c|c|c|c|c|c|c|c|}
\hline Cores & Grupo & Média & D.P. & Mínimo & Máximo & $\mathbf{F}$ & $\bar{p}$ & d de Cohen \\
\hline & G1 & 16,44 & 9,14 & 4 & 42 & & & \\
\hline \multirow[t]{3}{*}{ Azul } & G2 & 16,22 & 7,18 & 7 & 33 & 0,079 & 0,92 & $\leq 0,001$ \\
\hline & G3 & 15,33 & 11,78 & 0 & 46 & & & \\
\hline & G1 & 20,44 & 11,78 & 7 & 47 & & & \\
\hline \multirow[t]{3}{*}{ Vermelho } & G2 & 15,67 & 5,76 & 2 & 24 & 1,37 & 0,26 & 0,04 \\
\hline & G3 & 15,70 & 10,79 & 0 & 53 & & & \\
\hline & G1 & 16,06 & 6,10 & 2 & 24 & & & \\
\hline \multirow[t]{3}{*}{ Verde } & G2 & 19,17 & 8,23 & 9 & 38 & 0,67 & 0,52 & 0,02 \\
\hline & G3 & 18,27 & 8,82 & 2 & 42 & & & \\
\hline & G1 & 10,13 & 5,35 & 0 & 20 & & & \\
\hline \multirow[t]{3}{*}{ Violeta } & G2 & 11,67 & 7,44 & 0 & 29 & 0,14 & 0,87 & $\leq 0,001$ \\
\hline & G3 & 10,90 & 10,41 & 0 & 42 & & & \\
\hline & G1 & 8,13 & 8,15 & 2 & 36 & & & \\
\hline \multirow[t]{3}{*}{ Laranja } & G2 & 9,17 & 7,89 & 0 & 36 & 0,13 & 0,88 & $\leq 0,001$ \\
\hline & G3 & 8,17 & 6,04 & 0 & 27 & & & \\
\hline & G1 & 10,31 & 6,43 & 2 & 27 & & & \\
\hline \multirow[t]{3}{*}{ Amarelo } & G2 & 9,94 & 5,01 & 2 & 20 & 1,59 & 0,21 & 0,05 \\
\hline & G3 & 7,50 & 6,06 & 0 & 22 & & & \\
\hline & G1 & 3,44 & 2,50 & 0 & 9 & & & \\
\hline \multirow[t]{3}{*}{ Marrom } & G2 & 5,17 & 4,15 & 0 & 13 & 2,71 & 0,07 & 0,08 \\
\hline & G3 & 2,87 & 3,19 & 0 & 11 & & & \\
\hline & G1 & 5,25 & 6,11 & 0 & 18 & & & \\
\hline \multirow[t]{3}{*}{ Preto } & G2 & 5,11 & 4,73 & 0 & 20 & 4,30 & $\mathbf{0 , 0 2}$ & 0,12 \\
\hline & G3 & 11,00 & 9,99 & 0 & 42 & & & \\
\hline & G1 & 5,69 & 6,11 & 0 & 20 & & & \\
\hline \multirow[t]{3}{*}{ Branco } & G2 & 3,39 & 2,28 & 0 & 9 & 2,08 & 0,13 & 0,06 \\
\hline & G3 & 7,50 & 8,62 & 0 & 36 & & & \\
\hline & G1 & 3,94 & 2,62 & 0 & 11 & & & \\
\hline \multirow[t]{2}{*}{ Cinza } & G2 & 4,33 & 3,79 & 0 & 13 & 0,06 & 0,94 & $\leq 0,001$ \\
\hline & G3 & 4,37 & 4,83 & 0 & 16 & & & \\
\hline
\end{tabular}


Nota-se que a distribuição de frequência de uso das cores do Pfister entre os adolescentes e as crianças dos três grupos avaliados sinalizou-se bastante similar. Houve diferença estatisticamente significativa apenas na cor preta (porém, com efeito reduzido), sendo que o Teste pós-hoc de Bonferroni $(p \leq 0,05)$ evidenciou que os grupos clínicos (G1 e G2) utilizaram o preto com frequência significativamente inferior ao grupo de comparação (G3). Poder-se-ia hipotetizar, portanto, que crianças e adolescentes com epilepsia (independentemente de seu atual tratamento) sinalizaram menor controle inibitório da impulsividade, como simbolizado pelo menor uso da cor preta no Pfister. No entanto, essa interpretação deve ser relativizada pelo reduzido efeito, sinalizado nas análises estatísticas acima apontadas.

A seguir foram organizados os dados referentes à distribuição das porcentagens médias das síndromes cromáticas do Teste de Pfister, considerando-se os grupos avaliados. Esses resultados compõem a Tabela 16, incluindo a comparação estatística entre G1, G2 e G3 (ANOVA, $p \leq 0,05$ ).

Tabela 16: Resultados descritivos e comparação estatística das porcentagens médias das principais síndromes cromáticas do Teste de Pfister em função dos grupos (G1=préoperatório, G2=pós-operatório, G3=grupo de comparação).

\begin{tabular}{|c|c|c|c|c|c|c|c|c|}
\hline Síndrome cromática & Grupo & Média & D.P. & Mínimo & Máximo & $\mathbf{F}$ & $p$ & d de Cohen \\
\hline \multirow{3}{*}{ Normal } & G1 & 52,94 & 14,70 & 29 & 87 & & & \\
\hline & $\mathrm{G} 2$ & 51,06 & 8,00 & 40 & 69 & 0,47 & 0,63 & 0,02 \\
\hline & G3 & 49,30 & 12,99 & 2 & 71 & & & \\
\hline \multirow{4}{*}{ Estímulo } & G1 & 38,87 & 13,51 & 24 & 78 & & & \\
\hline & $\mathrm{G} 2$ & 34,78 & 11,97 & 15 & 61 & 1,38 & 0,26 & 0,04 \\
\hline & G3 & 31,37 & 16,66 & - & 69 & & & \\
\hline & G1 & 42,62 & 11,99 & 15 & 55 & & & \\
\hline \multirow[t]{3}{*}{ Fria } & $\mathrm{G} 2$ & 47,06 & 11,56 & 31 & 71 & 0,63 & 0,54 & 0,02 \\
\hline & G3 & 44,30 & 11,67 & 27 & 79 & & & \\
\hline & G1 & 14,87 & 12,02 & - & 40 & & & \\
\hline \multirow[t]{3}{*}{ Incolor } & $\mathrm{G} 2$ & 12,83 & 5,78 & 4 & 24 & 4,35 & $\mathbf{0 , 0 2}$ & 0,13 \\
\hline & G3 & 22,87 & 15,22 & - & 55 & & & \\
\hline & G1 & 29,81 & 12,14 & 6 & 51 & & & \\
\hline \multirow[t]{2}{*}{ Dinamismo } & $\mathrm{G} 2$ & 34,28 & 7,35 & 23 & 54 & 1,15 & 0,32 & 0,04 \\
\hline & G3 & 29,37 & 12,73 & 4 & 55 & & & \\
\hline
\end{tabular}

A análise dos achados apontou que apenas na Síndrome Incolor do Teste de Pfister a distribuição de porcentagem média foi estatisticamente diferente entre G1, G2 e G3. O Teste 
pós-hoc de Bonferroni $(p \leq 0,05)$ apontou que crianças e adolescentes dos grupos clínicos (G1 e G2) apresentaram porcentagem média inferior na Síndrome Incolor comparativamente a G3 (grupo de comparação). Mais uma vez há que se apontar que essa diferença estatisticamente significativa obteve, no entanto, valor de efeito reduzido.

Depreende-se que os grupos clínicos (antes ou após a cirurgia para controle da epilepsia) possuem padrão de escolhas cromáticas marcado por indicativos de menor inibição afetiva comparativamente às crianças e adolescentes não pacientes, configurando-se especificidade de preferências em termos de escolhas cromáticas no Teste de Pfister, embora em reduzido efeito e número de variáveis.

Em termos gerais, houve frequência maior das Síndromes Normal e Fria nos três grupos avaliados, padrão comum diante desse método projetivo de avaliação da personalidade nessa faixa etária. Esses resultados são sugestivos de preservação das vivências emocionais dessas crianças e adolescentes, apesar das diferentes condições clínicas de seu desenvolvimento (pré ou pós-operatório da epilepsia ou desenvolvimento típico).

A Tabela 17 apresenta a comparação estatística dos aspectos formais das pirâmides de Pfister em função dos grupos

Tabela 17: Resultados descritivos e comparação estatística das porcentagens médias dos tipos de formação no Teste de Pfister em função dos grupos (G1=pré-operatório, G2=pósoperatório, G3=grupo de comparação).

\begin{tabular}{|c|c|c|c|c|c|c|c|c|c|}
\hline \multirow{2}{*}{ Aspectos Formais } & \multicolumn{2}{|c|}{ G1 } & \multicolumn{2}{|c|}{ G2 } & \multicolumn{2}{|r|}{ G3 } & \multirow{2}{*}{$\chi^{2}$} & \multirow{2}{*}{$p$} & \multirow{2}{*}{ V de Cramer } \\
\hline & $f$ & $\%$ & $f$ & $\%$ & $f$ & $\%$ & & & \\
\hline Tapete & 41 & 85,42 & 37 & 68,52 & 36 & 40,00 & & & \\
\hline Formação & 6 & 12,50 & 16 & 29,63 & 48 & 53,33 & 29,75 & $<0,001$ & 0,28 \\
\hline Estrutura & 1 & 2,08 & 1 & 1,85 & 6 & 6,67 & & & \\
\hline
\end{tabular}

Percebe-se que a maior parte dos participantes dos grupos clínicos realizaram tapetes, com cores distribuídas aleatoriamente, com reduzida integração com a forma, o que reflete menor grau de desenvolvimento intelectual e emocional. Já no grupo de comparação, a maior parte das crianças e adolescentes realizou formações que respondem a um funcionamento cognitivo e emocional mais amadurecido. As estruturas foram pouco frequentes nas crianças e adolescentes avaliados, como esperado em função de sua atual etapa de desenvolvimento. Foi identificada diferença estatisticamente significativa na frequência de tapetes, formações e estruturas construídas pelos integrantes dos três grupos, o que se mostrou com efeito 
moderado. Diante desses achados, pode-se apontar que os voluntários com epilepsia tendem a apresentar menor organização lógica e emocional em sua produção diante do Pfister, comparativamente aqueles sem epilepsia.

Os resultados derivados do Teste de Pfister ainda preveem a avaliação dos processos de execução das pirâmides. Esse tipo de dados foi sistematizado e comparado entre os grupos, como mostra a Tabela 18.

Tabela 18: Resultados descritivos e comparação estatística das porcentagens médias dos processos de execução das pirâmides do Teste de Pfister em função dos grupos (G1=préoperatório, G2=pós-operatório, G3=grupo de comparação).

\begin{tabular}{|c|c|c|c|c|c|c|c|c|c|}
\hline \multirow{2}{*}{ Execução } & \multicolumn{2}{|c|}{ G1 } & \multicolumn{2}{|c|}{ G2 } & \multicolumn{2}{|c|}{ G3 } & \multirow{2}{*}{$\chi^{2}$} & \multirow{2}{*}{$p$} & \multirow{2}{*}{ V de Cramer } \\
\hline & $f$ & $\%$ & $f$ & $\%$ & $f$ & $\%$ & & & \\
\hline Metódica & 3 & 18,75 & 1 & 5,56 & 4 & 13,33 & & & \\
\hline Ordenada & 11 & 68,75 & 17 & 94,44 & 26 & 86,67 & 7,91 & 0,09 & 0,25 \\
\hline Desordenada & 2 & 12,50 & - & - & - & - & & & \\
\hline
\end{tabular}

Os dados apontam que houve organização no modo de construir as pirâmides do Pfister entre os voluntários do estudo, independentemente de sua condição clínica. A maioria das crianças e adolescentes trabalhou de modo ordenado, seguindo um padrão de colocação mais ou menos constante, com alguma variação, o que denota flexibilidade. Cabe destacar, por fim, que o único grupo onde houve execução desordenada foi G1, ou seja, dos casos com epilepsia no período pré-operatório, embora com reduzida proporção.

Na sequência de análise dos dados do Pfister tem-se o estudo das fórmulas cromáticas, em termos de amplitude e de estabilidade. Esses dados compõem a Tabela 19. 
Tabela 19: Resultados descritivos e comparação estatística das porcentagens médias das fórmulas cromáticas do Teste de Pfister em função dos grupos (G1=pré-operatório, G2=pósoperatório, G3= grupo de comparação).

\begin{tabular}{|c|c|c|c|c|c|c|c|c|c|c|}
\hline \multicolumn{2}{|c|}{ Fórmula Cromática } & \multicolumn{2}{|c|}{ G1 } & \multicolumn{2}{|c|}{ G2 } & \multicolumn{2}{|c|}{ G3 } & \multirow[b]{2}{*}{$\chi^{2}$} & \multirow[b]{2}{*}{$p$} & \multirow{2}{*}{$\begin{array}{c}\text { Vde } \\
\text { Cramer }\end{array}$} \\
\hline Amplitude & Estabilidade & $f$ & $\%$ & $f$ & $\%$ & $f$ & $\%$ & & & \\
\hline \multirow{3}{*}{ Ampla } & Estável & 11 & 68,75 & 9 & 50,00 & 12 & 40,00 & \multirow{9}{*}{16,89} & \multirow{9}{*}{0,26} & \multirow{9}{*}{0,36} \\
\hline & Flexível & - & - & - & - & 1 & 3,33 & & & \\
\hline & Instável & 3 & 18,75 & 6 & 33,33 & 4 & 13,33 & & & \\
\hline \multirow{3}{*}{ Moderada } & Estável & 1 & 6,25 & - & - & - & - & & & \\
\hline & Flexível & - & - & 1 & 5,55 & 1 & 3,33 & & & \\
\hline & Instável & 1 & 6,25 & 2 & 11,11 & 7 & 23,33 & & & \\
\hline \multirow{3}{*}{ Restrita } & Estável & - & - & - & - & - & - & & & \\
\hline & Flexível & - & - & - & - & 1 & 3,33 & & & \\
\hline & Instável & - & - & - & - & 4 & 13,33 & & & \\
\hline
\end{tabular}

Não foram identificadas diferenças estatisticamente significativas entre os grupos clínicos e de comparação no tocante à amplitude e à estabilidade de suas fórmulas cromáticas no Pfister. Percebe-se que a maior parte dos participantes dos três grupos apresentou fórmulas cromáticas amplas e estáveis, o que indica grande receptividade e tendência à estabilidade nas escolhas das cores (e, em decorrência, nas expressões afetivas). Entretanto, podem sugerir comodismo e imaturidade, compatível com a fase atual de seu desenvolvimento.

\subsection{Perfil geral do grupo clínico e comparação com dados normativos}

Em função dos resultados prévios sugestivos de reduzidas especificidades de desempenho nos pacientes do grupo pré-operatório $(n=17)$ e do grupo pós-operatório $(n=18)$, considerou-se oportuno aglutinar esses indivíduos num único grupo clínico de crianças e adolescentes com epilepsia $(n=35)$, de modo a compará-los com expectativas normativas disponíveis na literatura da área. Desse modo foi possível realizar novas análises descritivas (medidas de tendência central e de variabilidade) de seus resultados, examinando-os comparativamente (em termos de dados médios) com os dados normativos de cada teste. 


\subsubsection{WISC-III}

Buscou-se detalhar as características cognitivas das crianças e adolescentes com epilepsia por meio do WISC-III. A Tabela 20 apresenta as porcentagens da classificação intelectual dos casos clínicos nesse exame cognitivo, esmiuçando informações anteriormente apontadas na Tabela 11 .

Tabela 20: Distribuição dos casos clínicos $(n=35)$ em função de sua classificação diagnóstica no WISC-III.

\begin{tabular}{ccc}
\hline Classificação diagnóstica & $\boldsymbol{f}$ & $\boldsymbol{\%}$ \\
\hline Intelectualmente deficiente & 19 & 54 \\
Limítrofe & 4 & 12 \\
Média inferior & 5 & 14 \\
Média & 7 & 20 \\
TOTAL & 35 & 100 \\
\hline
\end{tabular}

Como já descrito anteriormente, a junção de G1 e G2 em único grupo de casos clínicos reapresenta o dado de prejuízo cognitivo existente nas crianças e adolescentes com epilepsia. Nota-se que a maior parte do grupo apresenta classificação intelectualmente deficiente, englobando mais da metade dos casos.

A Tabela 21, por sua vez, apresenta as médias dos escores em QI alcançados pelos casos clínicos em comparação com o estudo de adaptação e padronização do WISC-III para a amostra brasileira (Figueiredo, 2002) com crianças e adolescentes de seis a 16 anos ( $\mathrm{n}=206)$. Para essa análise foi preciso eliminar os participantes que apresentaram resultados que seriam classificados apenas como inferiores ao QI 50, sem detalhamento exato de seu rendimento, conforme tabela normativa disponível para o instrumento.

Tabela 21: Resultados descritivos e comparação estatistica dos QI médios no WISC-III em função da amostra normativa brasileira (Figueiredo, 2002*).

\begin{tabular}{lcccccccc}
\hline \multicolumn{1}{c}{ WISC-III } & N & Média & D.P. & Mínimo & Máximo & $\begin{array}{c}\text { Dado médio } \\
\text { normativo* }\end{array}$ & $\boldsymbol{t}$ & $\boldsymbol{p}$ \\
\hline QI Total & 28 & 75,25 & 16,90 & 50 & 109 & 102,9 & $-8,66$ & $<\mathbf{0 , 0 0 1}$ \\
QI Verbal & 35 & 71,69 & 17,07 & 45 & 116 & 101,5 & $-10,33$ & $<\mathbf{0 , 0 0 1}$ \\
QI Execução & 34 & 71,94 & 21,58 & 45 & 108 & 104,2 & $-8,72$ & $<\mathbf{0 , 0 0 1}$ \\
\hline
\end{tabular}


Foram identificadas diferenças estatisticamente significativas no QI total, verbal e de execução do grupo clínico de crianças e adolescentes com epilepsia em relação ao grupo normativo. Os participantes do grupo clínico tiveram resultados claramente inferiores às expectativas para sua faixa etária, sinalizando prejuízo cognitivo associado ao quadro de epilepsia.

Também foi realizada a comparação entre as médias dos escores em QI alcançados pelos casos clínicos com as médias obtidas em estudo com crianças americanas com epilepsia $(n=20)$ realizado por pesquisadors independentes e apresentado no manual de Figueiredo (2002). Esses resultados compõem a Tabela 22.

Tabela 22: Resultados descritivos e comparação estatística dos QI médios no WISC-III em função de amostra com epilepsia (Figueiredo, 2002*).

\begin{tabular}{lcccccccc}
\hline \multicolumn{1}{c}{ WISC-III } & N & Média & D.P. & Mínimo & Máximo & $\begin{array}{c}\text { Dado médio } \\
\text { clínico* }\end{array}$ & $\boldsymbol{t}$ & $\boldsymbol{p}$ \\
\hline QI Total & 28 & 75,25 & 16,90 & 50 & 109 & 74,3 & 0,30 & 0,77 \\
QI Verbal & 35 & 71,69 & 17,07 & 45 & 116 & 77,4 & $-1,98$ & 0,06 \\
QI Execução & 34 & 71,94 & 21,58 & 45 & 108 & 75,0 & $-0,83$ & 0,41 \\
\hline
\end{tabular}

Percebe-se que não houve nenhuma diferença estatisticamente significativa entre as médias dos escores em QI alcançados pelos casos clínicos presentemente colhidos em relação ao estudo com crianças americanas com epilepsia realizado por pesquisadors independentes apresentado no manual de Figueiredo (2002). Entretanto, esses dados devem ser interpretados com cautela, visto o reduzido tamanho amostral de ambos os grupos comparados.

Por fim, a Tabela 23 apresenta os pontos ponderados nos subtestes do WISC-III desse grupo clínico $(n=35)$ em comparação com o estudo de adaptação e padronização do teste para a amostra brasileira (Figueiredo, 2002) com crianças e adolescentes de seis a 16 anos $(\mathrm{n}=206)$. 
Tabela 23: Resultados descritivos e comparação estatística dos pontos ponderados nos subtestes do WISC-III em função da amostra normativa brasileira (Figueiredo, 2002*).

\begin{tabular}{lccccccc}
\hline \multicolumn{1}{c}{ Subtestes } & Média & D.P. & Mínimo & Máximo & $\begin{array}{c}\text { Dado médio } \\
\text { normativo* }\end{array}$ & $\boldsymbol{t}$ & $\boldsymbol{p}$ \\
\hline Informação & 4,63 & 3,35 & 1 & 15 & 10,4 & $-10,18$ & $<\mathbf{0 , 0 0 1}$ \\
Semelhança & 5,46 & 3,58 & 1 & 16 & 10,3 & $-7,99$ & $<\mathbf{0 , 0 0 1}$ \\
Aritmética & 5,14 & 3,01 & 1 & 12 & 10,2 & $-9,94$ & $<\mathbf{0 , 0 0 1}$ \\
Vocabulário & 6,11 & 2,32 & 1 & 11 & 10,1 & $-10,15$ & $<\mathbf{0 , 0 0 1}$ \\
Compreensão & 6,23 & 3,79 & 1 & 15 & 10,1 & $-6,04$ & $<\mathbf{0 , 0 0 1}$ \\
Dígitos & 5,43 & 3,08 & 1 & 14 & 10,3 & $-9,36$ & $<\mathbf{0 , 0 0 1}$ \\
Completar Figuras & 7,03 & 4,06 & 1 & 14 & 10,6 & $-5,20$ & $<\mathbf{0 , 0 0 1}$ \\
Códigos & 4,77 & 2,98 & 1 & 10 & 10,9 & $-12,16$ & $<\mathbf{0 , 0 0 1}$ \\
Arranjo de Figuras & 6,06 & 4,19 & 1 & 17 & 10,6 & $-6,41$ & $<\mathbf{0 , 0 0 1}$ \\
Cubos & 5,97 & 3,50 & 1 & 13 & 10,4 & $-7,48$ & $<\mathbf{0 , 0 0 1}$ \\
Armar Objetos & 4,80 & 3,92 & 1 & 12 & 10,3 & $-8,29$ & $<\mathbf{0 , 0 0 1}$ \\
Procurar Símbolos & 5,97 & 3,50 & 1 & 15 & 10,0 & $-6,81$ & $<\mathbf{0 , 0 0 1}$ \\
\hline
\end{tabular}

O detalhamento dos resultados no WISC-III em função dos subtestes reafirmou a existência de significativo prejuízo nos resultados das crianças e adolescentes com epilepsia, comparativamente a um grupo normativo (Figueiredo, 2002). Houve diferenças estatisticamente significativas em todos os subtestes avaliados, tendo o grupo clínico resultados abaixo da média normativa em todas as variáveis examinadas.

Os resultados específicos por subtestes do WISC-III apresentam sinalizadores das dificuldades específicas enfrentadas pelos portadores de epilepsia nas diferentes atividades cognitivas exigidas nesse teste psicológico. Houve grande variabilidade entre as crianças e os adolescentes, porém, em termos gerais, apresentaram resultados que indicam limites cognitivos em todas as funções examinadas pelo WISC-III, evidenciando relevante efeito da epilepsia no desenvolvimento lógico nessa faixa etária.

\subsubsection{Teste de Blocos de Corsi}

Dentro de nosso conhecimento não existem normas brasileiras para o TBC. Para o presente estudo, portanto, recorreu-se aos parâmetros de desempenho no TBC obtidos por Siquara (2014) com 149 crianças de sete a 12 anos do Estado da Bahia. Esses resultados estão compilados na Tabela 24. 
Tabela 24: Resultados descritivos e comparação estatística do TBC do grupo clínico $(n=35)$ com referencial normativo brasileiro (Siquara, 2014*).

\begin{tabular}{cccccccc}
\hline TBC & Média & D.P. & Mínimo & Máximo & $\begin{array}{c}\text { Dado médio } \\
\text { normativo* }\end{array}$ & $\boldsymbol{t}$ & $\boldsymbol{p}$ \\
\hline Direto & 5,57 & 2,03 & 2 & 9 & 7,89 & $-6,75$ & $<\mathbf{0 , 0 0 1}$ \\
Inverso & 3,71 & 2,23 & 0 & 8 & 7,44 & $-9,88$ & $<\mathbf{0 , 0 0 1}$ \\
\hline
\end{tabular}

Pelas comparações realizadas entre o grupo clínico de crianças e adolescentes com epilepsia e as crianças avaliadas no estudo de Siquara (2014), percebe-se que houve diferenças estatisticamente significativas entre as médias da pontuação alcançada pelos participantes, tanto na versão direta, quanto na versão inversa do teste. Os participantes do grupo clínico apresentaram resultados significativamente inferiores, sugestivos de pior desempenho em termos de raciocínio e memória espacial.

\subsubsection{Teste de Pfister}

Como exposto anteriormente, um participante do grupo clínico teve que ser eliminado, visto não ter completado o Teste de Pfister. Desse modo o grupo aqui considerado ficou com 34 participantes para a comparação com os dados normativos.

Cada variável técnica do Pfister está exposta separadamente, a fim de detalhar seu significado, proporcionando adequada análise dos resultados referentes às cores e às síndromes cromáticas. A Tabela 25 traz as porcentagens médias das escolhas cromáticas das crianças e adolescentes com epilepsia, ao lado dos dados normativos de Barroso (2013), também expressos em porcentagens médias. Esses resultados foram comparados, em termos inferenciais, de modo a buscar caracterizar especificidades do funcionamento afetivo. 
Tabela 25: Porcentagens médias de escolhas cromáticas do grupo clínico $(n=34)$ no Teste de Pfister e comparação com dados normativos.

\begin{tabular}{cccccccc}
\hline Cor & Média & D.P. & Mínimo & Máximo & $\begin{array}{c}\text { Dado médio } \\
\text { normativo * }\end{array}$ & $\boldsymbol{t}$ & $\boldsymbol{p}$ \\
\hline Azul & 16,32 & 8,04 & 4 & 42 & 18,6 & $-1,65$ & 0,11 \\
Vermelho & 17,91 & 9,27 & 2 & 47 & 15,0 & 1,83 & 0,08 \\
Verde & 17,71 & 7,37 & 2 & 38 & 15,7 & 1,59 & 0,12 \\
Violeta & 10,94 & 6,49 & 0 & 29 & 12,8 & $-1,67$ & 0,11 \\
Laranja & 8,68 & 7,91 & 0 & 36 & 7,0 & 1,24 & 0,23 \\
Amarelo & 10,12 & 5,63 & 2 & 27 & 8,7 & 1,47 & 0,15 \\
Marrom & 4,35 & 3,53 & 0 & 13 & 3,0 & 2,23 & $\mathbf{0 , 0 3}$ \\
Preto & 5,18 & 5,33 & 0 & 20 & 6,9 & $-1,88$ & 0,07 \\
Branco & 4,47 & 4,58 & 0 & 20 & 8,9 & $-5,64$ & $<\mathbf{0 , 0 0 1}$ \\
Cinza & 4,15 & 3,25 & 0 & 13 & 2,8 & 2,42 & $\mathbf{0 , 0 2}$ \\
\hline
\end{tabular}

* Barroso (2013)

Nota-se que o vermelho foi a cor que teve a média mais alta de escolhas entre os adolescentes e crianças com epilepsia, seguido pelas cores verde e azul. Logo após, em sequência decrescente, tem-se: violeta, amarelo, laranja, preto, marrom, branco e, por último, o cinza. Comparando-se esses dados com os referenciais normativos, as crianças e adolescentes com epilepsia obtiveram porcentagens médias de escolhas das cores marrom e cinza significativamente maiores.

A cor marrom aumentada está relacionada à extroversão, porém vinculada à esfera mais primitiva dos impulsos e a uma disposição para descargas mais intensas e violentas. Essa porcentagem aumentada do marrom também pode ser associada a dificuldades de adaptação, insegurança, necessidade de amparo e proteção e sentimentos de inferioridade. VillemorAmaral (1978) já destacou o aumento dessa cor nos casos de retardo intelectual.

Já a cor cinza aumentada relaciona-se à carência afetiva e sentimento de vazio, além de sinalizar ansiedade, insegurança, repressão dos afetos, timidez e restrição nos contatos emocionais. Esse dado pode favorecer problemas de relacionamento interpessoal, com oposicionismo e tendência a criar conflitos.

Destaca-se que a porcentagem média das escolhas de branco pelo grupo clínico foi significativamente menor do que a média normativa, o que sugere que as crianças e adolescentes com epilepsia estão, de certa forma, preservados em termos de mecanismos de controle e em seu contato com a realidade. 
Ainda para caracterizar o grupo clínico, fez-se a estatística descritiva dos valores das síndromes cromáticas, novamente expressos em porcentagens. As síndromes cromáticas são constituídas pelas somas das frequências de cores que têm significados quando aparecem em conjunto. Sendo assim, são cinco as principais síndromes do Teste de Pfister: Normal (azul + vermelho + verde), Estímulo (vermelho + amarelo + laranja), Fria (azul + verde + violeta), Incolor (preto + branco + cinza) e Dinamismo (verde + amarelo + marrom). A Tabela 26 apresenta os dados encontrados.

Tabela 26: Porcentagens médias das síndromes cromáticas do grupo clínico $(n=34)$ no Teste de Pfister e comparação com dados normativos.

\begin{tabular}{lcccccccc}
\hline $\begin{array}{l}\text { Síndrome } \\
\text { Cromática }\end{array}$ & Média & DP & Mínimo & Máximo & $\begin{array}{c}\text { Dado médio } \\
\text { normativo }\end{array}$ & $\boldsymbol{t}$ & $\boldsymbol{p}$ \\
\hline Normal & 51,94 & 11,49 & 29 & 87 & 49,50 & 1,24 & 0,22 \\
Estímulo & 36,71 & 12,70 & 15 & 78 & 30,80 & 2,71 & $\mathbf{0 , 0 0 1}$ \\
Fria & 44,97 & 11,80 & 15 & 71 & 47,20 & $-1,10$ & 0,28 \\
Incolor & 13,79 & 9,16 & 0 & 40 & 18,70 & $-3,12$ & $<\mathbf{0 , 0 0 1}$ \\
\hline
\end{tabular}

* Barroso (2013).

Com maiores porcentagens médias tem-se as Síndromes Normal e Fria, seguidas pelas Síndromes Estímulo, Dinamismo e Incolor. Percebe-se que a Síndrome Incolor atingiu um valor mínimo de zero. Esse dado demonstra que houve protocolos (embora poucos) em que as três cores da síndrome não foram utilizadas pelas crianças e adolescentes deste estudo, apontando marcador relevante a ser examinado de modo reflexivo, mediante seus significados clínicos.

Comparativamente aos dados normativos produzidos por Barroso (2013), as crianças e adolescentes do grupo clínico apresentaram significativa maior incidência da Síndrome Estímulo. Isso geralmente se relaciona à tendência ao egocentrismo e à desadaptação social. Em contrapartida, as crianças e adolescentes com epilepsia apresentaram porcentagem média da Síndrome Incolor significativamente mais baixa do que a média dos dados normativos, o que pode sinalizar falta de elementos estabilizadores internos para os afetos.

A distribuição dos aspectos formais das pirâmides do Pfister construídas pelo grupo clínico pode ser vista na Tabela 27. 
Tabela 27: Distribuição (em frequência simples e em porcentagem) dos tipos de pirâmides do Pfister construídas pelo grupo clínico $(n=34)$.

\begin{tabular}{|c|c|c|c|c|c|}
\hline & \multirow{2}{*}{ Aspecto formal } & \multirow[b]{2}{*}{$f$} & \multirow[b]{2}{*}{$\%$} & \multicolumn{2}{|c|}{ TOTAL } \\
\hline & & & & $f$ & $\%$ \\
\hline \multirow{4}{*}{ Tapete } & Furado & 43 & 42,16 & \multirow{4}{*}{78} & \multirow{4}{*}{76,47} \\
\hline & Puro & 7 & 6,86 & & \\
\hline & Desequilibrado & 4 & 3,92 & & \\
\hline & Com início de ordem & 24 & 23,53 & & \\
\hline \multirow{5}{*}{ Formação } & Em camada monotonal & 4 & 3,92 & \multirow{5}{*}{22} & \multirow{5}{*}{21,57} \\
\hline & Em camadas monocromáticas & 2 & 1,96 & & \\
\hline & Em camadas multicromáticas & 11 & 10,79 & & \\
\hline & Alternada & 4 & 3,92 & & \\
\hline & Simétrica & 1 & 0,98 & & \\
\hline \multirow{5}{*}{ Estrutura } & Em escada & - & - & \multirow{5}{*}{2} & \multirow{5}{*}{1,96} \\
\hline & Simétrica & - & - & & \\
\hline & Assimétrica dinâmica & 1 & 0,98 & & \\
\hline & Em manto & 1 & 0,98 & & \\
\hline & Em mosaico & - & - & & \\
\hline & TOTAL & 102 & 100,00 & 102 & 100,00 \\
\hline
\end{tabular}

Destaca-se, com facilidade, a elevada frequência dos tapetes entre as crianças e os adolescentes avaliados. Dentre esses, aqueles com maior incidência foram os tapetes furados, sugerindo indícios de dissociações no curso do pensamento. Apareceram também os tapetes com início de ordem, sugerindo esforço adaptativo e de contenção interna dos afetos por parte dos indivíduos do grupo clínico. Os demais tipos de formação das pirâmides do Pfister ocorreram em frequência inferior, não merecendo destaque interpretativo.

A seguir, foram examinados os processos de execução utilizados pelo grupo clínico para construir as pirâmides do Pfister. Esses dados compõem a Tabela 28. 
Tabela 28: Distribuição (em frequência simples e em porcentagem) dos processos de execução das pirâmides do Pfister construídas pelo grupo clínico $(n=34)$.

\begin{tabular}{ccc}
\hline Execução & $f$ & $\%$ \\
\hline Metódica & 4 & 11,77 \\
Ordenada & 28 & 82,35 \\
Desordenada & 2 & 5,88 \\
Relaxada & - & - \\
TOTAL & 34 & 100,00 \\
\hline
\end{tabular}

Destaca-se a preferência pela execução ordenada das pirâmides, seguindo um padrão de colocação mais ou menos constante, permitindo-se alguma variação. As crianças e os adolescentes com epilepsia sinalizaram, portanto, flexibilidade, porém conseguindo manter seu trabalho organizado.

Por fim, detalhou-se a produção do grupo clínico em termos da classificação das fórmulas cromáticas diante do Teste de Pfister. A Tabela 29 apresenta esses dados.

Tabela 29: Distribuição (em frequência simples e em porcentagem) das fórmulas cromáticas do grupo clínico (n=34) no Pfister, em função da amplitude e da estabilidade das escolhas.

\begin{tabular}{|c|c|c|c|c|c|}
\hline \multirow{2}{*}{\multicolumn{2}{|c|}{ Fórmula Cromática }} & \multirow{3}{*}{$\frac{f}{20}$} & \multirow[b]{2}{*}{$\%$} & \multicolumn{2}{|c|}{ TOTAL } \\
\hline & & & & $f$ & $\%$ \\
\hline \multirow{3}{*}{ Ampla } & Estável & & 58,83 & \multirow{3}{*}{29} & \multirow{3}{*}{85,30} \\
\hline & Flexível & - & - & & \\
\hline & Instável & 9 & 26,47 & & \\
\hline \multirow{3}{*}{ Moderada } & Estável & 1 & 2,94 & \multirow{3}{*}{5} & \multirow{3}{*}{14,70} \\
\hline & Flexível & 1 & 2,94 & & \\
\hline & Instável & 3 & 8,82 & & \\
\hline \multirow{3}{*}{ Restrita } & Estável & - & - & \multirow{3}{*}{-} & \multirow{3}{*}{-} \\
\hline & Flexível & - & - & & \\
\hline & Instável & - & - & & \\
\hline
\end{tabular}

Destaca-se o claro predomínio das fórmulas cromáticas amplas, sugerindo receptividade acentuada e forte sensibilidade das crianças e dos adolescentes com epilepsia em relação aos estímulos afetivos. A maior frequência das fórmulas cromáticas foi classificada como ampla e estável $(58,83 \%)$, o que está relacionado a esteriotipia e perseveração no padrão de respostas emocionais. Isso pode ainda sugerir comodismo e 
indiferenciação afetiva, relacionando-se com sinais de imaturidade, até certo ponto esperados para a faixa etária aqui examinada.

\subsection{Associação entre resultados no WISC-III e no Teste de Pfister}

Foi realizado cálculo estatístico para examinar a possível associação entre indicadores do desempenho cognitivo no Teste WISC-III e do funcionamento lógico sinalizado pelo tipo de formação no Teste de Pfister de crianças e de adolescentes com epilepsia nas três pirâmides realizadas.

Deve-se lembrar que foram excluídos da amostra um participante do grupo clínico e um participante do grupo controle, por não terem completado a tarefa de preenchimento completo das pirâmides. Sendo assim, a amostra agora examinada ficou composta por 34 participantes do grupo clínico somados a 30 participantes do grupo controle $(n=64)$.

Os casos foram divididos em função da classificação intelectual obtida no WISC-III, independentemente de sua condição clínica: a) subgrupo deficiente, limitrofe e média inferior ( $\mathrm{n}=36)$; b) subgrupo com inteligência média, média superior e superior $(\mathrm{n}=28)$, verificando-se a distribuição de seus tipos de formação (aspecto formal) nas pirâmides do Pfister. A tabela 30 apresenta esses resultados e sua comparação estatística.

Tabela 30: Distribuição (em frequência simples e em porcentagem) dos tipos de pirâmides do Pfister em função do nível intelectual (WISC-III) dos participantes $(n=64)$.

\begin{tabular}{cccccccc}
\hline Nível intelectual & \multicolumn{2}{c}{ Deficiente, } & \multicolumn{2}{c}{ Médio, médio } \\
limítrofe e médio & \multicolumn{2}{c}{$\begin{array}{c}\text { superior e } \\
\text { inferior }\end{array}$} & \multicolumn{2}{c}{ superior } & $\chi \mathbf{2}$ & $\boldsymbol{p}$ & $\begin{array}{c}\text { Vde } \\
\text { Cramer }\end{array}$ \\
Tipo de formação & $\boldsymbol{f}$ & $\boldsymbol{\%}$ & $\boldsymbol{f}$ & $\mathbf{\%}$ & & & \\
\hline Tapete & 80 & 74,08 & 34 & 40,48 & & & \\
Formação & 24 & 22,22 & 46 & 54,76 & 22,832 & $<\mathbf{0 , 0 0 1}$ & 0,345 \\
Estrutura & 4 & 3,70 & 4 & 4,76 & & & \\
TOTAL & 108 & 100,00 & 84 & 100,00 & & & \\
\end{tabular}

Pelos resultados obtidos verifica-se que houve associação entre nível intelectual geral (WISC-III) e capacidade de organização lógica (Pfister) no grupo de crianças e adolescentes avaliados $(\mathrm{n}=64)$. Os participantes que alcançaram as classificações intelectuais, por meio do WISC-III, abaixo da média construíram com significativa maior frequência tapetes no Pfister, 
o que de acordo com Villemor-Amaral (2005) sugere menor grau de desenvolvimento intelectual. Já os participantes que apresentaram resultados de nível intelectual na média ou acima dela, construíram pirâmides do tipo de formações no Pfister em proporção estatisticamente superior. As pirâmides classificadas como formações, segundo VillemorAmaral (2005), geralmente são elaboradas por pessoas com funcionamento cognitivo e emocional mais elaborado do que aquelas que constroem tapetes, como aqui ficou empiricamente demonstrado. $\mathrm{O}$ tamanho do efeito dessa diferença estatística foi moderado, ou seja, é indicador relevante para explicar a associação entre nível intelectual da criança ou adolescente no WISC-III e sua habilidade para construir pirâmides mais ou menos elaboradas no Pfister. 



\section{DISCUSSÃO}

Desde o início, a presente investigação científica teve por objetivo caracterizar o funcionamento cognitivo e afetivo de crianças e adolescentes com quadros de epilepsia, tendo em vista que a grande concentração de estudos sobre o tema pouco considerava variáveis relacionadas ao desenvolvimento emocional. Para operacionalizar esse objetivo central, recorreu-se a instrumentos específicos de avaliação psicológica, envolvendo aspectos cognitivos e de neurodesenvolvimento (WISC-III e Blocos de Corsi), indicadores relativos à saúde mental (SDQ) e à afetividade (Teste de Pfister), evidenciando recursos e eventuais dificuldades adaptativas ao contexto de vida em indivíduos com epilepsia.

Ao examinar o conjunto dos resultados, algumas especificidades da produção das crianças e dos adolescentes com epilepsia merecem o devido destaque neste momento. Entre elas, tem-se a diferença estatisticamente significativa com relação ao início das crises entre os participantes dos grupos clínicos, verificando-se que crianças e adolescentes do pré-operatório apresentaram início de suas crises epiléticas com idades maiores em relação ao grupo pósoperatório. Essa marca clínica pareceu relacionada a própria constituição da amostra do presente estudo, obtida por conveniência entre os pacientes do CIREP do HC-FMRP-USP, durante o ano de 2013. Em adição a esse dado, identificou-se diferença estatisticamente significativa com relação à frequência das crises entre os grupos clínicos, sendo que crianças e adolescentes do pré-operatório apresentaram mais crises epiléticas por mês. Esse achado faz todo sentido dentro do contexto da intervenção cirúrgica realizada, onde a expectativa (e a própria justificativa desse procedimento médico) é a redução do número de crises e a estabilização do quadro de epilepsia, favorecendo o desenvolvimento infanto-juvenil.

Campos-Castelló e Campos-Soler (2004), em estudo de revisão bibliográfica, exploraram variáveis que poderiam influenciar na deterioração cognitiva dos pacientes pediátricos com epilepsia, abrindo outras perspectivas para exploração clínica desse tipo de casos. Além do período de início e da frequência das crises, esses pesquisadores destacaram que o tipo e a etiologia da epilepsia constituem fatores bastante relevantes em perdas cognitivas, assim como a utilização de drogas antiepiléticas (uso de poli ou monoterapia).

Resultados semelhantes foram encontrados por Nolan e Redoblado (2003), ao realizarem avaliações neuropsicológicas em 169 crianças portadoras de síndromes epiléticas comuns da infância, dentre elas: síndrome generalizada idiopática, epilepsia generalizada sintomática, epilepsia do lobo temporal, epilepsia do lobo frontal, epilepsia central e epilepsia 
localizada. De acordo com o estudo foram encontradas diferenças estatisticamente significativas entre as crianças de acordo com idade de início, duração da epilepsia, frequência de crises e politerapia. Já em relação à inteligência, as crianças com síndromes generalizada idiopática, epilepsia central e epilepsia do lobo temporal tiveram melhor desempenho e não diferiram estatisticamente entre si. Crianças com epilepsia generalizada sintomática tiveram coeficientes de inteligência estatisticamente menores do que outros grupos avaliados, exceto por crianças com epilepsias localizadas. Já as crianças com epilepsia do lobo frontal diferenciaram-se significativamente do grupo com epilepsia generalizada sintomática, com melhor desempenho intelectual, mas não diferiram estatisticamente dos demais grupos.

Embora seja interessante explorar resultados de crianças e adolescentes com epilepsia em função de suas variáveis clínicas específicas (como tipo, etiologia, terapia medicamentosa, entre outras), não foi possível efetivar essas análises no presente estudo, tendo em vista a composição final da amostra clínica. O número de casos clínicos, embora suficiente para as análises realizadas, não se mostrou adequado para explorações específicas das múltiplas variáveis clínicas envolvidas na epilepsia. Desse modo, preservou-se o objetivo central de caracterizar o funcionamento cognitivo e afetivo dessas crianças e adolescentes com epilepsia. Inicialmente pensou-se que poderiam existir diferenças importantes na dinâmica intelectual e emocional desses casos pelo fato de estarem em processo pré-operatório ou em momento pósoperatório, já com razoável controle das crises. No entanto, os resultados apontaram grande similaridade no padrão geral de resultados dos dois grupos clínicos avaliados (G1 e G2), de modo a se tornar possível, inclusive, uni-los para posterior comparação com referenciais normativos da faixa etária nos diferentes instrumentos de avaliação psicológica utilizados.

Ao focalizar os achados referentes aos indicadores de saúde mental, obtidos a partir do SDQ (respondido pelos pais), foi possível identificar diferenças estatisticamente significativas entre os grupos presentemente examinados nos fatores relacionados aos sintomas emocionais, hiperatividade e problemas com colegas. Verificou-se que essa diferenciação deveu-se ao resultado superior dos grupos clínicos (G1 e G2), comparativamente ao grupo de comparação (G3), sem diferenciação entre crianças e adolescentes do pré e do pós-operatório. De modo geral, os pais dos participantes dos grupos clínicos relataram que as dificuldades vivenciadas por seus filhos (vinculadas ao controle dos impulsos e a inquietação) são incômodas e causam aborrecimento importante aos mesmos, prejudicando seu rendimento acadêmico. Também informaram que seus filhos tinham dificuldades no aprendizado escolar em proporção significativamente maior do que as crianças e adolescentes do grupo de comparação. Os 
pacientes do pré-operatório e do pós-operatório não mostraram, segundo relato dos pais, efeitos diferentes de suas dificuldades nas várias áreas e competências examinadas pelo SDQ.

Em síntese, os achados desse instrumento de avaliação psicológica apontaram que o nível de saúde mental das crianças e dos adolescentes com epilepsia (G1 e G2) apresentou significativos indicadores de maior comprometimento, comparativamente ao padrão referido pelos pais do grupo de comparação (G3). Os resultados, desse modo, atestam efeito relevante da epilepsia nas vivências relativas à saúde mental nessa faixa etária, conforme avaliado pelo SDQ respondido pelos pais dos participantes do estudo.

No tocante à análise dos componentes cognitivos, de modo mais específico, os achados derivados do WISC-III apontaram diferenças estatisticamente significativas entre os grupos clínicos (G1 e G2) em relação ao grupo de comparação (G3) em todas as variáveis analisadas. Observou-se que o grupo de comparação (G3) é quem se diferencia dos demais (G1 e G2), sempre com indicadores de melhor desempenho cognitivo. Não foram encontradas diferenças estatisticamente significativas entre os grupos de pacientes do pré e do pós-operatório nos resultados no WISC-III.

Foi possível observar que crianças e adolescentes com epilepsia sinalizaram, apesar de resultados gerais inferiores à média normativa, desempenho superior em atividades de execução, comparativamente a atividades de raciocínio verbal. Esse achado deve ser associado ao fato de que praticamente todo o grupo pós-operatório (15 dos 18 casos) realizou a cirurgia no hemisfério esquerdo cerebral, provocando maior suscetibilidade a déficits em atividades que envolvam os processos verbais, especificamente nas habilidades de nomeação e de memória verbal. Essa tendência de resultados é bastante similar ao relatado por estudos da área, como os realizados por Davies et al. (1998) e Sanyal et al. (2005). Portanto, esse tipo de interferência merece ser examinada com o devido destaque no acompanhamento longitudinal das intervenções cirúrgicas nos quadros de epilepsia, sobretudo em crianças e em adolescentes, de modo a oferecer estímulos adequados a suas necessidades de desenvolvimento.

Como expõe Furtado (2003), o processo de linguagem depende do desenvolvimento das estruturas anátomo-funcionais e dos estímulos ambientais, sendo constituída por uma série de habilidades tais como a expressão, a recepção, a nomeação, a leitura e a escrita. À medida que a criança vai se desenvolvendo, a relação entre a aquisição da linguagem e a cognição tornase mais evidente, pois esta pode influenciar o raciocínio, as concepções de tempo e espaço, a expressão de sentimento e a formação de conceitos, além de ser fundamental para a formação das categorias mentais e das ideias. 
Ao retomar os baixos resultados dos grupos clínicos presentemente avaliados por meio do WISC-III, evidenciou-se que crianças e adolescentes com epilepsia (independentemente de terem ou não realizado cirurgia) sinalizaram reduzida resistência à distração e baixa velocidade de processamento informativo. Esses sinais de limites, provavelmente vinculados ao quadro da epilepsia, podem estar associados ao prolongado tempo de uso de diversas medicações. Loring e Meador (2004) apontam que a terapêutica medicamentosa de longa duração, embora necessária nos quadros de epilepsia, pode favorecer prejuízos cognitivos, diminuição da excitabilidade ou aumento da inibição neuronal, sedação, sonolência, distração e insônia, fatores estes que podem ocasionar ou intensificar prejuízos na performance na avaliação cognitiva, sobretudo no processamento das informações.

A relação entre as habilidades intelectuais e a ausência de crises epiléticas no pósoperatório foi discutida em estudo realizado por Gleissner et al. (2006). Verificaram que o coeficiente intelectual analisado isoladamente não foi um bom preditor de ocorrência de crises de epilepsia no pós-operatório. Resultados semelhantes foram obtidos por Chelune et al. (1998), que avaliaram extenso grupo de pacientes refratários ao tratamento medicamentoso. Os autores destacaram que baixos escores de coeficiente intelectual geral no pré-operatório não se constituiria em fator de contraindicação para a realização da cirurgia de epilepsia, sendo que esses pacientes não deveriam ser excluídos como possíveis candidatos à intervenção cirúrgica, baseando-se somente nas medidas de eficiência intelectual. Nesses casos, segundo Meador et al. (2007), somente a redução do número de crises e a administração de drogas antiepilépticas após o procedimento cirúrgico já podem trazer benefícios para o paciente, sendo, portanto, importante seu devido acompanhamento pré e pós intervenção.

A partir dos dados do WISC-III, utilizado no presente trabalho, foi possível identificar diferenças estatisticamente significativas entre os grupos clínicos e o grupo de comparação em todos os subtestes. Os desempenhos das crianças e dos adolescentes sem epilepsia foram estatisticamente superiores no conjunto dos subtestes do WISC-III, atestando efeito relevante desse quadro clínico (epilepsia) sobre o potencial e funcionamento cognitivo nessa faixa etária.

Como já descrito anteriormente, a junção de G1 e G2 em único grupo de casos clínicos foi possível pela similaridade de seus resultados nas medidas utilizadas, reafirmando evidências empíricas de prejuízo cognitivo nas crianças e adolescentes com epilepsia. Notouse, inclusive, que a maior parte do grupo clínico $(\mathrm{G} 1+\mathrm{G} 2, \mathrm{n}=35)$ presentemente examinado apresentou classificação intelectualmente deficiente, representando mais de metade dos casos. 
Com relação à comparação do grupo clínico com os dados normativos apresentados no manual de adaptação e padronização do teste para a amostra brasileira (Figueiredo, 2002) percebe-se que houve diferenças estatísticas significativas em todos os escores de QI e nos subtestes avaliados. Novamente as crianças e os adolescentes com epilepsia apresentaram escores mais baixos do que o grupo normativo em todas as variáveis. Destaca-se que não foram identificadas diferenças estatisticamente significativas entre as médias dos escores em QI alcançados pelos casos clínicos do presente estudo em relação ao estudo com crianças americanas com epilepsia realizado por pesquisadors independentes e apresentado no manual de Figueiredo (2002). Ou seja, em amostras diferentes de crianças com epilepsia, o resultado foi similar, indicando prejuízo cognitivo bastante importante nesses quadros.

Ainda no campo do exame cognitivo, porém com foco nos resultados advindos do Teste dos Blocos de Corsi, foi possível identificar diferenças estatisticamente significativas entre G1, G2 e G3, tanto na aplicação direta, quanto na inversa. Verificou-se que o grupo de crianças e adolescentes sem epilepsia apresentou resultado significativamente superior nas duas tarefas. Não foram encontradas diferenças estatisticamente significativas entre os grupos de pacientes do pré-operatório $(\mathrm{G} 1)$ e de pós-operatório (G2), ou seja, entre crianças e adolescentes com epilepsia, independentemente de sua condição atual de tratamento clínico.

Além disso, pelas comparações realizadas entre o grupo clínico de crianças e adolescentes com epilepsia e as crianças avaliadas no estudo de Siquara (2014), também houve diferenças estatisticamente significativas entre as médias da pontuação alcançada pelos participantes, tanto na versão direta, quanto na versão inversa do teste. Os participantes do grupo clínico apresentaram resultados significativamente mais baixos. Os achados atestam, portanto, evidências empíricas sinalizadoras de relevante prejuízo na memória espacial advindo da condição de portador de epilepsia.

Cabe lembrar ainda que a literatura científica da área aponta que as funções de memória estão mais especificamente localizadas no lobo temporal. No caso do presente estudo, 13 dos 35 casos dos grupos clínicos (seis casos de G1 e sete casos de G2) apresentaram sinais de envolvimento do lobo temporal nos quadros de epilepsia, o que pode também estar associado aos prejuízos de desempenho identificados no Teste dos Blocos de Corsi.

Nesse estudo, diante do conjunto de indicadores técnicos registrados, sobretudo relativos à consistência entre dados do WISC-III e do Teste dos Blocos de Corsi, os atuais achados podem ser considerados como evidências de validade desse último, tendo por base os cuidadosos critérios clínicos utilizados para composição da amostra. Foi possível observar que o desempenho das crianças e adolescentes com epilepsia mostrou-se diferenciado com 
relação às variáveis cognitivas estudadas em comparação aos indicadores obtidos com o grupo de não pacientes, apontando evidências de validade (a partir do critério clínico) dos instrumentos de avaliação psicológica utilizados, nomeadamente o Teste de Corsi, ainda pouco investigado no Brasil.

Cabe destacar que a validade é uma característica fundamental dos instrumentos de avaliação, referindo-se à legitimidade das interpretações dadas a partir dos indicadores observados na aplicação de testes, analisados com base nos comportamentos característicos dos indivíduos durante a tarefa proposta. O estudo dos indicadores de validade traz embasamento científico aos instrumentos de avaliação psicológica e está associado ao conjunto de evidências empíricas favoráveis ao significado que se está atribuindo a seus indicadores. As pesquisas de validade sustentam cientificamente e justificam as associações propostas entre os indicadores técnicos e as características psicológicas (Primi, Nascimento \& Souza, 2004)

De acordo com Anastasi e Urbina (2000), a validade precisa ser estabelecida com referência ao uso específico para o qual o instrumento psicológico será considerado. A investigação científica a respeito das evidências de validade, portanto, é composta de várias pesquisas, cada uma testando algum aspecto interpretativo do instrumento avaliativo. Assim, vários estudos podem ser vistos como pequenas provas que se acumulam sobre o que e como se deve interpretar os indicadores obtidos a partir da referida prova. O presente trabalho, dessa forma, pretende ser uma dessas contribuição em favor das evidências de validade do Teste de Blocos de Corsi no contexto sociocultural do Brasil.

$\mathrm{Na}$ sequência das análises foram examinados os indicadores referentes ao Teste das Pirâmides Coloridas de Pfister. Esperava-se identificar por meio desse método projetivo de avaliação psicológica, conforme a literatura científica da área, sinais de desequilíbrio emocional e dificuldades na estabilização afetiva entre os portadores de epilepsia, independentemente de sua condição atual de tratamento (pré ou pós-cirúrgico). No entanto, notou-se que a distribuição de frequência de uso das cores do Pfister entre os adolescentes e as crianças dos grupos avaliados sinalizou-se bastante similar. Identificou-se apenas uma diferença estatisticamente significativa entre os grupos (na cor preta), sendo que os grupos clínicos utilizaram o preto com frequência significativamente inferior ao grupo de comparação.

Em termos da análise das síndromes cromáticas do Teste de Pfister, os achados apontaram que apenas na Síndrome Incolor a distribuição de porcentagem média foi estatisticamente diferente entre os grupos avaliados. Notou-se que crianças e adolescentes dos 
grupos clínicos apresentaram porcentagem inferior na Síndrome Incolor, comparativamente ao grupo de comparação. Poder-se-ia apontar, portanto, que crianças e adolescentes com epilepsia (independentemente de seu atual tratamento) sinalizaram menor controle inibitório da impulsividade, como simbolizado pelo menor uso da cor preta e inferior Síndrome Incolor no Pfister. Não foi possível identificar até o momento outros estudos, desenvolvidos no Brasil, que exploraram o quadro clínico da epilepsia por meio do Teste de Pfister, o que limita as possibilidades de comparação dos atuais resultados com outros trabalhos advindos de mesmo contexto sociocultural.

Em comparação com os dados normativos do Teste de Pfister para adolescentes (Barroso, 2013), depreende-se que os grupos clínicos (antes ou após a cirurgia para controle da epilepsia) possuem padrão de escolhas cromáticas marcado por indicativos de menor inibição afetiva comparativamente às crianças e adolescentes não pacientes, configurando-se em especificidade de preferências em termos de escolhas cromáticas, embora em reduzido número de variáveis. Entende-se que o controle afetivo pode estar relacionado com as funções executivas, envolvendo uma série de habilidades como a antecipação, seleção de um objetivo, planejamento, organização de uma ação, avaliação dos resultados, autocrítica, autocorreção, persistência dentro de uma tarefa, capacidade de adaptação a mudanças, essenciais a todo comportamento dirigido, autônomo e adaptado. Essas funções nos ajudam a resolver todos os problemas mais complexos ou menos complexos do cotidiano, como argumentam Vanderlinden (2004) e Lagae (2006). Em termos neurobiológicos, a esfera atencional e as funções executivas localizam-se no lobo frontal. No presente estudo, oito (22,86\%) dos 35 casos clínicos avaliados apresentaram indicadores de envolvimento da região frontal em seus quadros de epilepsia.

Ainda com base nas evidências derivadas da comparação dos dados do Pfister dos grupos clínicos em relação aos referenciais normativos (Barroso, 2013), pode-se inferir que as crianças e adolescentes com epilepsia sinalizaram disposição para descargas dos impulsos mais intensas e violentas e falta de elementos estabilizadores. Esses indicadores, por sua vez, podem se associar a dificuldades de adaptação, ansiedade, insegurança, necessidade de amparo e proteção, sentimentos de inferioridade e carência afetiva. Além disso, a instabilidade nos contatos emocionais tende a promover dificuldades na interação social, podendo marcar-se como oposicionismo e egocentrismo, o que, por sua vez, acaba por criar conflitos interpessoais. Os sinais identificados no Pfister dos grupos clínicos podem ainda ser considerados sugestivos de perseveração e comodismo, o que geralmente se encontra em crianças e adolescentes mais imaturos. 
O interessante é apontar que muitas dessas possibilidades interpretativas derivadas dos sinais do Pfister foram frequentemente referidas pelos pais diante do SDQ, caracterizando-se em evidências clínicas cruzadas entre os instrumentos avaliativos. Isso, de fato, tende a reforçar os próprios achados e a fortalecer as hipóteses interpretativas derivadas do método projetivo utilizado, configurando-se como evidências de sua validade.

Ainda foi relevante notar a preferência pela realização de tapetes furados nas pirâmides construídas pelas crianças e adolescentes com epilepsia, sugerindo indícios de dissociações no curso do pensamento. No entanto, essa hipótese exige novas investigações, visto que esse tipo de formação do Teste de Pfister foi também bastante frequente entre adolescentes considerados normativos (Barroso, 2013).

As expectativas inicialmente formuladas sobre possíveis dificuldades emocionais entre os portadores de epilepsia, embora presentes, não foram os únicos indicadores advindos do Teste de Pfister. Foi possível identificar muitos sinais sugestivos de preservação em termos de mecanismos de controle e no contato com a realidade, flexibilidade e receptividade afetiva e emocional, comparativamente às crianças e aos adolescentes sem epilepsia. Portanto, os atuais resultados apontaram, com clareza, que as vivências emocionais dos pacientes de epilepsia encontram-se prioritariamente preservadas, apesar das condições clínicas de seu desenvolvimento.

A partir desse estudo com crianças e adolescentes com epilepsia, apesar da apresentação de indicadores específicos, os atuais achados podem ser considerados como evidências de validade do Teste de Pfister, tendo por base os cuidadosos critérios clínicos utilizados para composição da amostra. O instrumento possibilitou observar que o desempenho do grupo clínico mostrou-se estatisticamente diferenciado em algumas variáveis, comparativamente ao grupo de não pacientes. Outros estudos de validade e precisão relativos ao Teste de Pfister estão disponíveis no novo manual do teste, elaborado por Villemor-Amaral (2014), porém nenhum abordou o quadro da epilepsia como critério clínico de estudo.

Com relação aos métodos projetivos de avaliação psicológica, embora sejam utilizados preferencialmente na clínica, estudos psicométricos dos mesmos são necessários para os avanços nas pesquisas da área. Entretanto, devido a sua complexidade de características e natureza ambígua de seus estímulos e liberdade de respostas, os estudos psicométricos mostram-se mais difíceis de quantificar e padronizar. Desse modo, o método projetivo encontra dificuldades para satisfazer os critérios de mensuração, enquanto os testes objetivos de avaliação psicológica, que, no geral, trabalham com um número mais reduzido de variáveis 
e com resultados mais objetivos, apresentam maior facilidade de quantificação (Primi, Nascimento \& Souza, 2004).

É possível compartilhar das noções apontadas pelos referidos pesquisadores a respeito da dificuldade de validação dos métodos projetivos de avaliação psicológica, pelo fato de serem instrumentos que demandam mais habilidade e conhecimentos do psicólogo, um tempo maior de aplicação e complexo processo para se constituir amostras significativas para pesquisa. Isso tudo tende a reduzir a quantidade de investigações nessa área. O presente trabalho, no entanto, configura-se como uma possibilidade de verificação empírica de evidências de validade de um método projetivo de avaliação psicológica, o Teste das Pirâmides Coloridas de Pfister, no contexto do interior do Estado de São Paulo. Ainda que limitado em termos de número de casos, esse trabalho traz contribuição relevante para a área, sobretudo no campo do estudo da afetividade nos quadros de epilepsia infanto-juvenil.

Contudo, ressalta-se que a adequada utilização de um instrumento de avaliação psicológica não se reduz à técnica e a seus indicadores psicométricos, na medida em que continua sendo preponderante a figura do psicólogo e de seu raciocínio clínico para adequadamente compreender o indivíduo naquela interação humana. Os dados obtidos a partir de qualquer instrumento avaliativo se constituem como um quadro global e dinâmico, dentro do complexo processo da avaliação psicológica.

Por fim, verificou-se que houve significativa e relevante associação entre nível intelectual geral (WISC-III) e capacidade de organização lógica (Pfister) no grupo de crianças e adolescentes avaliados no presente trabalho. Os participantes que alcançaram classificações intelectuais abaixo da média apresentaram significativo maior número de tapetes em suas pirâmides no Pfister, o que confirma a hipótese interpretativa existente a respeito desse indicador técnico deste teste: tapetes são representantes de menor grau de desenvolvimento intelectual (Villemor-Amaral, 2005). Já os participantes com nível intelectual médio ou superior construíram, com frequência estatisticamente superior, pirâmides do tipo formações, geralmente elaboradas por pessoas com funcionamento cognitivo e emocional mais aprimorado, conforme postulado no manual desse método projetivo de avaliação psicológica.

Em estudo realizado com crianças do Estado de Goiás também focalizou a possível associação entre o nível de inteligência geral e o desempenho nas Pirâmides Coloridas de Pfister (Resende \& Chagas, 2014). Seus resultados apontaram significativa maior frequência das formações entre as pirâmides construídas pelas crianças com inteligência mediana, além de significativo aumento das estruturas entre as crianças com inteligência superior. $O$ conjunto desses dados mostrou-se condizente com argumentos apresentados por Villemor- 
Amaral (2015) no manual do Teste de Pfister, apontando que pirâmides com o aspecto formal do tipo formações geralmente são elaboradas por pessoas com funcionamento cognitivo e emocional de nível intermediário, enquanto aquelas que constroem estruturas relacionam-se com níveis intelectuais superiores.

Diante do exposto, pode-se argumentar que o presente estudo alcançou seus objetivos, apresentando aos psicólogos do Brasil evidências de validade de um teste cognitivo (Teste de Blocos de Corsi) e de um método projetivo de avaliação psicológica (Teste das Pirâmides Coloridas de Pfister). Foi possível, ainda, colecionar informações relevantes e caracterizar o funcionamento cognitivo e afetivo de crianças e adolescentes com quadros de epilepsia, a partir de instrumentos específicos de avaliação psicológica, evidenciando seus recursos e eventuais dificuldades adaptativas em seus contextos de vida, elementos que poderão ser úteis à prática clínica dos profissionais de saúde. 


\section{CONSIDERACÕES FINAIS}

Os resultados apontaram que os grupos de pacientes com epilepsia apresentaram mais indicadores de problemas relacionados a sintomas emocionais, hiperatividade, problemas com colegas e aprendizado escolar do que as crianças e adolescentes do grupo de comparação. Esses achados foram baseados nas evidências obtidas pelo SDQ, a partir do relato dos pais das crianças e dos adolescentes avaliados.

Por meio dos testes cognitivos (WISC-III e Teste de Corsi), verificou-se que os casos clínicos apresentaram desempenho cognitivo e funcionamento da memória espacial significativamente inferior ao grupo de comparação. Os achados relativos ao empobrecimento intelectual associado à epilepsia tem sido recorrentes na literatura científica da área, porém pouco se investigou, até o momento, a respeito de seu processamento mnemônico espacial por meio de métodos de avaliação psicológica, como presentemente realizado. Essa contribuição torna-se relevante para estimular novas investigações promotoras de intervenções reabilitadoras e de estímulos ao desenvolvimento em crianças e adolescentes com epilepsia.

Já o método projetivo de avaliação de personalidade (Teste de Pfister) apresentou indicativos de menor inibição afetiva nos casos clínicos, comparativamente às crianças e adolescentes não pacientes. No entanto, os achados foram mais específicos, relativos a dificuldade de coordenação emocional, com indícios de preservação das vivências e da sensibilidade emocionais, mesmo com os limites cognitivos identificados. Esse dado, mais uma vez, torna-se importante para a prática clínica e para as intervenções com casos de epilepsia, onde os recursos afetivos e a vinculação emocional podem se tornar grandes aliados à reabilitação de funções cognitivas e, sobretudo, atencionais e de controle executivo.

Cabe, nesse momento do trabalho, comentar que os processos de avaliação neuropsicológica podem ser dificultados na faixa etária infanto-juvenil, sobretudo em portadores de epilepsia, por exigirem longos períodos com a atenção dirigida para a realização dos testes e procedimentos avaliativos. No entanto, a atitude interessada e afetiva do avaliador, recorrendo ao vínculo interativo positivo, mostrou-se estímulo suficiente para que as crianças e os adolescentes pudessem completar o processo avaliativo realizado no presente estudo, mostrando-se como um caminho promissor.

Ainda sobre eventuais desafios inerentes à avaliação neuropsicológica há que se comentar sobre o reduzido número de instrumentos e baterias neuropsicológicas padronizadas para a população brasileira, podendo ocorrer problemas de adaptação cultural ao nosso meio, 
como comentaram Alchieri e Cruz (2003), entre outros autores. Além desse limite técnico da área, é importante apontar que o presente trabalho foi desenvolvido com amostra de conveniência, com tamanho reduzido, o que restringe as possibilidades de generalização de seus resultados, bem como a estabilidade dos mesmos, sem, contudo, comprometer seus relevantes achados empíricos.

Deve-se também considerar que os casos clínicos de maior gravidade e limitação cognitiva existentes no CIREP, por questões práticas, não foram incluídos no estudo, visto não apresentarem condições adequadas para realizarem as atividades solicitadas nos testes psicológicos. Desse modo, não foi possível examinar, do ponto de vista de indicadores afetivos, esses quadros de maior limitação intelectual, existentes (inclusive com certa frequência) em serviços que atendem crianças e adolescentes com epilepsia. Este aspecto poderá ser eventualmente sanado a partir de próximos estudos que busquem utilizar e examinar escalas de avaliação de comportamento adaptativo, com o intuito de mensurar o funcionamento afetivo-social nas crianças com deficiência cognitiva severa e profunda.

Outro aspecto relevante a se considerar nesse momento é que o presente trabalho se configurou como um estudo transversal. Desse modo, o acompanhamento dos casos, em termos cognitivos e afetivos, não foi examinado, o que poderia ser uma proposição bastante profícua para futuras investigações científicas na área.

A partir desse estudo houve alguma clarificação a respeito de aspectos cognitivos e afetivos de crianças e adolescentes com epilepsia, o que pode favorecer sua compreensão por parte dos profissionais de saúde que atuam nesses casos, sobretudo na articulação do trabalho em equipe multidisciplinar. Essa compreensão e acolhimento, no geral, favorecem também informações e orientações mais precisas a respeito destes elementos aos pacientes e a seus familiares, no geral produzindo efeitos positivos nas intervenções clínicas. Permanecem como desafios à investigação científica uma série de indagações relativas à dinâmica afetiva e cognitiva de crianças e adolescentes com epilepsia, a serem somadas aos atuais achados. Assim, faz-se necessário estimular novas investigações nesse campo, a fim de garantir o contínuo aprimoramento técnico-científico na área da neuropsicologia e nos instrumentos e processos de avaliação psicológica, em especial nos casos de portadores de epilepsia. 


\section{REFERÊNCIAS}

Alchieri, J. C. \& Cruz, R. M. (2003). Avaliação psicológica: conceito, métodos e instrumentos. São Paulo: Casa do Psicólogo.

Alchieri, J. C. (2003). Produção científica brasileira em neuropsicologia: análise de artigos publicados de 1930 a 1999. Revista de Psicologia da Vetor Editora, 4(1), 6-13.

Alchieri, J. C. (2004). Aspectos instrumentais e metodológicos da avaliação psicológica. Em Andrade, V. M., Dos Santos F. H. \& Bueno, O. F. A. (Orgs.). Neuropsicologia Hoje. São Paulo: Artes Médicas.

Almeida, L. S. \& Cruz, O. M. S. R. (1988). O uso dos testes como revelador de modelos de prática psicológica: estudo junto dos psicólogos portugueses. Psicologia: Teoria $e$ Pesquisa, 4(3), 207-224.

Anastasi, A. \& Urbina, S. (2000). Testagem psicológica. Porto Alegre: ArtMed Editora.

Anzieu, D. Os métodos projetivos. (1978). Rio de Janeiro: Campus.

Austin, J. K., Dunn, D. W., Caffrey, H.M., Perkins, S. M., Harezlak, J. \& Rose, D. F. (2002). Recurrent seizures and behavior problems in children with first recognized seizures: a prospective study. Epilepsia, 43(12), 1564-1573.

Barcia, D. \& Fuster, P. (1970). Relation between obsessions and epileptic psychoses in children. Revista española de oto-neuro-oftalmología y neurocirugía, 28(166), 311-318.

Barroso, J, B. (2013). O Teste das Pirâmides Coloridas de Pfister: Um estudo normativo com adolescentes. Dissertação (Mestrado em Pós Graduação Em Psicologia) - Faculdade de Filosofia Ciências e Letras de Ribeirão Preto Usp, Fundação de Amparo à Pesquisa do Estado de São Paulo. Orientador: Sonia Regina Pasian.

Beghi, E. (2002). Emotional and affective disturbances in patients with epilepsy. Epilepsy \& Behavior, 3, 255-261.

Busch, R.M., Farrell, K., Lisdahl-Medina, K., \& Krikorian, R. (2005). Corsi block-tapping task performance as a function of path configuration. Journal of Clinical and Experimental Neuropsychology, 27, 127-134.

Campos-Castelló, J., Campos-Soler, S., Neuropsychology and Epilepsy. Revista de Neurología. 2004. 39(2): 166-77

Capitão, C. G., Scortegagna, S. A. \& Baptista, M. N.(2005). A importância da avaliação psicológica na saúde. Avaliação Psicológica, 4(1), 75-74.

Chabert, C. (2004). Psicanálise e métodos projetivos. São Paulo: Vetor. 
Chaudhury, S., Augustine, M., Saldanha, D., Srivastava, K., Kundeyawala, S. M., Pawar, A. A. \& Ryali, V. S. S. R. (2006). Norms of the Rorschach test for indian subjects. Medical Journal Armed Forces India, 62(2), 153-160.

Chelune G J, Naugle R I, Hermann B P, Barr W B, Trenerry M R, Loring D W, Perrine K, Strauss E, Westerveld M (1998) Does Presurgical IQ predict Seizure Outcome after Temporal Lobectomy? Evidence from the Bozeman Epilepsy Consortium. Epilepsia 39(3): 314-318

Cornoldi, C., \& Mammarella, I. C. (2008). A comparison of backward and forward spatial spans. Quarterly Journal of Experimental Psychology, 61A, 674-682.

Costa, D. I., Azambuja, L. S., Portuguez, M. W. \& Costa, J. C. (2004). Avaliação neuropsicológica da criança. Jornal de Pediatria, 80(2), 111-116.

Costa, O. R. S. \& Villemor-Amaral, A. E. (2004). Um estudo correlacional do nível formal das pirâmides de Pfister e a BPR-5. Em Congresso Nacional da Sociedade Brasileira de Rorschach e outros métodos projetivos - trabalhos completos. Técnicas projetivas: produtividade em pesquisa. Porto Alegre: Casa do Psicólogo.

Cunha, J. A. (2000a). Estratégias de avaliação: perspectivas em psicologia clínica. Em Cunha, J. A. \& Cols. Psicodiagnóstico- $V$. Porto Alegre: Artes Médicas.

Cunha, J. A. (2000b). Fundamentos do psicodiagnóstico. Em Cunha, J. A. \& Cols. Psicodiagnóstico- $V$. Porto Alegre: Artes Médicas.

Da Costa, J. C., \& Portela, E. J. (2006). Tratamento cirúrgico das epilepsias na criança. Journal of Epilepsy and Clinical Neurophysiology, 12(1), 32-43.

Davies, K. G., Bell, B. D., Bush, A. J., Hermann, B. P., Dohan, F. C., Jaap, A. S. Naming Decline after Left Anterior Temporal Lobectomy correlates with Pathological Status of Resected Hippocampus. Epilepsia, 1998. 39(4): 407-419.

Davies, S., Heyman, I. \& Goodman, R. (2003). A population survey of mental health problems in children with epilepsy. Developmental Medicine \& Child Neurology, 45(5), 292-295.

De Renzi, E., \& Nichelli, P. (1975). Verbal and non-verbal short-term memory impairment following hemispheric damage. Cortex, 11, 341-354.

Dorazco-Valdes, J. (1968). Estudio Comparativo entre los Aspectos Clinicos, Electroencefalogrfificos y la Prueba del Dibujo de la Figura Humana en el Nifio Epileptico. Journal of the neurological Sciences, 6, 373-380.

Engel, J. Jr. Surgical Treatment of Epilepsies. New York: Raven Press; 1993. 621p.

Fernandes, P. T. \& Souza, E. A. P. (2001a). Procedimento educativo na epilepsia infantil. Estudos de Psicologia, 6(1), 115-120. 
Fernandes, P. T. \& Souza, E. A. P. (2001b). Protocolos de investigação de variáveis psicológicas na epilepsia infantil. Psicolgia: Teoria e Pesquisa, 17(2), 195-197.

Fernandes, P. T. \& Souza, E. A. P. (2001c). Identification of family variables in parents' groups of children with epilepsy. Arquivos de Neuro-Psiquiatria, 59(4), 854-858.

Figueiredo, V. L. M. (2002). WISC-III: Escala de Inteligência Wechsler para Crianças adaptação e padronização de uma amostra brasileira. Adaptação brasileira: Figueiredo, V. L. M. São Paulo: Casa do Psicólogo.

Fleitlich, B., Cortázar, P. G. \& Goodman, R. (2000). Questionário de Capacidades e Dificuldades (SDQ). Infanto - Revista de Neuropsiquiatria da Infância e Adolescência, 8, 44-50.

Furtado, E. F. Infant Development of Cognition and Language: A Conceptual Framework in Developmental Psychopathology. Jornal Brasileiro de Psiquiatria. 2003. 52 (2): 87-96.

Gaitatzis, A., Trimble, M. R. \& Sander, J. W. (2004). The psychiatric comorbidity of epilepsy. Acta Neurologica Scandinavica, 110, 207-220.

Galera, C. \& Souza, A.L.P. (2010) Memória visuoespacial e cinestésica de curto prazo em crianças de 7 a 10 anos. Estudos de Psicologia, 15(2), 137-143.

Garcia, R.B., Mammarella, I.C., Tripodi, D., \& Cornoldi, C. (em preparo). Specific deficits of children with dyslexia and nonverbal learning disability in visuospatial working memory for locations, colours and binding.

Germano, E., Gagliano, A., Magazu, A., Sferro, C., Calarese, T., Mannarino, E., et al. (2005). Benign childhood epilepsy with occipital paroxysms: Neuropsychological findings. Epilepsy Research, 64(3), 137-150.

Gleissner U, Clusmann H, Sassen R, Elger C E, Helmstaedter C (2006) Postsurgical Outcome in Pediatric Patients with Epilepsy: A Comparison of Patients with Intellectual Disabilities, Sub average Intelligence, and Average-range Intelligence. Epilepsia 406-414

Gomes, M. M. (2008). Aspectos epidemiológicos das comorbidades psiquiátricas em epilepsia. Journal of Epilepsy and Clinical Neurophysiology, 14(4), 162-170.

Gomes-Correia, A. (2000). Drawing of the family and of the human figure: a comparative study between children with epilepsy and a control group. Revista de Neurologia, 31(5), 401-407.

Guerreiro, C. A. M. (1996). Aspectos gerais em Epilepsia. (1996). Guerreiro, C. A. M. \& Guerreiro, M. M. Epilepsia. São Paulo: Lemos.

Guey, J., Bureau, M., Dravet , C. \& Roger, J. (1969). A study of the rhythm of petit mal absences in children in relation to prevailing situations. The use of EEG telemetry during psychological examinations, school exercises and periods of inactivity. Epilepsia, 10(4), 441-451. 
Gulgonen, S., Demirbilek, V., Korkmaz, B., Dervent, A. \& Townes, B. D. (2000). Neuropsychological functions in idiopathic occipital lobe epilepsy. Epilepsia, 41(4), 405411.

Holden, J. C. (1957). Temporal-lobe epilepsy associated with severe behavioral disturbances. The Lancet, 12(10), 724-725.

ILAE - International League Against Epilepsy. The Epidemiology of the Epilepsies: Future Directions. Epilepsia. 1997. 38(5): 614-618.

Jimeno, A. L. \& Paniagua, J. L. (1969). The gyrus cinguli and aggressivity. Actas lusoespañolas de neurología y psiquiatría, 28(4), 289-298.

Kaplan De-Nour, A. \& Bauman, A. (1980). Psychiatric treatment in severe brain injury. General Hospital Psychiatry, 2, 23-34.

Lagaer, L. Cognitive Side Effects of Anti-epileptic drugs. The relevance in Childhood Epilepsy. Seizure. 2006. 15: 235-241.

Liga Brasileira de Epilepsia (LBE). (2015). Acessado em 30 de Janeiro de 2015, de http://www.epilepsia.org.br/site/index.php

Loring, D. W. \& Meador, K. J. Cognitive Side Effects of Antiepileptic Drugs in Children. Neurology. 2004. 62: 872-877.

Luria, A. R. Desenvolvimento Cognitivo. Editora Ícone. 1994. p. 38.

Maia Filho, H. S., Costa, C. R. M. \& Gomes, M. M. (2006). Epilepsia e saúde mental na infância. Journal of epilepsy and clinical neurophysiology, 12(2), 79-88.

Matulay, K. \& Pavlovkin, M. (1972). Personality traits of disabled epileptics. Epilepsia, $13(1), 47-50$.

Meador, J. K., Baker, G., Cohen, M. J., Gaily, E., Westerveld, M. Cognitive/behavioral Teratogenetic Effects of Antiepileptic Drugs. Epilepsy \& Behavior. 2007. 11: 292-302.

Mendilaharsu, A. S, Pérez, L. G, Pasquet, G. E, Mirabal, P. M. (1975). Comparative study of the cognitive functions and symbolic order in temporal and centerencephalic epilepsy of long development of difficult therapeutic control. Acta neurológica latinoamericana, 21(1-4), 86-92.

Mirsky, A. F., Primac, D. W., Marsan, C. A., Rosvold, H. E. \& Stevens, J. R. (1960). A comparison of the psychological test performance of patients with focal and nonfocal epilepsy. Experimental Neurology, 2, 75-89.

Nolan, M. A.; Redoblado, M., A; Lah, S., Sabaz, M.; Lawson, J. A.; Cunningham, A. M.; Bleasel, A. F.; Bye, A. M. Intelligence in Childhood Epilepsy Syndromes. Epilepsy Research. 2003. 53: 139-150. 
Noronha, A. L. A., Borges, M. A., Marques, L. H. N., Zanetta, D. M. T., Fernandes, P. T., Boer, H., Espíndola, J., Miranda, C. T., Prilipko, L., Bell, G. S., Sander, J. W., LI, L. M. Prevalence and Pattern of Epilepsy Treatment in Different Socioeconomic Classes in Brazil. Epilepsia. 2007. 48(5): 880-885.

Noronha, A. P. P. \& Vendramini, C. M. M. (2003). Parâmetros Psicométricos: Estudo Comparativo entre Testes de Inteligência e de Personalidade. Psicologia: Reflexão e Crítica, 16(1), 177-182.

Nunes, C. H. S. S. \& Primi, R (2010). Aspectos técnicos e conceituais da ficha de avaliação dos testes psicológicos. Em Conselho Federal de Psicologia - CFP (Org.) Avaliação psicológica: diretrizes na regulamentação da profissão. Brasília: CFP.

Oostrom, K. J., Schouten, A., Olthof, T., Peters, C. B. \& Jennekens-Schinkel, A. (2000). Negative emotions in children with newly diagnosed epilepsy. Epilepsia, 41(3), 326-331.

Orsini, A., Pasquadibisceglie, M., \& Picone, L. (2001). Factors which influence the difficulty of the spatial path in Corsi Block-Tapping Test. Perceptual Motor Skills, 200, 732-738.

Ortinski, P. \& Meador, K. J. Cognitive Side Effects of Antiepileptic Drugs. Epilepsy \& Behavior. 2004. 5: S60-S65.

Pacheco, E. M. C. (2005). Produção científica e avaliação psicológica. Em Witter, G. P. Metaciência e Psicologia. Campinas: Alínea.

Parmentier, F. B. R., \& Andrés, P. (2006). The impact of path crossing on visuo-spatial serial memory: Encoding or rehearsal effect? Quarterly Journal of Experimental Psychology, 59, 1867-1874.

Pasquali, L. (1999). Instrumentos psicológicos: manual prático de elaboração. Brasília: Lab PAM.

Portuguez, M. W., Costa, D. I. \& Marroni, S. P. (2005). Novas Perspectivas na Avaliação Neuropsicológica em Pacientes com Epilepsia Refratária. Journal of Epilepsy and Clinical Neurophysiology, 11(4), 26-30.

Primi, R. (2010). Avaliação psicológica no Brasil: fundamentos, situação atual e direções para o futuro. Psicologia: Teoria e Pesquisa, 26, 25-35.

Primi, R., Nascimento, R. S. G. F., \& Souza, A. S. (2004). Critérios para avaliação de testes psicológicos. Em Conselho Federal de Psicologia - CFP (Org.), Avaliação dos testes psicológicos: relatório (pp. 31-55). Brasília: CFP.

Pruyser, P. W. \& Folsom, A. T. (1955). The Rorschach experience balance in epileptics. Journal of Consulting Psychology, 19(2), 112-116.

Resende, A. C. \& Chagas, L. E. Validade e Precisão: a inteligência geral e o desempenho nas Pirâmides Coloridas de Pfister em crianças - estudo de validade. Em: Villemor-Amaral, A. E. (2014). As pirâmides coloridas de Pfister - versão para crian- ças e adolescentes. São Paulo: Casa do Psicólogo. 
Rossi-Arnaud, C., Pieroni, L. \& Baddeley, A. (2006). Symmetry and binding in visuo-spatial working memory. Neuroscience, 139, 393-400.

Sanyal, S. K., Chandra, P. S., Gupta, S., Tripathi, M., Singh, V. P., Jain, S., Padma, M. V., Mehta, V. S. Memory and Intelligence Outcome Following Surgery for Intractable Temporal Lobe Epilepsy: Relationship to Seizure Outcome and Evaluation using a Customized Neuropsychological Battery. Epilepsy \& Behavior. 2005. 6(2): 147-155.

Saur, A.; Correia, S.; Pasian, S.; Loureiro, S. (2009) Questionário de Capacidades e Dificuldades (SQD): revisão de estudos de validade e fidedignidade. In: IV Congresso Brasileiro de Avaliação Psicológica; XIV Conferência Internacional de Avaliação Psicológica; V Congresso Brasileiro de Rorschach e métodos projetivos, Campinas. Avaliação psicológica: formação, atuação e interface, 1. (pp. 463).

Schelini, P. W. (2007). Alguns domínios da avaliação psicológica. Campinas: Alínea.

Schlindwein-Zanini, R.; Portuguez, M. W. \& Costa, J. C. (2007). Epilepsia do lobo frontal na infância: aspectos psicológicos e neuropsicológicos. Scientia Medica, 17(2), 93-96.

Shaw, M. C. \& Cruickshank, W. M. (1956). The use of the Bender-Gestal Test with epileptic children. Journal of Clinical Psychology, 12, 192-193.

Shaw, M. C. \& Cruickshank, W. M. (1957). The Rorschach performance of epileptic children. Journal of Consulting Psychology, 21(5), 422-424.

Silva, A. N. S; Andrade, V. M \&Oliveira, H. A. (2007). Avaliação neuropsicológica em portadores de epilepsia do lobo temporal. Arquivos de Neuro-Psiquiatria, 65(2), 492-497.

Siquara, G. M. (2014). A influência da memória operacional no desempenho acadêmico em crianças de 7 a 12 anos de idade. Dissertação de Mestrado, Instituto de Psicologia, Universidade Federal da Bahia, Salvador.

Souza, M. T. C. C. (2011). As relações entre afetividade e inteligência no desenvolvimento psicológico. Psicologia: Teoria e Pesquisa, 27(2), 249-254.

Souza-Oliveira, C., Escorsi-Rosset, S., Terra, V. C., Muxfeldt-Bianchin, M., Machado, H. R. \& Sakamoto, A. C. (2012). Impact of pediatric epilepsy surgery on intellectual efficiency. Revista de Neurologia, 54(4), 214-221.

Souza-Oliveira, C., Escosi-Rosset, S., Funayama, S. S., Terra, V. C., Machado, H. R. \& Sakamoto, A. C. (2010). Funcionamento intelectual em pacientes pediátricos com epilepsia: comparação de crianças controladas com medicação, não controladas com medicação e controladas com cirurgia. Jornal de Pediatria, 86(5), 377-383.

Stafstrom, C. E. \& Havlena, J. (2003). Seizure drawings: insight into the self-image of children with epilepsy. Epilepsy \& Behavior, 4, 43-56.

Stafstrom, C. E., Havlena, J. \& Krezinski, A. J. (2012). Art therapy focus groups for children and adolescents with epilepsy. Epilepsy \& Behavior, 24, 227-233. 
Tizard, B. (1962). The personality of epiletics: a discussion of the evidence. Psychological Bulletin, 59(3), 196-210.

Vanderlinden, L., Lagae, L. G. Clinical Predictors for Outcome in Infants with Epilepsy. Pediatric Neurology. 2004. 31(1): 152-155.

Villemor Amaral, F (1978). Pirâmides Coloridas de Pfister. Rio de Janeiro:CEPA.

Villemor-Amaral, A. E. (2005). O Teste das Pirâmides Coloridas de Pfister. São Paulo: CETEPP.

Villemor-Amaral, A. E. (2014). As pirâmides coloridas de Pfister - versão para crianças e adolescentes. São Paulo: Casa do Psicólogo.

Villemor-Amaral, A. E., \& Franco, R. R. (2008). Novas contribuições para o Teste das Pirâmides coloridas de Pfister. Em A. E. Villemor-Amaral, \& S. G. Werlang (Orgs.), Atualizações em métodos projetivos para avaliação psicológica. (pp. 415-423). São Paulo: Casa do psicólogo.

Vladislav, E. O., Marc, G., Agavriloaei, E. M., Maracineanud, I. \& Stefane, L. (2012). Research on the use of the Hand Test in clinical assessment of children and adolescents. Procedia - Social and Behavioral Sciences, 33, 959-963.

Woscoboinik, J. (1960). Relation between the psychogram and clinical aspects in epilepsy in children. Revista de la Asociación Médica Argentina, 74(4), 162-163.

Wyllie E, Comair Y G, Kotagal P, Bulacio J, Bingaman W, Ruggieri P (1998) Seizure Outcome after Epilepsy Surgery in Children and Adolescents. Annals of Neurol. 44(5): 740-748 



\title{
8. APÊNDICES e ANEXOS
}

\subsection{APÊNDICE A: Termo de Consentimento Livre e Esclarecido (TCLE) para pais e/ou responsáveis de crianças ou adolescentes dos Grupos 1 e 2 (grupos clínicos)}

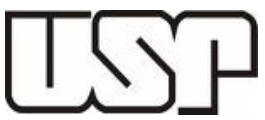

\author{
UNIVERSIDADE DE SÃO PAULO
}

Faculdade de Filosofia, Ciência e Letras de Ribeirão Preto

Departamento de Psicologia - Centro de Pesquisas em Psicodiagnóstico (CPP)

\section{TERMO DE CONSENTIMENTO LIVRE E ESCLARECIDO}

Estamos desenvolvendo uma pesquisa em Ribeirão Preto (SP), intitulada "AVALIAÇÃO PSICOLÓGICA DE CRIANÇAS E ADOLESCENTES COM EPILEPSIA”, que pretender conhecer características do desenvolvimento cognitivo e emocional de crianças e adolescentes de sete a dezesseis anos idade em tratamento de epilepsia. Este trabalho será desenvolvido pela psicóloga Carolina Ruiz Longato, aluna de Mestrado em Psicologia da Faculdade de Filosofia, Ciências e Letras de Ribeirão Preto (FFCLRP) da Universidade de São Paulo (USP) e da Profa. Dra. Sonia Regina Pasian, professora do Departamento de Psicologia desta mesma Faculdade.

Essa pesquisa estudará cerca de 40 pacientes do Centro de Cirurgia de Epilepsia (CIREP) do Hospital das Clínicas (HC) da Faculdade de Medicina de Ribeirão Preto, onde seu(ua) filho(a) encontra-se em tratamento. Gostaríamos de contar com sua colaboração, no sentido de avaliar a possibilidade de autorizar a participação dele(a) nesta pesquisa. Cada criança ou adolescente selecionado passará por uma breve avaliação psicológica, sendo que este processo implica em que o participante responda uma prova de raciocínio, uma atividade de memória e que construa figuras com quadradinhos coloridos, a fim de se conhecer algumas características de seu raciocínio, memória e aspectos emocionais. Estas atividades não apresentam riscos ou prejuízos para as crianças ou adolescentes, sendo exigido apenas o tempo e a atenção às atividades, respeitando-se o ritmo e os recursos de cada indivíduo. Estima-se que estas atividades sejam realizadas em aproximadamente dois encontros de uma hora cada, sendo realizadas em trabalhos individuais com a psicóloga responsável pelo estudo e seus colaboradores. Aos pais será solicitado que preencham um questionário sobre capacidades e dificuldades de seu (sua) filho (a), caso autorizem sua participação nesta pesquisa.

Todas as informações desta pesquisa são confidenciais e somente serão utilizadas para investigação científica, sem nenhuma identificação das pessoas que as forneceram. A sua cooperação e a de seu (sua) filho (a) será muito valiosa e necessária para tornar possível esta pesquisa. Não será oferecido aos participantes desta pesquisa nenhum pagamento por sua colaboração neste trabalho. Colaborar com essa pesquisa poderá ajudar a conhecer as características afetivas, de memória e do raciocínio dos pacientes do CIREP-HC de Ribeirão Preto e isso poderá auxiliar em planejamentos futuros para serviços de Psicologia neste centro. A não aceitação deste convite não acarretará qualquer prejuízo às crianças ou aos adolescentes atendidos no CIREP, nem a seus pais e/ou responsáveis, sendo que a participação no estudo poderá ser interrompida ou retirada a qualquer momento, sem qualquer constrangimento.

Desde já, agradecemos sua colaboração e estaremos disponíveis para outras informações, caso necessário.

Atenciosamente,
Carolina Ruiz Longato
(CRP: 06/109046)
Profa. Dra. Sonia Regina Pasian
(CRP: 06/24018-0)

$\mathrm{Eu}$, , RG declaro que estou cordo com a participação de meu (minha) filho (a) como voluntário no projeto de pesquisa “AVALIAÇÃO PSICOLÓGICA DE CRIANÇAS E ADOLESCENTES COM EPILEPSIA", sob responsabilidade da psicóloga Carolina Ruiz Longato e da Profa. Dra. Sonia Regina Pasian, assim como estou ciente de que os registros relativos a esse trabalho serão utilizados como material de trabalho científico e poderão ser divulgados em congressos e publicados em revistas ou livros especializados, resguardando-se o devido sigilo quanto à nossa identificação.

Ribeirão Preto, de de 20 



\title{
8.2. APÊNDICE B: Termo de Consentimento Livre e Esclarecido (TCLE) para pais elou responsáveis de crianças ou adolescentes do Grupo 3 (grupos de comparação)
}

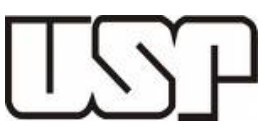

\author{
UNIVERSIDADE DE SÃO PAULO
}

Faculdade de Filosofia, Ciência e Letras de Ribeirão Preto

Departamento de Psicologia - Centro de Pesquisas em Psicodiagnóstico (CPP)

TERMO DE CONSENTIMENTO LIVRE E ESCLARECIDO

Estamos desenvolvendo uma pesquisa em Ribeirão Preto (SP), intitulada "AVALIAÇÃO PSICOLÓGICA DE CRIANÇAS E ADOLESCENTES COM EPILEPSIA”, que pretender conhecer características do desenvolvimento cognitivo e emocional de crianças e adolescentes de sete a dezesseis anos idade em tratamento de epilepsia, comparativamente a estudantes com adequado desenvolvimento. Este trabalho será desenvolvido pela psicóloga Carolina Ruiz Longato, aluna de Mestrado em Psicologia da Faculdade de Filosofia, Ciências e Letras de Ribeirão Preto (FFCLRP) da Universidade de São Paulo (USP) e da Profa. Dra. Sonia Regina Pasian, professora do Departamento de Psicologia desta mesma Faculdade.

Essa pesquisa estudará, além de pacientes em tratamento para epilepsia, crianças e adolescentes regularmente matriculados em escolas públicas de Ribeirão Preto (SP). Gostaríamos de contar com sua colaboração, no sentido de avaliar a possibilidade de autorizar a participação dele(a) nesta pesquisa. Cada criança ou adolescente selecionado passará por uma breve avaliação psicológica, sendo que este processo implica em que o participante responda uma prova de raciocínio, uma atividade de memória e que construa figuras com quadradinhos coloridos, a fim de se conhecer algumas características de seu raciocínio, memória e aspectos emocionais. Estas atividades não apresentam riscos ou prejuízos para as crianças ou adolescentes, sendo exigido apenas o tempo e a atenção às atividades, respeitando-se o ritmo e os recursos de cada indivíduo. Estima-se que estas atividades sejam realizadas em aproximadamente dois encontros de uma hora cada, sendo realizadas em trabalhos individuais com a psicóloga responsável pelo estudo e seus colaboradores. Aos pais será solicitado que preencham um questionário sobre capacidades e dificuldades de seu (sua) filho (a), caso autorizem sua participação nesta pesquisa.

Todas as informações desta pesquisa são confidenciais e somente serão utilizadas para investigação científica, sem nenhuma identificação das pessoas que as forneceram. A sua cooperação e a de seu (sua) filho (a) será muito valiosa e necessária para tornar possível esta pesquisa. Não será oferecido aos participantes desta pesquisa nenhum pagamento por sua colaboração neste trabalho. Colaborar com essa pesquisa poderá ajudar a conhecer as características afetivas, de memória e do raciocínio de crianças e de adolescentes com epilepsia comparativamente a estudantes sem dificuldades, e isso poderá auxiliar em planejamentos futuros para serviços de Psicologia. A não aceitação deste convite não acarretará qualquer prejuízo às crianças ou aos adolescentes, nem a seus pais e/ou responsáveis, sendo que a participação no estudo poderá ser interrompida ou retirada a qualquer momento, sem qualquer constrangimento.

Desde já, agradecemos sua colaboração e estaremos disponíveis para outras informações, caso necessário.

Atenciosamente,

Carolina Ruiz Longato (CRP: 06/109046)
Profa. Dra. Sonia Regina Pasian (CRP: 06/24018-0)
$\mathrm{Eu}$, declaro que estou de acordo com a participação de meu (minha) filho (a)

como voluntário no projeto de pesquisa "AVALIAÇÃO PSICOLÓGICA DE CRIANÇAS E ADOLESCENTES COM EPILEPSIA", sob responsabilidade da psicóloga Carolina Ruiz Longato e da Profa. Dra. Sonia Regina Pasian, assim como estou ciente de que os registros relativos a esse trabalho serão utilizados como material de trabalho científico e poderão ser divulgados em congressos e publicados em revistas ou livros especializados, resguardando-se o devido sigilo quanto à nossa identificação.
Ribeirão Preto, de de 20 

8.3. ANEXO 1: Documento de aprovação do projeto pelo Comitê de Ética em Pesquisa com Seres Humanos da FFCLRP-USP.

Universidade de São Paulo

Faculdade de Filosofia, Ciências e Letras de Ribeirão Preto

Comitê de Ética em Pesquisa

Campus de Ribeirão Preto

Of.CEtP/FFCLRP-USP/123/-jsI

Ribeirão Preto, 31 de outubro de 2012

Prezada Pesquisadora,

Comunicamos a V. Sa. que o projeto de pesquisa intitulado "AVALIAÇÃo PSICOlógICA de CRIANÇAS E AdOLESCENTES COM EPILEPSIA REFRATÁRIA" foi reanalisado pelo Comitê de Ética em Pesquisa da FFCLRP-USP, em sua $113^{a}$ Reunião Ordinária, realizada em 25.10.2012, e enquadrado na categoria: APROVADO (CAAE - 06338612.0.0000.5407).

Solicitamos que eventuais modificações ou emendas ao projeto de pesquisa sejam apresentadas ao CEP, de forma sucinta, identificando a parte do projeto a ser modificada e suas justificativas, e que, ao término do estudo, um relatório final seja entregue, via Plataforma Brasil.

Atenciosamente,

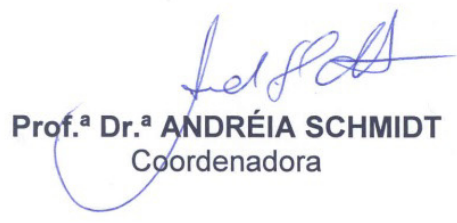

À Senhora

Carolina Ruiz Longato

Programa de Pós-graduação em Psicologia da FFCLRP USP

Com cópia para a orientadora:

Profa. Dra. Sonia Regina Pasian

Departamento de Psicologia da FFCLRP USP

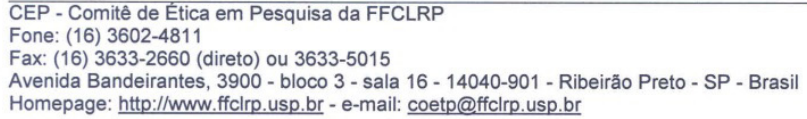



8.4. ANEXO 2: Documento de aprovação do projeto pelo Comitê de Ética em Pesquisa com Seres Humanos da FMRP-HC-USP

HOSPITAL DAS CLINICAS DA FACULDADE DE MEDICINA DE RIBEIRÃO PRETO DA UNIVERSIDADE DE SÃO PAULO

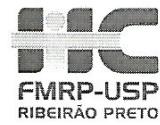

Ribeirão Preto, 30 de novembro de 2012

Projeto de pesquisa: "Avaliação psicológica de crianças e adolescentes com epilepsia refratária"

Pesquisadores responsáveis: Carolina Ruiz Longato e Profa. Dra. Sonia Regina Pasian Instituição Proponente: Faculdade de Filosofia, Ciências e Letras de Ribeirão Preto USP

"O CEP do HC e da FMRP-USP concorda com o parecer ético emitido pelo CEP da Instituição Proponente, que cumpre as Resoluções Éticas Brasileiras, em especial a Resolução CNS 196/96. Diante disso, o HCFMRP-USP, como instituição coparticipante do referido projeto de pesquisa, está ciente de suas co-responsabilidades e de seu compromisso no resguardo da segurança e bem-estar dos sujeitos desta pesquisa, dispondo de infra-estrutura necessária para a garantia de tal segurança e bem-estar.

Ciente e de acordo:

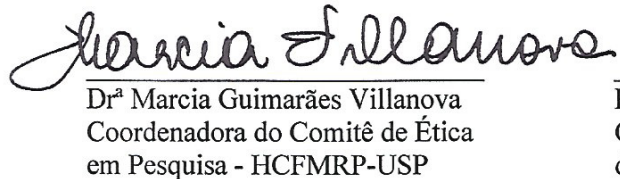

Coordenadora do Comitê de Ética em Pesquisa - HCFMRP-USP
Prof. Dr. José/Alexandre de Souza Crippa Coordenador Xécnico Científico da Unidade de Pesquisá Clínica - HCFMRP-USP 